\title{
ELEMENTARY
}

\section{PHYSICS AND CHEMISTRY}

\section{GREGORY AND SIMMONS}

\section{SHEOND STAGE}

\section{HIST}

$Q C$

23

M32

1900

Bk. 2

C.2

Storage - Item EDUCATION

LP6 - J35B

EL UBC Library 


$$
\text { . C : P . . X }
$$


Marion E. Laurence, Revelstoke Arigholchool, Revelstoke,

B.e.

Oct., 1915.

HISTORICAL COLLECTION EDUCATION LIBRARY UPC 
Digitized by the Internet Archive in 2010 with funding from University of British Columbia Library 
QC 23

132

1900

rs. 2
0.2

ELEMENTARY PHYSICS AND CHEMISTRY 


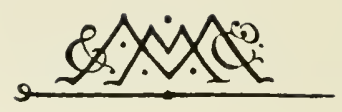

\author{
MACMILLAN AND CO,, LIMITED \\ LONDON - BOMBAY - CALCUTTA \\ MELBOURNE \\ THE MACMILLAN COMPANY \\ NEW YORK - BOSTON - CHICAGO
ATLANTA - SAN FRANCISCO
}

THE MACMILLAN CO. OF CANADA, Ltd. TORONTO 


\section{ELEMENTARY}

\section{PHYSICS AND CHEMISTRY}

\section{SECOND STAGE}

BY

R. A. GREGORY, F.R.A.S.

PROFESSOR OF ASTRONOMY, QUEEN'S COLLEGE, LONDUN

AND

- A T SIMMONS, B.Sc.(Lond.)

ASSOCIATE UF THE KOVAL COLLEGE OF SCIENCE, I.ONDON

MACMILLAN AND CO., LIMITED ST. MARTIN'S STREET, LONDON 1908 
First Erition 1900.

Reprinted 1901, 1902, 1904, 1906, 1908.

GIASOOW: PRINTED AT THF UNIVRRAITY PRKSS BY HOBERT MACLHOSE AND CO. LTD. 


\section{PREFACE.}

THIS book is the second of three little volumes containing a course of experimental work on the elementary principles of Physics and Chemistry. A knowledge of the scientific meaning of such facts of ordinary experience as are described and examined in this and the two companion volumes ought to be possessed by everyone. Wherever the study of science is being commenced, it should be through the consideration of the properties of familiar things; for this is the best way to encourage an intelligent interest in scientific reasons and results. The course of work here followed is thus as suitable for the lower forms of secondary schools as for schools of other grades.

The value of practical exercises in all scientific instruction, however elementary, is now so widely recognised that it is almost unnecessary to advise that the experiments described in each lesson should be actually performed. Unfortunately. it is not often possible to provide accommodation and apparatus sufficient to enable individual pupils to experiment. This difficulty has been borne in mind in designing the form of the following lessons, each of which is divided into two parts - the first consisting of instructions for the performance of simple experiments, the second of explanations of the principles taught by the practical work.

When circumstances permit, every pupil should perform the experiments, and when this is impossible he should see them done by someone else. The descriptive text, which is 
complete in itself, and independent of the experimental work, though covering the same ground, provides suitable lessons to be studied at home.

Every effort has been made to arrange a practicable and instructive first course of science based upon sound educational principles. No difficult point has been passed without attempting to present it in the simplest possible way. Thus, the lessons on heat capacity represent an endeavour to give clear and accurate ideas on a subject which usually offers much difficulty to elementary students.

Many of the illustrations have been specially engraved for the book by Mr. O. L. Lacour, and all of them have been inserted with the object of simplifying the text, or impressing some fact upon the mind of the pupil.

For the help readily given us by $\mathrm{Mr}$. J. A. Humphris, Science Demonstrator for the Bristol School Board, we gladly take this opportunity of recording our thanks.

R. A. G.

A. T. S.

LoNDON, June, I900. 


\section{CONTENTS.}

PAGE

Summary of First Stage, - $\quad$ - $\quad$ - $\quad$ - $\quad$ - $\quad$ - I

LESSON

I. Evaporation, - $\quad$ - $\quad$ - $\quad$ - $\quad$ - $\quad$ - $\quad$ -

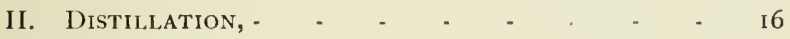

III. MOISTURE IN THE AIR, - - - - - - 22

IV. How the AMOUNT OF WATER VAPOUR in the

Air is Measured, - $\quad$ - $\quad$ - $\quad$ - $\quad$ - 28

V. Changes of Volume and Density or IVater, * 33

VI. Maximum Density of Water, - . $\quad$ - $\quad$ - 39

VII. Heat and Temperature, - - - - $\quad 46$

VIII. The Measurement of Heat, - - $\quad 53$

IX. Quantity of Heat, - $\quad$ - $\quad$ - 56

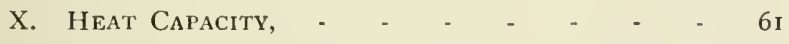

XI. Relative Capacities for IIEAT, - - - - 66

XII. Specific HeAT, - - - - $\quad$ - $\quad$ - 7 - 7

XIII. Heat Absorbed in the Fusion of ICE, - - 77

XIV. Convection. Heat Absorbed in the

Conversion of Water into Steam, - . $8_{3}$ vii 
LESSON PAGE

XV. Increase of Mass Accompanies Burning, - - 93

XVI. The Rusting of Iron, - - - $\quad 98$

XVII. The Action of Phosphorus on Air, - - - IO2

XVIII. Changes Produced by Burning Phosphokus in IIR, - $\quad$ - $\quad-\quad$ - $\quad$ - $\quad$ - $\quad$ - 108

XIX. The Burning of a Candle, - - - - II2

XX. The Burning of a Cande (continned), - - 1 I6

XXI. The Burning of Oil and Gas, - - - 120

XXII. Search for the Active Part of Air, - - 124

XXIII. Preparation of Oxygen, - - * - - $12 S$

XXIV. Chemical Conduct of Oxygen, - - - - I $\quad$ - 2 


\section{ELEMENTARY PHYSICS AND CHEMISTRY.}

\section{SUMMARY OF FIRST STAGE.}

Before beginning new work it is a good plan to make sure of what has been studied before. For this reason the chief subjects already dealt with in the First Stage are briefly described in the early pages of this book. The new subjects commence on p. Io.

\section{PROPERTIES OF COMMON STUFFS.}

The study of science. - Facts about things are found out by means of the five senses - seeing, feeling, hearing, smelling, and tasting. There is no difference between science and ordinary knowledge learnt by the senses, for organised common knowledge, or common sense, is science.

To all those things which are studied by means of the senses the name matter, or things, or stuffs, is given. There are many kinds of things, but they can be arranged into classes according to their properties. Substances differ in hardness, shape, size, colour, and other properties, and a study of these properties enables different things to be arranged in classes.

Solids, liquids, and gases.-All things can be arranged by such a study of their properties into three classes - solids, liquids, and gases. Solids, liquids, and gases are not alike as regards size and shape. Solids have a size and stape of their own, which differ for each solid, but remain the same for one 
particular solid. Liquids have a size of their own, but no particular shape, and when they are not held by any vessel they at once flow; they also form drops. Gases have no definite size or shape; and they fill any vessel in which they are confined. However small a quantity of gas may be taken, it always spreads out until something prevents it from taking up more space.

Properties of common stuffs. - Things differ from one another in many other ways, and their different properties are given certain names. Thus, glass can be seen through, or is transparent; it is also easily broken, or is brittle. Opaque things cannot be seen through. Lead is heavy in comparison with the same bulk of many other substances, or is dense ; it is malleable, or can be beaten into thin sheets; it is also pliable, or can be bent or twisted into different shapes. India-rubber is elastic, or returns to its original shape after the shape has been changed. Flexible things also return to their original shape after being bent. Sponge is porous, or contains numerous small holes or pores. All things are more or less porous. Things through which water will not pass are impervious. Salt and sugar are crystalline, or are made up of little crystals, each having a certain regular shape; they are soluble in water, that is, they disappear when put in water. Particles of soot and flour have no regular shape, or are amorphous. Things which burn are combustible, and things which will not burn are incombustible.

Every substance has many properties, but it usually differs from all other substances in one property or another. By making use of this fact it is possible to distinguish one thing from another.

\section{MEASUREMENT OF SIZE AND MASS.}

Measurement of length.-Whenever you measure a length you use a rule or tape measure having certain divisions marked upon it. An inch, or a foot, or a yard, always means a definite length, and in order that everyone shall use the same inches, and feet, and yards, a standard length has been agreed upon. The British standard of length is the distance between two lines upon a bronze bar kept at the Board of Trade, and is 
called a yard. The length of one third of a yard is called a foot, while one twelfth the length of a foot is called an inch. The table known as "Long Measure" shows how British standards of length are related to one another. In France, and most other countries, the metric system of measurement is used. The metric standard of length is the metre. It is divided into tenths or decimetres, hundredths or centimetres, and thousandths or millimetres. Similarly a length which contains exactly ten metres is called a dekametre; one which just contains a hundred metres is called a hektometre; and one which is exactly a thousand times as long as a metre is called a kilometre. The length of a metre in British units is roughly 3 feet 35 inches.

Measurement of area.-Area is found by measuring length in two directions. A foot square is a square which has each side I foot in length. Square Measure is derived from Long Measure; it tells the standards which must be used in measuring areas.

Some of the units of area, and the way they are related to units of length in the British system, are shown in the following table :

$144(=\mathrm{I} 2 \times 12)$ square inches make I square foot.

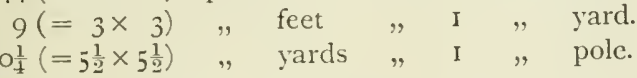

The measures of area or surface in the metric system can be shown in a similar way:

$$
\begin{aligned}
& \mathrm{I} 00(=\mathrm{I} O \times \mathrm{IO}) \text { square millimetres make I square centimetre. } \\
& 100(=10 \times 10) \quad, \quad \text { centimetres }, 1 \text { I " decimetre. } \\
& 100(=10 \times 10) \quad " \text { decimetres , I , metre. }
\end{aligned}
$$

Measurement of volume.-The amount of room a solid takes up, or the space it fills, or its cubical content, is called its volume. Length, breadth, and thickness have to be measured in determining volume. Cubic Measure is derived from Long Measure in the way the following table makes clear :

$1728(=\mathrm{I} 2 \times 12 \times 12)$ cubic inches make I cubic foot.

$$
27(=3 \times 3 \times 3) \quad, \text { feet " } \quad \text { I }, \text { yard. }
$$

The litre.-If a hollow cube is made I decimetre long, 1 decimetre broad, and I decimetre deep, it will hold I000 cubic centimetres of liquid. This capacity is called a litre, 
The chief measures of capacity in the metric system are connected with one another as follows :

Io centilitres make I decilitre.

Io decilitres " $\quad$ I litre (I000 cubic centimetres).

Io litres

Io dekalitres

Io hektolitres "

I dekalitre.

I hektolitre.

1 kilolitre or I cubic metre.

Measurement of mass. - The amount of stuff or matter of whatever kind a thing contains is called its mass. The mass of a thing is not the same as its weight, though one is often confused with the other. Mass is the amount of substance in a thing, but its weight is the force with which the thing is pulled down by the earth. In this country the standard of mass is the amount of matter in a lump of platinum which is kept with the standard yard at the Board of Trade. The lump of platinum is called the imperial standard pound avoirdupois. The divisions, etc., of the imperial pound you have already learnt in your arithmetic lessons, under the name of "Avoirdupois Weight."

The standard of mass which is adopted in the metric system is called the kilogram. This standard is bigger than the British pound, being equal to about two and one-fifth of our pounds. The mass of one-thousandth of a kilogram is called a gram, and is the unit generally used in scientific work. A gram is the mass of one cubic centimetre of water at $4^{\circ} \mathrm{C}$.

The fractions and multiples of a gram are connected as follows :

Io milligrams $=$ I centigram.

Io centigrams $=\mathbf{I}$ decigram.

Io decigrams = I gram.
10 grams $=\mathbf{I}$ dekagram.

Io dekagrams $=$ I hektogram. Io hektograms = I kilogram.

The balance is used to compare masses. The principle upon which it depends is that, when two masses placed at the same distance on opposite sides of the turning point balance one another, they are equal.

\section{DENSITY AND RELATIVE WEIGHT.}

Meaning of density.-It is found that equal volumes of different substances may have different masses; and that equal masses of different substances may have different volumes. It 
is usual to speak of these facts by saying that things have different densities. Density is shown by the proportion which the mass of a thing bears to its volume. The mass of a cubic centimetre of water at a temperature of $4^{\circ} \mathrm{C}$. is I gram, and the density of water at this temperature is consequently taken as the standard density. The mass in grams of a cubic centimetre of any substance at $4^{\circ} \mathrm{C}$. is the density of the substance. It is easy to see that this gives the number of times the substance is heavier or lighter than an equal volume of water.

The density of liquids can easily be determined by means of a "density" or "specific gravity" bottle. The mass of any liquid which just fills the bottle is divided by the mass of water which just fills it, and the result gives the density of the liquid.

When columns of liquid balance one another in a $\mathrm{U}$-tube, the denser the liquid the shorter is the column. This gives another method of determining the density of a liquid, for if we balance the liquid against a column of water, then

$$
\text { Density of liquid }=\frac{\text { Length of water icolumn }}{\text { Length of liquid column }} \text {. }
$$

Some things sink, others float in water.-By noticing what happens when different substances are put in water you can easily divide them into two classes. Those in one division all sink, while those in the other all float.

When an object sinks in a liquid the volume of liquid displaced by the object is equal to its own volume. This fact provides the means of determining the volume of an irregular solid, for if it is insoluble in water, when it is immersed in water, the volume of water displaced can be observed, and tells the volume of the solid.

When an object floats in a liquid, the volume of liquid displaced is equal to the volume of the immersed portion of the object; but the mass of the liquid displaced is equal to the whole mass of the object. An object which floats in water sinks deeper into a liquid which is less dense than water, and not so deep into one which is denser than water. The lactometer is an instrument which depends for its use upon these facts.

The density of solids. - When an object is immersed in water it loses weight equal to the weight of the water displaced by the object. This fact is known as the Principle of Archimedes. By means of this principle the density of a solid compared with 
that of water can be readily determined. The object is first weighed in air, and then, while hanging in water. The density of the object compared with that of water can be found by dividing the weight in air by the loss of weight in water.

$$
\text { Density of the object }=\frac{\text { Weight of the object in air }}{\text { Loss of weight in water }} \text {. }
$$

\section{BAROMETERS AND THERMOMETERS.}

The air around us.- The air around us can be felt when winds are blowing or by waving the hands about througlı it. The bubbles which rise when an empty bottle is placed in water consist of air escaping from the bottle. The air has mass, and its mass can be found by weighing a tightly-stoppered bottle first full of air and then with the air pumped out. Because of its mass, the air has weight and exerts pressure upon objects on the earth's surface, as is shown by the use of a sucker as well as in other ways. When air is removed by suction from the inside of a tube dipping into a liquid, the pressure of the air outside forces the liquid up the tube. This explains the action of a squirt and of a common pump. The pressure of the air is best measured by means of a barometer.

Barometers.-A barometer is an instrument for measuring the pressure exerted by the atmosphere. The principle of a barometer is that a column of mercury in a tube containing no air is balanced by the pressure of the atmosphere outside the tube. The length of the column of mercury supported by the pressure of the atmosphere is, on the average, 30 inches at sealevel. The height of the top of the mercury column changes slightly from day to day on account of alterations in the pressure of the atmosphere. The pressure of the atmosphere at sea-level is, on the average, equal to the weight of 15 lbs. on every square inch. The higher we rise above sea-level the less is the pressure. At a height of $3 \frac{1}{2}$ miles the mercury column in a barometer stands at 15 inches instead of 30 inches. At such a height, the pressure is, therefore, equal to the weight of $7 \frac{1}{2} \mathrm{lbs}$. on every square inch instead of the weight of $15 \mathrm{lbs}$. per square inch. Mercury is generally used for barometers, because it is a very dense liquid, does not leave a mark upon the tube, and can easily be seen. 
Thermometers.-If a thing is made hotter and hotter, several changes in it may be noticed. These changes are the effects of heat, which may thus be stated: (I) Change of size, shown by the expansion and contraction of solids, liquids, and gases when heated or cooled. (2) Change of state, as when ice is converted into water, and water into vapour, or steam, by heat. (3) Change of temperature, which means the condition of bodies as regards heat, a hot body being at a higher temperature than a cold one.

Thermometers are instruments used for accurately measuring changes of temperature. The sense of touch cannot be trusted for this purpose, because our feeling does not tell us accurately how hot or cold a substance is. A thermometer usually consists of a sealed glass tube having a bulb at one end. The bulb and part of the stem contain a liquid, mercury or alcohol being the liquid generally used.

The liquid in a thermometer should ( 1 ) expand a great deal for a small increase of temperature, (2) not easily change into the solid or gaseous state, (3) be in a tube of equal bore having a comparatively large bulb at one end.

In order to mark the divisions upon a thermometer, that is, to graduate the thermometer, advantage is taken of two temperatures which have been proved to be constant. These temperatures are ( $\mathrm{I}$ ) the temperature at which ice melts or pure water freezes; (2) the temperature of the steam issuing from boiling water when the barometer stands at 30 inches. The difference of temperature between these two fixed points is divided into degrees.

Two common kinds of thermometers are the Centigrade and the Fahrenheit thermometers. The degrees of temperature indicated upon these instruments when they are placed in boiling water and in ice are as follows:

$\begin{array}{lcc}\text { Boiling point, } & 100^{\circ} & 212^{\circ} \\ \text { Freezing point, } & 0^{\circ} & 32^{\circ}\end{array}$

\section{SOLUTIONS AND CRYSTALS.}

Soluble and insoluble solids.-Solution is the process by which some substances, when placed in water or other liquids, 
disappear, and their particles spread through the entire mass of the liquid. A substance is said to be soluble in a liquid, or to dissolve in it, when it disappears in the liquid and forms a solution. Sugar, salt, and soda are soluble in water.

A substance is said to be insoluble in a liquid when it will not dissolve in the liquid. Sand, gravel, camphor, sulphur are insoluble in water. Substances which will not dissolve in water will often dissolve in other liquids. Camphor and shellac are soluble in spirits of wine; sulphur is soluble in carbon bisulphide. Small particles of insoluble substances are held in suspension in the liquid in which they do not dissolve, and they can be got rid of by filtering, or by letting the liquid stand undisturbed for a short time.

Soluble liquids and gases.-Some liquids mix or dissolve other liquids. Alcohol (whisky or brandy) dissolves in water ; so does vinegar. Some liquids do not mix, or are insoluble, in one another. For instance, oil, water, and mercury do not mix. Some gases dissolve in liquids. The gas in soda-water, and ammonia gas in the so-called liquid ammonia, are examples of gases dissolved in liquids. The air dissolved in water is necessary for the life of water animals and plants.

There is no loss during simple solution.-Matter is not lost when a substance is simply dissolved. A solid and liquid when separate have the same mass as when the solid is dissolved in the liquid.

\section{Mass of Solid + Mass of Solvent = Mass of Solution.}

When chemical action accompanies solution, changes in mass do occur, but there is no loss of matter. For example, if a piece of copper is dissolved in moderately strong nitric acid and the blue solution which is formed after all the brown fumes have been given off is evaporated to dryness, the blue residue left behind weighs more than the copper. But the total mass of the new substances obtained when a chemical change takes place is the same as that of those originally taken. Thus, if the masses of the copper and nitric acid be added together, the same result is obtained as by adding the masses of the blue residue, the gas evolved, and the steam given off during evaporation.

Saturated solutions.-A solution is saturated with a substance when it contains as much of that substance as it will hold at the temperature of the solution. The effect of increase of temperature on saturation is ustally to increase the amount of a substance 
which can be held in solution. The solubility of a substance usually decreases as the temperature is lowered. Water dissolves most substances, but in different degrees. Salt is more soluble in water than sugar, and sugar is more soluble than chalk.

The solubility of a substance in water can be found by shaking up the substance with a certain quantity of water until no more will dissolve, and then evaporating the water. The amount dissolved in this volume of water can afterwards be determined by weighing, and the amount which would dissolve in 100 cubic centimetres of water can be calculated.

Solubility of things in acids.-Certain metals dissolve in acids, and their solution is accompanied by the formation of new substances with new properties. Such solution is therefore an example of a chemical change. In this way copper dissolves in nitric acid, and zinc in dilute sulphuric acid.

Other substances besides metals will dissolve in acids. The solution of marble in weak hydrochloric acid is an example. This is also an instance of a chemical change.

Crystals. - Crystals are naturally formed lumps of certain substances having a regular shape, which is always the same for the same kind of thing. Rock-salt and some other substances form crystals which are perfect cubes. Diamond crystals have the shape of the octahedron.

Crystals can be made by allowing a warm saturated solution to cool.

Soda crystals can be obtained from carbonate of soda by making a saturated solution of the powder and allowing it to cool.

Water of crystallisation is the water contained in some crystals. It has something to do with their shape and sometimes with their colour.

Efflorescent crystals easily give up their water of crystallisation to the air. Deliquescent crystals readily take up moisture and become wet.

Two examples of waterless crystals are common salt and sulphur. Sulphur crystals can be obtained by melting sulphur and pouring out the liquid sulphur from the interior after a crust has been formed. 


\title{
SECOND STAGE.
}

\author{
LESSON I. \\ EVAPORATION \\ PRACTICAL WORK.
}

Things required.-Evaporating basins, sand bath, tripod stand. Laboratory burner. Flask. Balance and box of weights. Square piece of thin wood. Thin beaker. Narrow glass tube about nine inches long. A pair of bellows. Rain-water, tapwater, and sea-water. Carbon bisulphide, spirits of wine, and ether.

What to do.

Evaporation assisted by heat.-Put some water in an evaporating basin placed upon sand in a shallow iron saucer,

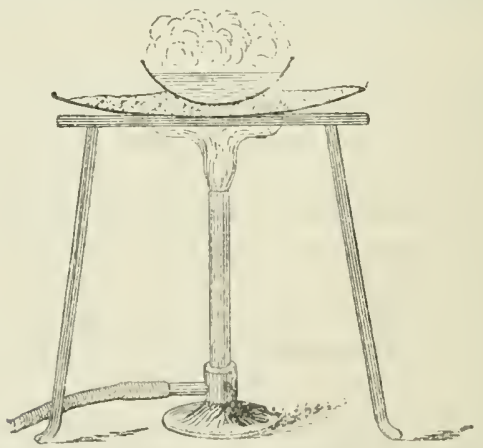

FIG. x.-A "sand bath." The basin containing liquid to be evaporated is placed upon a bed of sand.

known as a "sand bath," or upon a "water bath" made by placing a shallow dish upon the top of a beaker of boiling water (Fig. 2). Warm it gently by means of a laboratory 
burner or spirit lamp. Notice that as the heating is continued the water gradually disappears.

Evaporation of different kind's of water.-Evaporate equal amounts of (1) rain-water, (2) tap-water, (3) sea-water in evaporating basins. Notice that in the first case there is no residue, in the second there is a small residue, and in the third case a considerable quantity of material left behind.

Caution.-THE LIQUIDS REFERRED TO BELOW TAKE FIRE READILY, AND SHOULD NOT BE USED NEAR A FLAME.

Cooling produced by cuaporation.Sprinkle a few drops of (1) spirits of wine, (2) carbon bisulphide, (3) ether, on your hand in succession. Notice that the liquid soon dis-

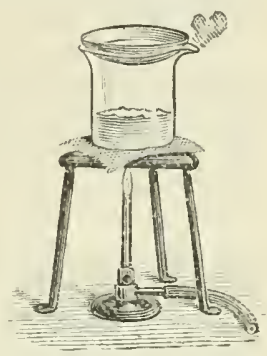

FIG. 2.- 1 "water bath." The basin containing liquid to be evaporated is placed upon the top of a beaker in which water is boiling. appears and its presence in the air can be detected by its smell. The rate at which the liquid evaporates is increased by waving the hand about.

Pour a few drops of water upon a dry piece of thin wood, and stand in the water a thin beaker containing a little ether.

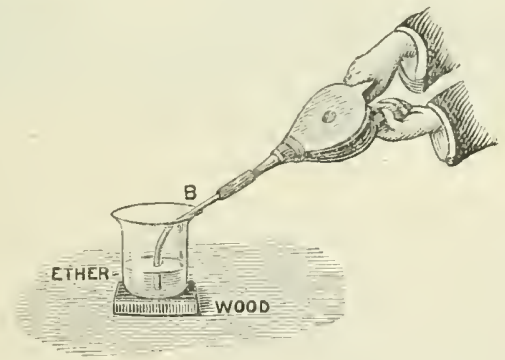

FIG. - Water can be frozen by the rapid evaporation of ether in a vessel in contact with it.

Blow vigorously down a tube having one end in the ether (Fig. 3), or use a pair of bellows. The ether rapidly evaporates, and in doing so takcs heat from the watcr 
between the beaker and piece of wood. The beaker and wood become frozen together.

Difference between quiet evaporation and boiling.-Boil some water in a flask and observe that, when boiling begins, bubbles of steam are formed everywhere throughout the mass of the liquid, and that the bubbles rise and burst at the top.

Put some water in an evaporating basin. Determine the mass of the basin and water. Place the basin, with the water in it, in an exposed place free from dust. Determine its mass every day by weighing. Notice that the mass daily decreases. What has become of the water which has disappeared?

\section{REASONS AND RESULTS.}

Everyday examples of evaporation.-In summer it is not long before a road becomes dry again after having been well watered by a water-cart. Wet clothes hung upon a line and exposed to

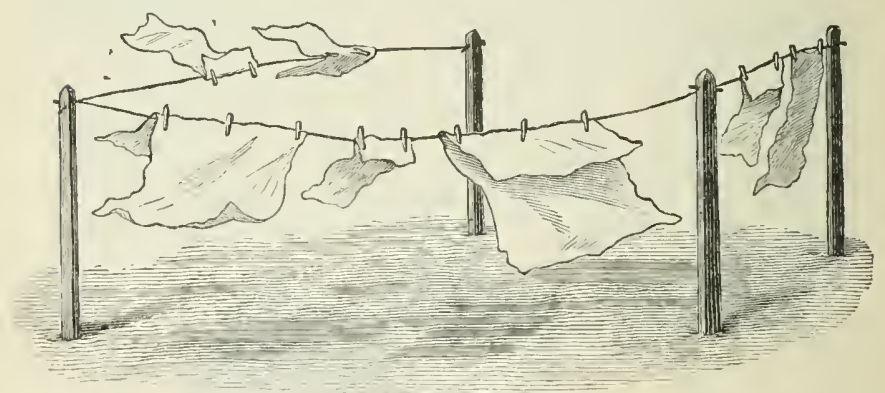

FIG. 4.-One way in which evaporation is utilised.

the sun and air soon become quite dry. Streams and rivers, ponds and lakes, are shallower during the hot days of summer than they are in other months of the year.

It is a common practice to expose shallow vessels of water in rooms which are warmed during winter by coke or gas stoves. From time to time such vesscls have to be refilled, for the water quickly disappears and exists in an invisible form throughout the air of the room.

Nearly everybody has observed the same process taking piace when sitting still after some violent exertion. The perspiration, which after the exercise stands in drops over the face and body, 
soon disappears by passing into the air as vapour, and leaves the skin dry. The cooling of the body which is also noticed at the same time will have to be explained a little later.

This process by which, in every one of the examples named, liquid water is continually being changed into an invisible substance which spreads throughout the air in the neighbourhood, is called evaporation.

Rate of evaporation.-Some days are better for drying clothes than others. A good "drying day," as the laundress or washerwoman calls it, is not only when the day is warm, but also when, as well as this, there is a good breeze. Even when the day is warm, if at the same time the air is still and damp, the wet clothes do not dry quickly. For the same reason a little spirit placed upon the hand dries up more quickly when the hand is moved about than when the hand is kept still.

It is well known that a sponge can absorb a good deal of water, but soon takes up as much as it can hold, when it is said to be saturated. In much the same way a certain amount of air can only hold a certain quantity of the invisible vapour into which liquids are changed by warming them. If the air near a liquid is quite still, it soon has as much vapour as it can hold, and evaporation from the liquid ceases. If, on the other hand, the air is continually moving, and fresh quantities of air are constantly being brought near the liquid, either by a breeze or by waving the hand to and fro, each fresh quantity of air takes up a fresh mass of water vapour, and evaporation never ceases as long as any liquid is left. Boys who have, when at the seaside, suddenly decided to bathe, though they have had no towels with them, know that on a bright sunny day it does not take long to get dry if they go for a run on the sand.

Coolness caused by evaporation.--When a liquid is changed into vapour a certain amount of heat is used up. It does not matter whether the liquid evaporates or boils ; every gram of it requires a certain amount of heat before it becomes converted into vapour. In boiling, this heat is supplied by the flame or fire, and in evaporation it is taken from the objects in contact with the liquid. The faster the evaporation the more heat is absorbed in this way. When a liquid evaporates very rapidly, the cooling produced is very noticeable. For instance, if a few drops of either spirits of wine, carbon bisulphide, or ether are sprinkled upon the hand, the liquid soon disappears and the 
hand feels cold. The heat necessary for the evaporation of these liquids is taken from the hand, or from any other things with which they are in contact, consequently the hand becomes cooler and cooler as the vapour is formed. So much heat may be absorbed in this way that, as illustrated by the experiment shown in Fig. 3, water can be frozen by the evaporation of ether in a vessel in contact with it.

Quiet evaporation and boiling are not the same.-It is very instructive to watch some vigorously boiling water in a flask or beaker and compare it with the evaporation of a solution in an

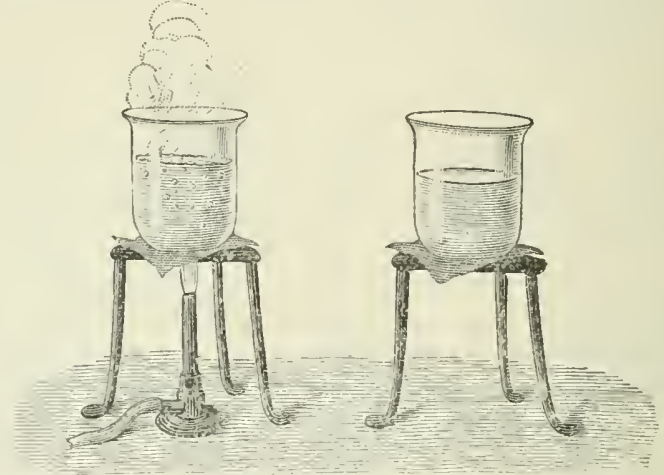

FIG. 5.-When water boils bubbles of vapour are formed in it; during quiet evaporation vapour only escapes at the surface.

evaporating basin, where only a small flame, or no flame at all, is used. The differences between quiet evaporation and boiling can soon be seen if this is done. In the case of the solution being gently evaporated, all the vapour is formed at the surface of the liçuid, and the process goes quietly on until no liquid is left in the basin. Indeed, this quiet evaporation is always taking place, to some extent, whenever a surface of liquid is exposed to the air. Even ice slowly evaporates away.

In the case of vigorously boiling water, bubbles of vapour are formed everywhere throughout the mass of the liquid. They can be seen at the bottom and the sides, and they rise from every point to the surface, each as it escapes there making a little noise. The sounds of the bursting bubbles added together make up the "singing" or "rattlins" which is heard when water is briskly boiling in a flask or other vessel. 
The reason for these differences which we are able to make out is explained by men of science in this way. The particles of which the liquid is made up are always moving about at a great speed, and as the liquid gets warmer this speed increases. When these rapidly moving particles get to the surface of the liquid some of them escape and travel off into the air. Of course, as the liquid gets hotter, more and more of these particles go astray, and evaporation proceeds more rapidly. But when the liquid boils, the particles of liquid which escape from the surface are so numerous that they drive the air particles before them and take their place. There is, moreover, a similar escape of particles from the bubbles which are formed in the mass of the liquid.

Rain water.-It has been explained that evaporation is always going on from the surface of all bodies of water-from rivers, lakes, and the sea. In this way a large amount of invisible water vapour becomes mixed with the air. When by any means a quantity of air is suddenly cooled, this water vapour becomes converted into the liquid form, and often falls as rain.

Artificial rain can be produced in much the same manner by cooling water vapour or steam sufficiently to convert it into liquid drops. Water formed in this way, that is, by cooling the vapour, is always pure, even though the vapour has come from dirty, or salt, water. That is why rain water collected in the country is so pure. When rain water caught in the country is heated in an evaporating basin, nothing remains behind, because. there are no substances dissolved in it. The way to produce pure water from ordinary water will be explained in the next lesson.

\section{TO BE REMEMBERED.}

Everyday examples of evaporation are the drying of roads and clothes.

Evaporation causes coojing. - Water and other liquids are only con. verted into vapour by taking up heat. Some liquids evaporate more rapidly than others at the same temperature.

Evaporation takes place more rapidly when the air abore the liquil is in motion. Clothes dry better on a windy day.

Quiet evaporation and boiling are not the same.-In quiet evaporation, rapour is formed only at the surface of the liquid; in boiling, everywhere throughout it. Evaporation takes place at all temperatures.

Rain water is pure water obtained by the cooling of water vapour in the air. 


\section{Exercise I.}

I. Give as many familiar everyday instances of evaporation as you can.

2. What causes evaporation? What experiment would you perform to prove your answer?

3. If some ether is sprinkled on the palm of your hand what do you notice, and why?

4. Write down what you observe when you watch a liquid which is vigorously boiling.

5. If some rain water and some sea water were put into two separate saucers and allowed to dry up, how could you tell which saucer had contained the sea water?

\section{LESSON II.}

\section{DISTILLATION.}

\section{PRACTICAL WORK.}

Things required.-Test-tube. Piece of narrow glass tubing about 12 inches long. Glass retort. Condenser. Retort stand. Laboratory burner, or spirit lamp. Flask and basin of water. Ether.

\section{What to do.}

How to obtain water from the air.--Put some pieces of ice into a test-tube, or other glass vessel, which is clean and dry on the outside. In a very few minutes the outer surface of the vessel will become covered with moisture.

If you cannot procure ice, put a little ether in a test-tube and make it evaporate quickly by blowing vigorously down a narrow tube on to the surface of the ether. As the air is cooled by the evaporation of the ether, the moisture in the air is given up and deposited on the outside of the test-tube in the form of minute drops : in other words, the water vapour in the air is changed to a liquid.

The distillation of water. - Obtain a glass retort containing some ordinary tap-water coloured with ink and in which some sand has been placed, and put it on a sand-bath, as shown in 
Fig. 7. Let the neck of the retort pass into the neck of a flask suitably supported over a basin of water. By means of a gas burner boil the water in the retort, and keep the flask cool by continually pouring water on to it. Notice that the steam which passes over into the flask is condensed again into water, which is quite clear and tasteless.

If a condenser like the one shown in Fig. 8 is available, examine it and use it to distil some dirty water in which salt has been dissolved. Taste the distilled water.

\section{REASONS AND RESULTS.}

Condensation.-By heating a liquid, as has been seen, the liquid is changed into vapour. This change may take place slowly and gently, as in evaporation; or quickly and vigorously, as in boiling. But by whichever process vapour is obtained, it can, by the reverse plan of cooling it, be reconverted into liquid. This change, from the state of vapour back again to the condition of liquid, is called condensation, and we say the vapour has been condensed to a liquid. Water-vapour is, as you know, invisible, but when it is cooled sufficiently, visible particles of water are formed from it. This can easily be seen byboiling water in a flask fitted as in Fig. 6. Water-vapour is produced inside the flask, but it cannot be seen. When, however, the hot vapour issues from the tube into the colder air out. side it is condensed and par-

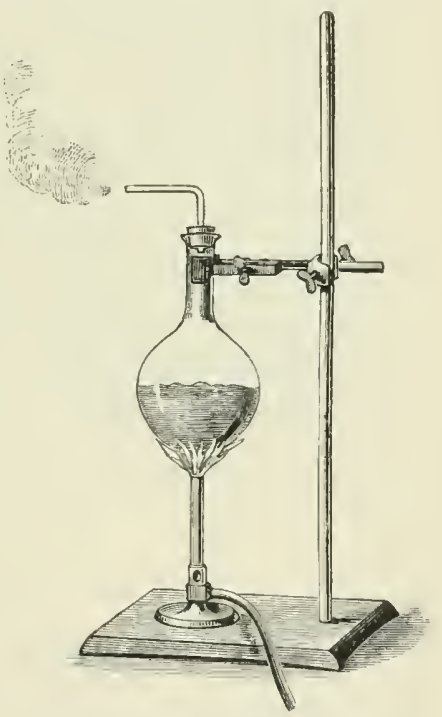

F1G. 6.-The invisible water vapour is condensed into visible steam when it comes in contact with the cooler air. ticles of water become visible as steam. A cold plate held close to the spout of a kettle from which steam is coming will cool the steam, converting it into water, which will be seen trickling down the plate. 
Common instances of condensation.--Most boys and girls have noticed the condensation of vapour taking place at some time or other on a cold day. For instance, if the doors and windows of a room are kept tightly closed, and there is a good fire burning, the inside of the window panes soon becomes covered with moisture, which, forming drops trickles down the glass and collects on the window frame as liquid water. The water must eridently come from the air in the room.

When a glass of cold water is blought into a warm room its outside immediately becomes dull and misty, for just the same reason that the window pane does. Still another common case of condensation is seen when travelling in a railway carriage in winter. If the windows and ventilators are closed, it soon becomes impossible to see anything outside, because of the moisture which is formed on the glass. And who has not noticed, when out walking on a bright frosty day, that a cloud of mist is formed as the warm moist air from the mouth meets the cold air outside?

What causes condensation? - The air outside a room or railway carriage is in winter much colder than that inside. This cools the glass of the windows very much, and consequently the air next to the cold surface itself becomes cooled and then cannot hold as much vapour as when it is warm, and some of the vapour which can no longer be held by the air is changed into water. So that condensation is caused when air containing water vapour is cooled.

The air always contains a certain amount of water vapour, and, if it is cooled enough, some of this vapour is changed into a liquid. Air can be cooled in many ways. For instance, if a tumbler containing ice is brought into a warm room, the outside of the glass is at once covered with a deposit of moisture from the air near the tumbler. Or, if ether contained in a glass ressel is made to evaporate quickly by blowing upon its surface, the outside of the ressel becomes covered in the same way with a layer of liquid water, which may, after blowing for a short time, be frozen into ice.

Distillation.- The change of liquids into vapours by heating them, and the condensation of the vapour into liquid by cooling it, is employed in an important process called distillation. This plan is frequently made use of for purifying water and other liquids. Pcrhaps the most useful application of distillation is to 
obtain fresh water for drinking purposes from sea water or other water not good to drink. Large ships, carrying as they often do more than a thousand people, cannot take enough fresh water on board for the needs, throughout a long voyage, of so many persons. Instead of attempting this difficult task, it is the custom to change sea water into fresh water by distillation. There is no difficulty in understanding this process after the way in which it is done on a small scale in laboratories has been described. Ordinary water may be boiled in a flask or retort,

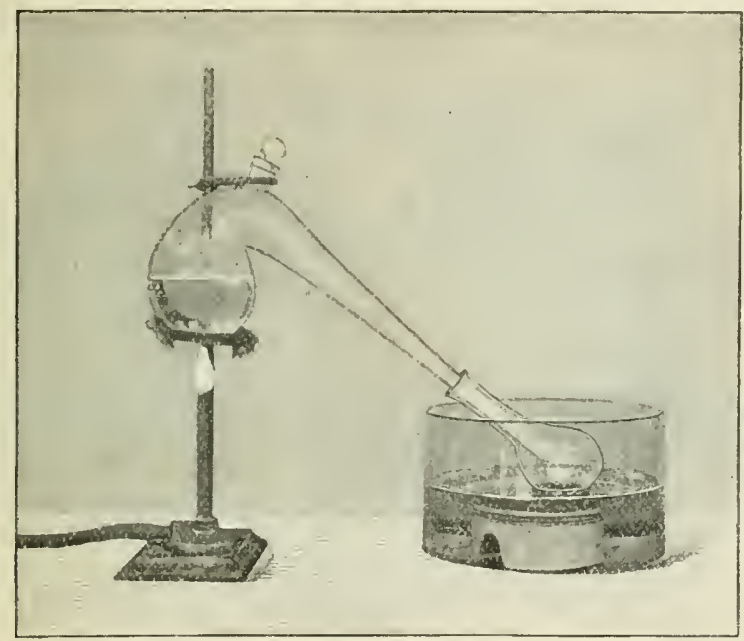

FIG. 7.-As the water boils it is converted into steam, and this steam is condensed again into water in the cooled flask.

the neck of which fits into a flask continually kept cold by pouring water upon it, as in Fig. 7. As the water boils it is converted into steam, and this steam is condensed again into water in the cooled flask. If some sand and salt were first added to the water in the retort they would be left behind, and the water found in the flask would neither taste of the salt nor be coloured by the sand; it would be purified from these by distillation. So that impurities which a liquid contains are left behind in the retort, and the liquid obtained by condensing the vapour is pure. 
Distilling Apparatus.-A convenient apparatus for distilling a liquid is shown in Fig. 8. The water, or other liquid, to be distilled is placed in a flask which is put on a piece of wire gauze, or a sand bath, and is then boiled. The flask is connected by a glass tube, which passes in an air-tight manner through a cork in the neck of the flask, with an arrangement called a condenser. This consists, in the illustration, of a wide glass tube fitted with corks at each end having two holes bored through them. A long narrow tube passes through one of the holes in each cork and down through the whole length of the wider tube. Short tubes are pushed through the remaining hole in each cork.

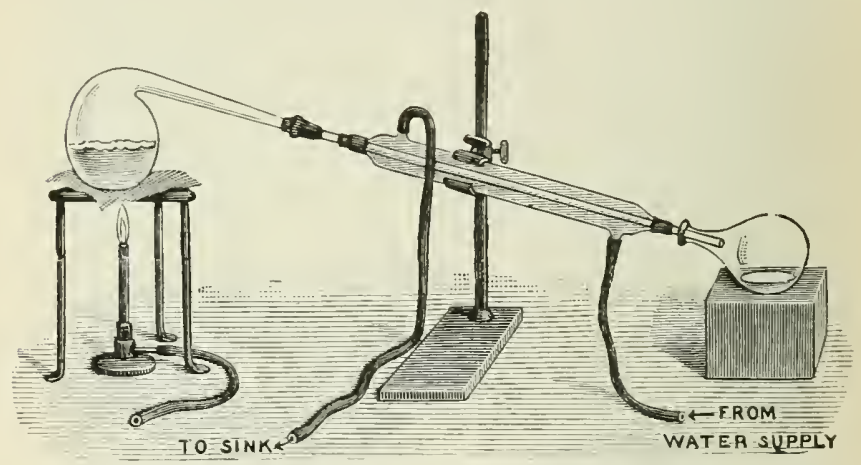

FtG. 8. - The steam issuing from the boiling water passes through a long tube surrounded by cold water, and is condensed into pure water which is caught in the flask.

One of these tubes is connected with the water-supply, the other carries the waste water to a drain or sink. In this way a stream of water can be made to circulate through the wider tube, outside the inner narrow one which it consequently keeps cool. A second flask is placed at the free end of the long narrow tube to catch the pure water as it is condensed. When water is boiled in the flask, steam passes along the inner narrow tube, and is cooled and condensed by the water in the outer and larger tube, and the drops of water formed pass on into the second flask. The water in this flask is thus the condensed steam only; for if the apparatus be properly constructed none of the water which flows around the inner tube can get into the flask. 
The flask in which the impure water is boiled is called the distilling flask, that in which the pure water is collected is known as the receiver. The stills used for obtaining fresh water from sea water are constructed on exactly the same plan. All that is wanted is a vessel to boil the water in, and an arrangement for condensing the steam and collecting the drops of water formed. An arrangement for distilling large quantities of water is shown in Fig. 9.

Differences between distilled and ordinary water.-It has already been learnt that the water which is found naturally

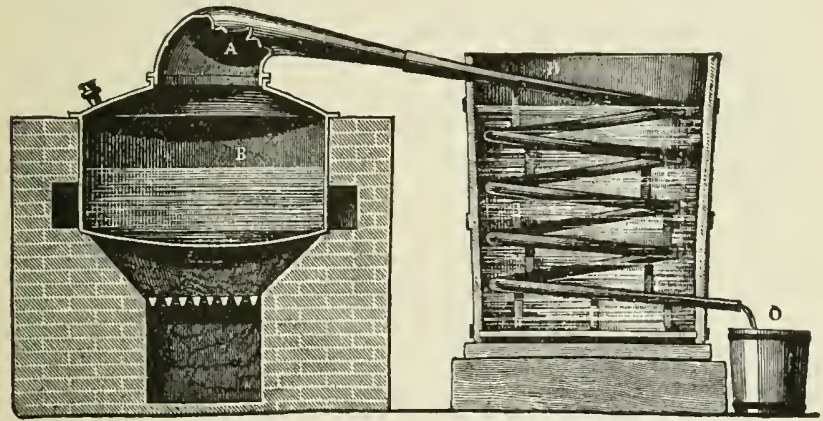

F1G. 9.-A large metal "still." The vapour of the liquid boiling in B passes through the neck $A$ and the spiral tube in D. The spiral is surrounded with cold water, so the vapour in it is condensed, and trickles in drops of liquid into 0.

in rivers, lakes, and especially in the sea, contains a large number of substances in solution which it has at some time in its history dissolved out of the earth. When any natural water is heated in a distilling flask it is only pure water which is converted into vapour; the solids dissolved are left behind. When all the water has been thus changed into vapour, the solids are left behind on the inside of the flask in the form of a residue. This residue, consisting of substances which were dissolved in water, forms the crust found inside a kettle or boiler which has been used for a long time. The great difference, then, between distilled and ordinary water is that the former contains no dissolved solids. Rain water is really water which has been naturally distilled from seas and other large quantities of water on the earth. 


\section{TO BE REMEMBERED.}

Condensation is the process by which vapours, such as steam, are reconverted into liquids by cooling.

Common instances of condensation are found in the moisture which collects on the inside of the window panes of a warm room, and the cloud formed when we breathe in the open air on a cold day.

Distillation consists in first converting a liquid into a vapour by evaporation or boiling, and then reconverting the vapour into liquid by condensation.

Distillation is the way of getting pure water from water having dissolved impurities in it. Such pure water is called distilled water. It differs from ordinary water in containing no solids dissolved in it.

Rain water is really distilled water.

\section{Exercise II.}

I. Explain what is meant by condensation. Give familiar instances.

2. What causes condensation? How would you prove your answer by an experiment?

3. How could you prove that the air contains moisture?

4. Describe the process known as distillation. Give a sketch of the apparatus which can be used for distilling water.

5. If a person wearing spectacles goes into a warm room on a cold winter's day, after being out in the open air, his glasses become dimmed. How do you account for this?

5. Describe some kind of condenser which is used in obtaining pure water.

7. In what way does distilled water differ from ordinary water?

8. Suppose you were on a small ship and the supply of fresh water had run short, how could you obtain water fit to drink from sea water?

\section{LESSON III.}

\section{MOISTURE IN THE AIR.}

PRACTICAL, WORK.

Things required.-As in the last lesson; also evaporating basin and small wide-mouthed bottles. Balance and box of weights. Calcium chloride (anhydrous) and strong sulphuric acid. 
STRONG SULPHURIC ACID SHOULD BE HANDLED WITH GREAT CARE.

\section{What to do.}

Repeat the experiments on condensation in the last lesson.

Moisture taken from the air by calcium chloride.-Place some lumps of dry white calcium chloride in a basin, and find the mass of the basin and its contents. Expose the calcium chloride to the air for two or three hours. Notice the solid has disappeared and a liquid is present in its place. Find the mass of the basin and liquid; you will find it greater than before. The increase shows the mass of the water taken out of the atmosphere by the calcium chloride.

Moisture taken from the air by sulphuric acid.Repeat the last experiment, substituting a small widemouthed bottle for the basin, and strong sulphuric acid for the calcium chlor-

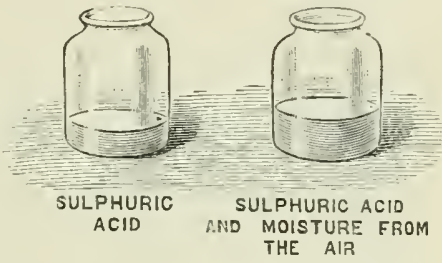

FIG. Io.-When sulphuric acid is exposed to the air for a few day's it absorbs so much moisture that a rise of level is produced. ide. Leave the acid exposed for a day, and, as before, notice the increase of mass. Weigh again after a second day's exposure and notice the further increase of mass.

\section{REASONS AND RESULTS.}

There is always water vapour in the air.-Since, as was learnt in the last lesson, evaporation is always going on from every surface of water, whether it be that of sea, lake, or river, there must always be some water vapour present in the air. The amount on hot days is greater than on cold ones, because the warmer the air the larger the amount of moisture it can take up. For this reason clothes usually dry more quickly on hot than on cold days. When describing conclensation, some of the ways in which the presence of this water vapour can be shown were explained. Whenever a cold surface comes into contact with warm air, the water vapour which the air contains is deposited in the form of visible moisture.

Some substances take water vapour out of the air.-If you examine the salt on the dinner-table from time to time, you will 
notice that on some days it is moist, on others quite dry. Some persons hang up seaweed in their houses, and observe that while on some days it is stiff and dry, on others it is moist and limp. The difference in the dampness of the salt or the seaweed on different days depends upon the amount of moisture cibtained from the air.

Another simple experiment may be made to show the power some substances have of absorbing moisture from the air; and it also proves that there is really water vapour in the atmosphere. Calcium chloride and strong sulphuric acid (oil of vitriol) both have this power of taking up moisture. Calcium chloride, in the form in which it is generally used in the laboratory, is a white solid. If a lump of it is placed in an

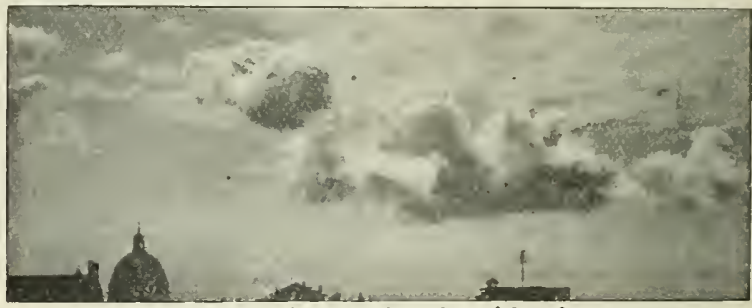

FIG. ir. - Clouds consist of condensed particles of water vapour.

evaporating basin and left freely exposed to the air for an hour or two, it is found on examining the contents of the basin after this time that, in the place of the dry white solid lump taken from the bottle, there is some liquid only to be found. This liquid is the water which has been absorbed from the air and has dissolved the lump of calcium chloride.

If the basin and dry calcium chloride are carefully weighed before exposing to the air, and the basin and liquid are again weighed after all the solid has disappeared, it will be found that the liquid has a greater mass than the calcium chloride which was used. In fact, the difference in the two weighings shows the mass of the water which the solid has taken out of the air.

If some strong sulphuric acid in a small wide-mouthed glass bottle is weighed, and then the acid is exposed to the air for a few days and the mass again determined, an increase in mass and also in volume is noticed. The increase shows exactly 
how much water vapour has been taken out of the air by the sulphuric acid.

The water vapour in the air sometimes becomes visible.-One instance of this has been already mentioned. When a person breathes on a cold frosty day, the moisture in his breath becomes condensed, and is visible as a cloud of mist in the air in front of his mouth.

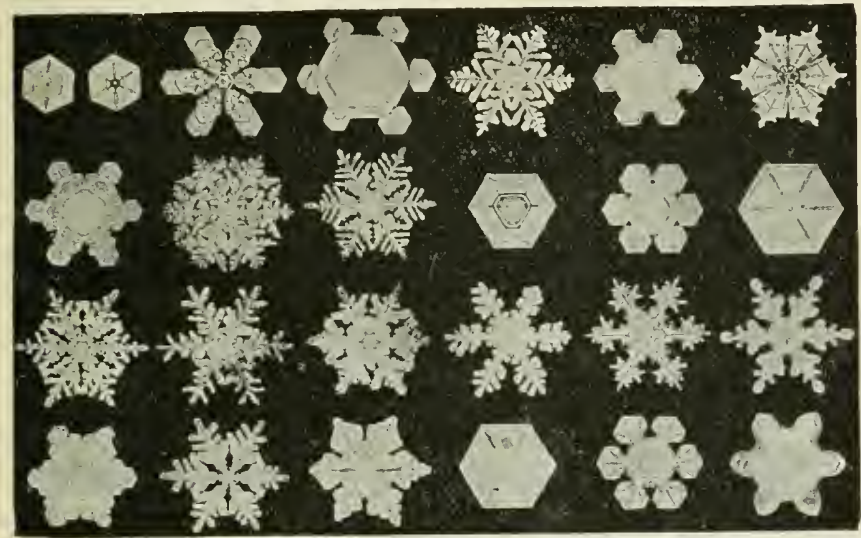

FIG. 12.-Snow Crystals. From Photographs by Mr. W. A. Bentley.

Whenever the air is cooled sufficiently there is a condensation . of water vapour, and the drops of water thus formed build up one of the following forms of condensed water vapour:
(a) Mists and fogs.
(d) Snow, hail, and hoar-frost.
(b) Clouds.
(e) Dew.
(c) Rain.

Mists, fogs, and clouds are very much alike, and all of them consist of small droplets of water condensed from the air. When a number of these droplets run together, on account of further cooling, drops of rain are produced. When the temperature is below the freezing point of water, hoar-frost and snow are formed from the moisture in the air instead of mist and cloud. You have probably noticed frost figures upon window panes in the winter. The figures consist of frozen moisture from the air. 
But whichever form the water vapour assumes when it becomes visible, one fact always remains the same. The visible fog, cloud, rain, or other form into which the vapour is converted is always the result of condensation brought about by cooling. This cooling may be produced by several causes. For instance, the air containing invisible water vapour may become colder by coming into contact with a second colder body of air, or with the surface of a cold mass of land, or by suddenly getting larger. Air, like other gases, always occupies as much space as it can, and if any quantity is permitted to expand it cools itself by the very act of expansion.

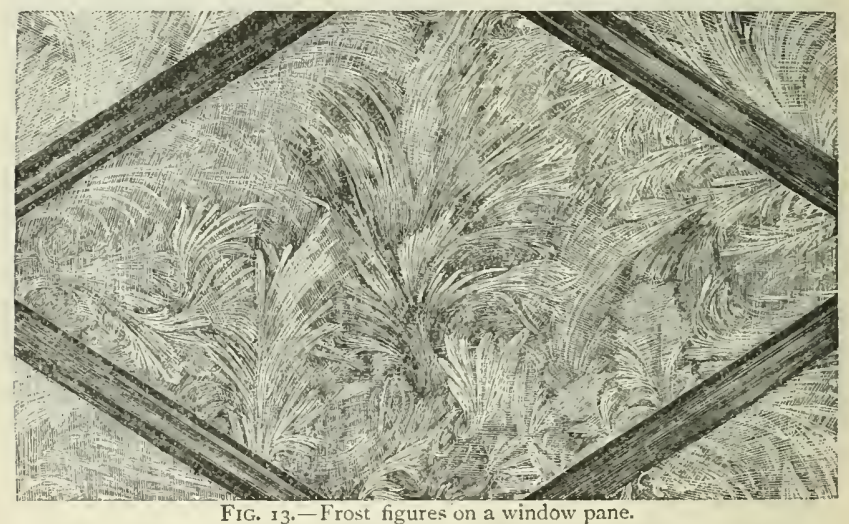

Effects of the water vapour in the air.-It is important for some purposes that the exact amount of water vapour in the air should be known. For instance, the "dryness" or "wetness" of the air has a very great influence upon health. Some persons are unable to keep in good health in a damp atmosphere. For this, and other reasons, it is often necessary to find out exactly how much water vapour the air contains. But it must not be supposed from this statement that the actual quantity of such moisture in the air decides whether the air is damp or dry. Air which feels damp may really only contain a small amount of vapour, and perhaps very much less than air which feels dry. Air feels dry when it contains considerably less water vapour than it is capable of holding. Damp air has as much, or nourly as much, water vapour as it can possibly take up. 
Evaporation goes on more readily in dry than damp air. This accounts for the fact that clothes hung out in the air often dry very quickly, while if the air already contains nearly as much water vapour as it can hold, it can take little from the wet clothes, and they therefore dry slowly.

TO BE REMFMBERED.

There is always water vapour in the air. - This is due to the continual evaporation which is going on from every surface of water.

Some substances, like calcium chloride and sulphuric acid, are able to take up or absorb moisture from the air.

By finding the mass of some calcium chloride or sulphuric acid before and after exposing it to the air, it is possible to ascertain how much water vapour has been taken out of the air.

The water vapour in the air is sometimes condensed and becomes visible as fog, cloud, rain, snow, hail, hoar-frost, and dew.

Damp air contains nearly as much water vapour as it is able to hold at the time; dry air is capable of holding a much larger quantity than it contains.

\section{EXERCISE III.}

I. How could you show there is always water vapour in the air? How does it get there?

2. Name two substances which are able to take water vapour out of the air. How would you use one of them to determine the mass of water vapour absorbed from the air in an hour?

3. The water vapour in the air sometimes becomes 1 isible. What forms does it assume at different times?

4. Why is it sometimes useful to know the amount of water vapour in the air?

5. In winter a cloud of mist seems to come out of the mouth when breathing out of doors, but in summer this cloud is not seen. How do you account for this?

6. In The Song of Hiawatha the following lines occur :

"Came as silent as the dew comes,

From the empty air appearing,

Into empty air returning.

Taking shape when earth it touches;

But invisible to all men

In its coming and its going."

Explain the meaning of these lines, especially lines 2 and 3,5 and 6 , using the information you have learnt in this lesson. 
7. Frost patterns are often seen upon window panes in winter. Are they on the outside or the inside, and what causes them?

8. Why is the cloud of steam from the funnel of a locomotive usually much larger in winter than in summer?

9. In a certain poem the following lines occur:

"I am the daughter of earth and water,

And the nursling of the sky;

I pass through the pores of the ocean and shores,

I change, but I cannot die."

To what does the poet refer? Explain the lines so far as you are able.

\section{LESSON IV.}

HOW THE AMOUN'T OF IVATER VAPOUR IN THE AIR IS MEASURED.

PRACTICAL WORK.

Things required. $-U$-tubes, etc., shown in Fig. I4. Dry handkerchief, or piece of soft muslin, and bobbin of thread. Piece of glass tubing. Laboratory burner. Two precisely similar unmounted thermometers. Retort stand. Tumbler of water. Piece of glass tubing about $\frac{1}{2}$ inch diameter and Io inches long, fitted with corks and tubes. Balance and weights.

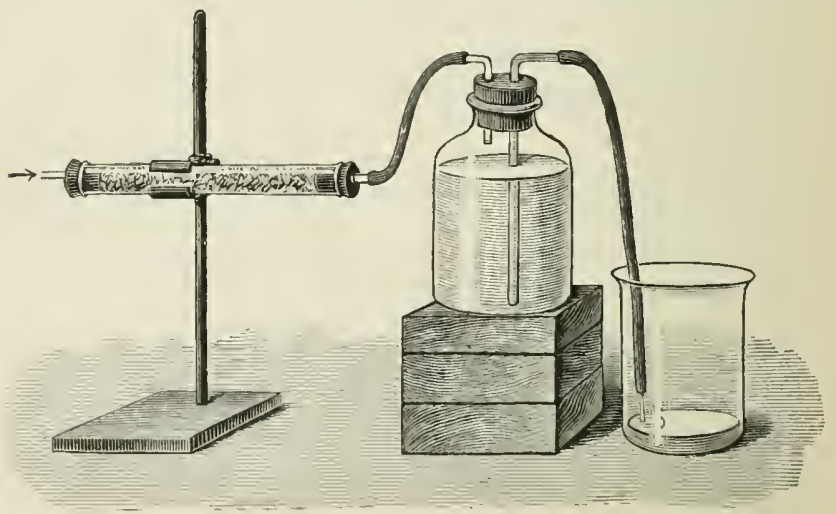

Fic. 14. - Air is being drawn through the horizontal tube, which contains calcium chloride to absorb the moisture. 


\section{What to do.}

Determination of proportion of moisture in air.-Obtain a piece of glass tubing about $\frac{1}{2}$ inch diameter and about Io inches long. Fit a good cork into each end and push through each a piece of narrow glass tubing. Fill the tube with pieces of calcium chloride and weigh the whole. Support the tube in the clamp of a retort stand and connect one end by means of an india-rubber tube to an aspirator. Allow the water to run out of the aspirator, when air will pass over the calcium chloride in the tube. Measure the water which runs from the aspirator, and so determine the volume of air which passes through the tube. At the end of the experiment again weigh the tube and calcium chloride, and so find its increase in mass.

Construction and use of a hygrometer.-Stand a lump of sugar and a lump of salt in a saucer containing a little ink and water. Notice that the liquid rises up the solids.

Place the corner of a dry handkerchief in a glass of water. Notice the rise of the water along the threads of the handkerchief, which in time becomes wet over a large part.

Also notice the rise of water up separate threads and narrow tubes. The tubes can be made by melting a piece of glass tubing in the flame of a laboratory burner and then drawing it out.

Take two precisely similar unmounted thermometers. Simply hang one from a suitable support, such as the ring of a retort stand. Cover the bulb of the other with a square of muslin tied up round it to form a bag. The muslin is best tied just above the bulb by a piece of thread. To this piece of thread attach several other long pieces of thread and let them dip into a glass of water. When the muslin has got thoroughly dainp, compare the readings of

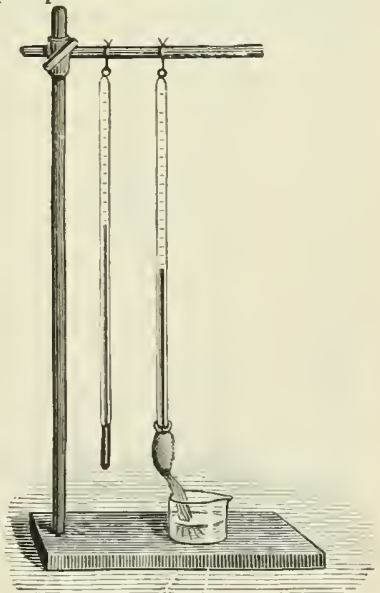

FIG. I5.-The bulb of one thermometer is kept moist, and the evaporation of this moisture causes this thermometer to show a lower temperature tban tbe other. 
the two thermometers. Notice that the temperature recorded by the one with the wet muslin round it is lower than that shown by the other.

'The two thermometers used in this way form what is known as a hysrometer, or a wet and dry-bulb thermometer.

\section{REASONS AND RESULTS.}

The amount of water vapour in the air.-The amount of water vapour in the air can be found by using the facts you have learnt about calcium chloride and sulphuric acid. If a weighed amount of either, or both, of these substances is placed in suitably arranged vessels, and then a known quantity of air is passed through these vessels, the calcium chloride or sulphuric acid will absorb all the moisture, and perfectly dry air will pass on. The only thing which remains to be done is to weigh the calcium chloride or sulphuric acid again, and the increase in mass tells the amount of water vapour in the air which has passed through the apparatus.

The chemical hygrometer.-An arrangement for making this experiment is shown in Fig. 16. $A$ is a vessel the size or volume of which is known. It is first completely filled with water and

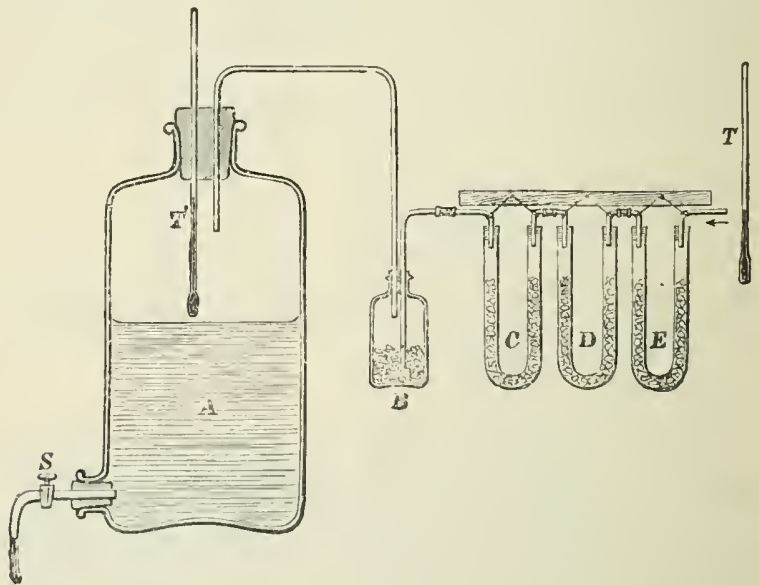

Fic. I6.-As the water runs out of $A$ air is drawn through the tubes $C, D$, $F$, and the bottle $B$. The moisture in this air is absorbed by the sub. stances in the tubes and bottle. 
the tap $S$ turned off. This vessel is connected by a glass tube with the bottle $B$, which in its turn is connected with three $\mathrm{U}$-tubes $C, D, E$. These tubes are similarly connected with one another by glass tubes. $C, D, E$ have small pieces of calcium chloride in them about the size of a pea. $B$ has pieces of pumice stone moistened with strong sulphuric acid. Before the experiment, $B, C, D$, and $E$ are weighed and then connected with $A$. The tap $S$ is turned on, and as the water runs away air is drawn through $E, D, C, B$ in succession, and by the time it gets to the vessel $A$ it is quite dry. The moment the water ceases to flow the tap is turned off, and the series of vessels $B, C, D, E$ are disconnected from $A$ and again weighed. Their increase in mass shows the amount of water vapour in a quantity of air which just fills the ressel $A$. Thus, suppose that the vessel $A$ holds a cubic foot of air, and that the experiment was performed on a summer day, it would probably be found that the bottle and tubes had gained about half a gram in mass.

Instruments which are used to measure the amount of water vapour in the air are called hygrometers, and the apparatus shown in Fig. I6 is a chemical hygrometer. There are many different kinds of hygrometers, but only one other form need be explained in addition to that just described.

The wet and dry-bulb thermometers.-A kind of hygrometer which is in more common use than the one just described is shown in Fig. 17. It consists of two exactly similar thermometers which are usually fixed side by side on a suitable frame, as shown in Fig. I7. One thermometer, however, has its bulb covered with a little muslin bag, from which hang several cotton threads. Tliese threads dip into a vessel of water. This is called the wet-bulb thermometer. The other, which only differs from the wet-bulb thermometer in having no wet muslin round it, is the $d r y$-bulb tnermometer.

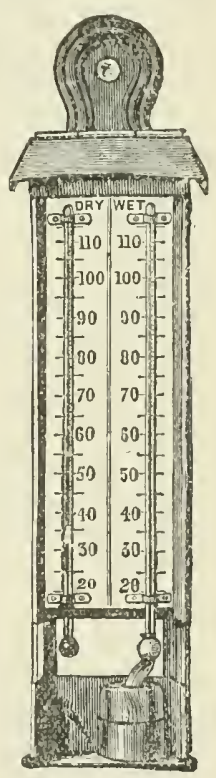

Fig. 17. - A hygro. meter for showing whether the air is dry or moist.

This hygrometer depends for its use upon two facts which 
have already been stated. The first is, that when liquid water is changed into water vapour it must take up heat in doing so. The other fact is, that the quantity of water vapour which air can take up depends upon the amount it already contains.

Now let us see how these facts are utilised in the instrument. When the cotton threads hanging from the muslin bag, surrounding the bulb of one thermometer, dip into the vessel of water, they soon become wet all the way up to the bag. After a moment or two the bag itself gets wet, and as long as the threads are hanging in the water the bag will remain wet.

But, as you also know, evaporation will begin to take place from the muslin bag as soon as it is wet. The heat necessary for the change of the water into water vapour is taken from the bulb of the thermometer inside the bag, and the bulb and quicksilver in it consequently get cooler. This causes the height of the quicksilver in the stem of the thermometer to fall; in other words, the temperature recorded by the thermometer is lower. The more water which is changed into vapour at the surface of the bag the more heat is taken from the bulb of the thermometer, and the lower is the temperature shown. This goes on until the air round the muslin bag can take up no more moisture.

If, therefore, the air is dry to start with, the water on the muslin bag will evaporate quickly, and the temperature of the wet-bulb thermometer will consequently be much lower than that of the other. But the dry-bulb thermometer gives the temperature of the air, and so we see that the drier the air to start with, the greater the difference in the readings of the two thermometers. It is the difference in the readings of these thermometers which is noticed, and which enables the observer to tell whether the air is dry or damp.

Hygrometers of this kind are frequently kept in cotton mills and other factories to indicate whether the air is in a proper condition of dampness or dryness.

By using two unmounted thermometers, and covering the bulb of one as directed at the commencement of this chapter, a wet and dry-bulb thermometer can easily be made.

\section{TO BE REMEMBERED.}

Hygrometers are instruments for measuring the amount of water vapour in the air. 
The chemical hygrometer depends upon the power of alsorbing water vapour possessed by calcium chloride and sulphuric acid.

The wet and dry-bulb thermometer consists of two precisely similar thermometers. The bulb of one is covered with a muslin bag from which hang threads that dip into water. The muslin thus becomes wet, and the evaporation of the water from it lowers the reading of this thermometer. The difference in the readings of the thermometers is great when the air is dry and small when the air has much moisture in it.

\section{EXERCISE IV.}

I. How could you measure the amount of water vapour in the air?

2. What is a chemical hygrometer? Make a sketch of one.

3. How could you prove that when water evaporates, cold is produced?

4. Describe how to use a wet and dry-bulb thermometer.

5. On a certain day the difference in the readings of wet and drybulb thermometers was five degrees, and on another day it was only two degrees. What does this tell you as to the state of the air as regards moisture on the two days?

\section{LESSON V.}

CHANGES OF VOLUME AND DENSITY OF WATER. PRACTICAL WORK.

Things required.-Density bottle, or flask fitted with a stopper through which a narrow tube passes. Retort stand. Coil of "compo" tubing fitted as in Fig. 19. Unmounted thermometer. Beaker. Laboratory burner. Balance. Box of weights. Copper wire. Ice.

\section{What to do.}

To show that hot water is not so dense as cold.-Fill a density bottle ${ }^{1}$ with water at the temperature of the room and determine by weighing the mass of the bottle and the water it contains. Now suspend it by a piece of copper wire in a beaker of water in such a way that the stopper of the bottle is out of water. Raise the temperature of the water in

${ }^{1}$ A small flask fitted with a well-fitting india-rubber stopper, through which passes a short piece of glass tubing with a fine bore, may be used if a density bottle is not at hand. 
the beaker about $20^{\circ} \mathrm{C}$. The water in the bottle expands, and some is forced through the hole in the stopper. When the required temperature has been reached, wipe the top of the stopper with blotting paper and remove the bottle from the beaker, wiping it all over. At the instant of removing the bottle it is full of water. The water soon contracts, and when it is at the temperature of the room the bottle is no longer full of water. When
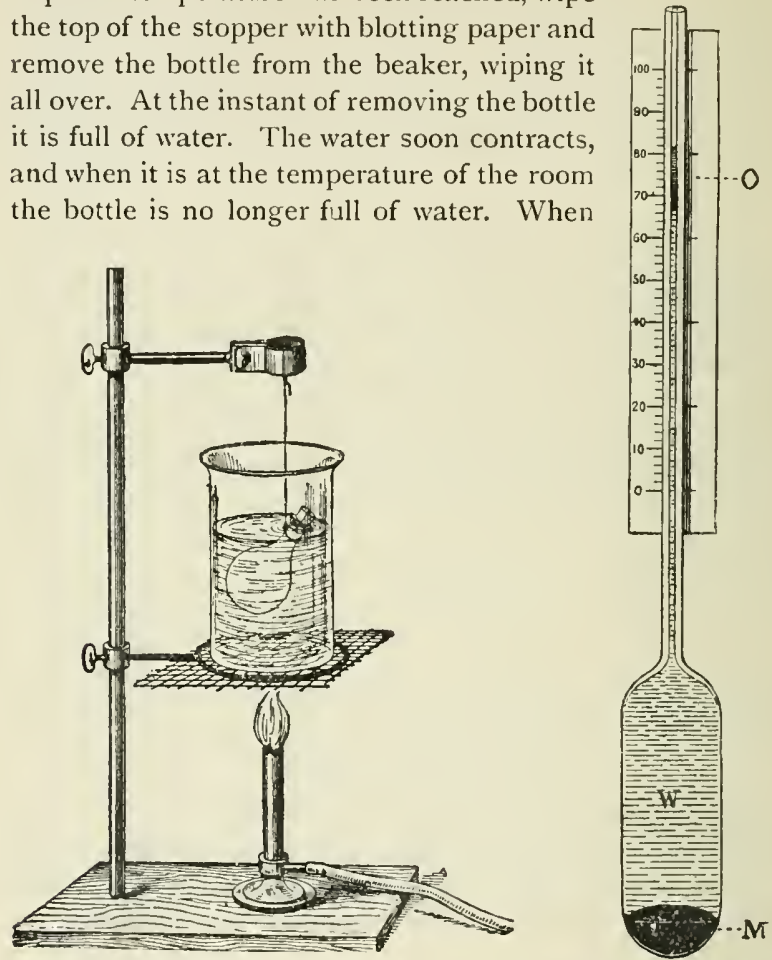

FtG. 18.-Experiment to show that warm water weighs less than the same volume of cold water.

FIG. 19.- Arrangement for showing that water expands when cooled below a temperature of $4^{\circ} \mathrm{C}$.

it has cooled, determine the mass of the bottle and water. It is less than before. The same volume of water has a smaller mass at a higher temperature than at a lower temperature.

Replace the bottle in the water and raise the temperature $20^{\circ} \mathrm{C}$. more than before. More water is lost by expansion. When cool weigh again; the result will be found even less than before. 
Expansion of water near the freezing point.-Procure an apparatus of the form shown in Fig. 19. Heat the bulb; and let it cool with the open end of the tube inverted in mercury. By this means sufficient mercury (M) may be introduced to occupy about one-seventh the volume of the bulb. Then introduce in a similar way sufficient boiled distilled water to fill the remainder of the bulb and part of the stem. A paper millimetre scale is then attached to the tube.

Support this apparatus in a wide test tube containing mercury, so as to secure uniformity of temperature. Place a thermometer in the mercury, and support the wide tube containing it and the apparatus in a beaker of cold water. Notice the position of the top of the liquid in the tube, and read the temperature shown by the thermometer. Add ice ${ }^{1}$ to the water, and as the temperature falls notice the level of the liquid in the tube for every degree down to $1^{\circ}$ or $2^{\circ} \mathrm{C}$. Then let the water in the beaker gradually rise in temperature, and again observe the positions at the same temperatures as before.

The observations will show the temperature at which the water in the apparatus has the least volume, and therefore the maximum density. It is seen that from $4^{\circ}$ C. water expands whether it is warmed or cooled.

\section{REASONS AND RESULTS.}

Hot water is lighter than the same volume of cold water.When a small bottle such as is used for determining the density of a liquid is filled with water, and the temperature is gradually raised above that of the room, by heating it in a vessel of water, the liquid in the bottle gradually expands and some of it is forced out. If the mass of the water which just fills the bottle at the temperature of the room is determined by weighing, it is found by weighing again that the water which just fills the bottle at a higher temperature has a smaller mass. Hot water is thus proved to be lighter than the same volume of cold water; in other words, the density of hot water is less than the density of cold water.

1 If ice cannot be obtained, a mixture of sodium sulphate and hydrochloric acid will make a freezing mixture, 
Changes in volume as water is cooled.-The first effect of cooling water is to make it get smaller in volume, that is, to contract. This goes on steadily until the temperature of four degrees centigrade $\left(4^{\circ} \mathrm{C}\right.$.) is reached. From this point, though the cooling is continued, the water no longer contracts, but begins to get larger or expand. This expansion continues until the temperature $0^{\circ} \mathrm{C}$. is reached, when the water begins to change into solid ice, which is, as will be shown in another lesson, much larger than the water from which it is formed.

Changes in volume as water is warmed.-If, instead of making warm water cooler, some ice-cold water, at a temperature of say $I^{\circ} \mathrm{C}$., were allowed to get warmer, which it would do simply by being exposed to the air in the room, it would be noticed that while the water was being warmed up to $4^{\circ} \mathrm{C}$. it would steadily get smaller in volume, but after this temperature was reached it would get larger and larger as it became warmer and warmer. Thus, unlike most other liquids, water at a temperature of $4^{\circ} \mathrm{C}$. expands not only if it is heated, but also if it is cooled.

Changes in density as water is cooled.-It has already been learnt that if the volume of a body gets greater, while its mass remains the same, what is called the density of the body must get less and less. It is quite clear that, if the same amount of matter is made to take up more space than before, it must be less closely packed into that space, and the closeness with which matter is packed into a space is called density. What changes in density take place when water is gradually cooled? Since the same mass of water gradually gets smaller and smaller in volume as it is cooled down to $4^{\circ} \mathrm{C}$., we can express the same fact in another way, and say that its density becomes greater and greater as it is cooled down to $4^{\circ} \mathrm{C}$. As below this temperature water gets larger as it is cooled, its density must get less and less. If water at $\mathrm{I}^{\circ} \mathrm{C}$. is gradually warmed, the density steadily increases up to $4^{\circ} \mathrm{C}$., and from that temperature upwards the density regularly diminishes.

At a temperature of $4^{\circ} \mathrm{C}$. water occupies its least volume and is therefore at its greatest density. The temperature $4^{\circ} \mathrm{C}$. is therefore known as the temperature of maximum density of water.

Graphic representation of results.-A simple way of graphically showing the changes in volume which water undergoes when cooled is scen in Fig. 20. The water is represented as 
contained in a thermometer tube, and the level of the water in the tube for each degree of temperature between $8^{\circ} \mathrm{C}$. and $0^{\circ} \mathrm{C}$. is shown. The size of the water is seen to get smaller down to $4^{\circ} \mathrm{C}$. and then to begin getting larger, which it continues to do up to $0^{\circ} \mathrm{C}$. So, too, the water is at once seen to be packed into a smaller space, and consequently to get denser and denser as it is cooled down to $4^{\circ} \mathrm{C}$., and then to become less dense

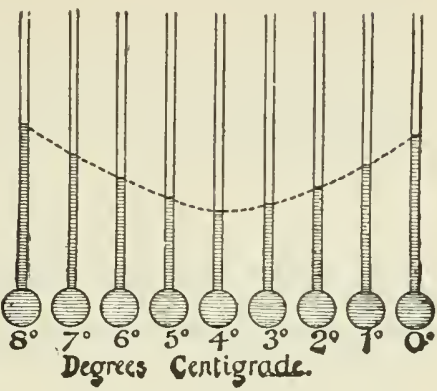

Fig. 20.-Changes of volume of water be. tween the temperature of $8^{\circ} \mathrm{C}$. and $0^{\circ} \mathrm{C}$. as the lowering of temperature is continued.

Instead of showing the facts in this way, squared paper may be used to represent the alterations in volume by the plan described in the First Stage of this course.

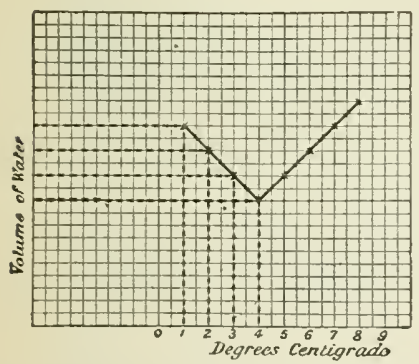

FIG. 2r.-Graphic representation of changes of volume of water near the freezing point.

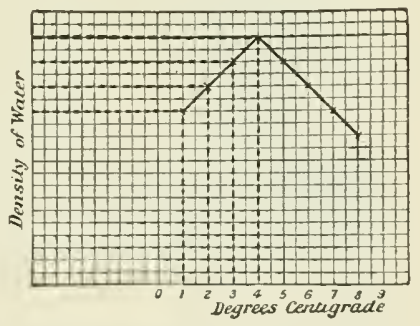

FIG. 22.- Graphic representation of changes of density of water near the freezing point.

Along the horizontal line the consecutive degrees of temperature on the centigrade scale are marked and numbered. The volume which the quantity of water experimented with has at each degree of temperature is represented, on a convenient scale, by the height of the rertical lines erected over the points representing the degrees of temperature. When the tops of these verticals are joined in by a continuous line we have a 
graphic representation of the various changes in volume experienced (Fig. 2I).

The changes in density can be also represented by this plan. As before, the degrees of temperature are marked along a horizontal line, and the density at each consecutive degree is represented by the height of the perpendicular erected at these points (Fig. 22).

\section{To he Remembered.}

The volume of a given mass of water changes as its temperature rises and falls.

Hot water is lighter, or its density is less, than the same volume of cold water.

Water has its least volume and greatest density at a temperature of $4^{\circ} \mathrm{C}$.

From the temperature $4^{\circ} \mathrm{C}$. water expands whether it is warmed or cooled.

The temperature of the maximum density of water is $4^{\circ} \mathrm{C}$.

\section{Exercise V.}

I. How could you prove that cold water is denser than hot water?

2. Describe carefully what changes occur in the volume and deusity of some water if the water is gradually coolet below the temperature of the room.

3. How would you show experimentally that water occupies a smaller volume at $4^{\circ} \mathrm{C}$. than at any other temperature?

4. Describe an experiment to prove that the density of water gets less and less as its temperature is raised above that of the room.

5. Draw a diagram to show graphically the changes in volume which a given mass of water undergoes as its temperature is raised from $\mathrm{l}^{\circ} \mathrm{C}$. to $10^{\circ} \mathrm{C}$.

6. Some hot water, coloured with ink, is poured gently into a beaker containing cold water. What would you notice about the mixture?

7. If you wished to quickly mix some hot and cold water, would you pour the hot water into the cold or the cold water into the hot? Give reasons for your answer. 


\section{LESSON VI. \\ MAXIMUM DENSITY OF IVATER}

PRACTICAL WORK.

Things required.-Burette, or graduated glass tube. Narrowmouthed, corked bottle to hold one fluid ounce, or a glass bulb blown upon a short piece of thermometer tubing. Duster. Unmounted thermometer. Small cast-iron cylinder with screw top. Paraffin oil. Ice and salt, and tin to hold them.

\section{What to do.}

Density of ice.- Half fill a burette or graduated glass tube with paraffin oil. Put the burette in a jar containing ice and water until the temperature is nearly $0^{\circ} \mathrm{C}$. Observe the level of the paraffin oil in the burette. Gently drop in pieces of dry ice, and observe the volume of the ice added, by noticing the rise of level of the oil. Let the ice melt, and when it is converted into water, again observe the reading of the burette; it will be less than before. This reading shows that the volume of water produced by the melting of a certain known volume of ice is less than the volume of ice. If the volume of the ice was Io cubic centimetres,

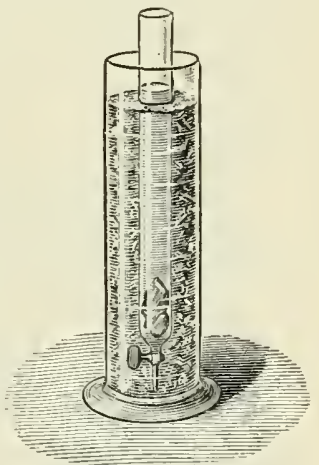

Fig. 23.-Arrangement for showing that the volume of water produced by melting ice is less than the volume of the ice used. the volume of the water produced from it would be 9 cubic centimetres.

Expansion of water when freezing.-Obtain a I-Oz. corked bottle with a narrow neck. Fill it with water and cork tightly, driving the cork in as far as possible. Pass strong fine twine several times round the bottle from top to botton and over the cork, to keep the latter in. If the string is likely to slip, notches in the cork will prevent it. A small piece of wood 
similarly notched and put at the bottom of the bottle will prevent the string slipping there. Place the bottle in a bowl and

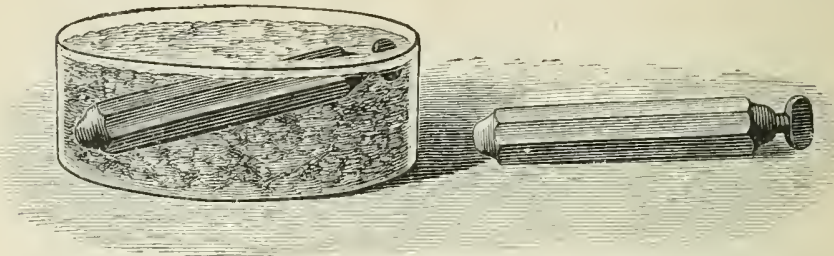

FIG. 24.- If an iron bottle is filled with water, and the stopper is screwed in, the ice bursts the bottle as the water freezes.

cover it with a freezing mixture of ice and salt. Carefully cover the bowl with a duster or cloth until you hear the bottle burst, then take off the covering and examine what has happened. Describe and explain the result of your experiment.

If possible, repeat the experiment with a small cast-iron cylinder, provided with a stopper which screws in. A louder explosion is heard.

You will understand from these experiments why water pipes burst in winter. Wby is it that the burst pipes are not found until the thaw sets in?

Why ice floats in woter.--Put a few pieces of ice in a glass of water. Does the ice float or sink?

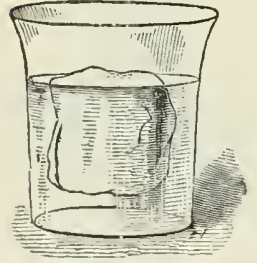

Fig. 25.- Ice floats in water, but the volume below the surface is nine times greater than that above it. Is ice heavier or lighter than an equal bulk of water? How do you account for the difference of density between ice and water?

Densities of solid and liquid wax.Cut a piece of wax candle into chips, and put them into a test-tube. Nelt the wax by gently heating the test-tube, and while the wax is liquid throw it in two or three more small pieces. Do these pieces float or sink? Can you tell from your observations whether wax contracts or expands when passing from the liquid to the solid state?

\section{REASONS AND RESUI.TS}

Maximum density of water.-It has been explained that any mass of water has a smaller volume at $4^{\circ} \mathrm{C}$. than at any other 
temperature. But when the volume is least the density is greatest, therefore the temperature of $4^{\circ} \mathrm{C}$. is the temperature at which water has its maximum density.

It may be remembered that in the First Stage of this course of work the mass of 1 cubic centimetre of water was said to be I gram. This, however, is only exactly true when the temperature of the water is $4^{\circ} \mathrm{C}$. At any other temperature the mass of a cubic centimetre of water is

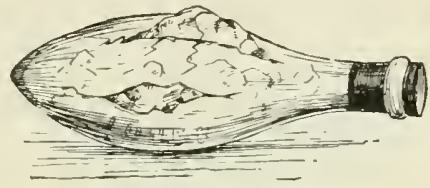

Fig. 26.-If a bottle filled with water, and corked, is left out of doors on a frosty night, the water freezes and bursts the bottle in doing so. less than I gram.

Expansion of water as it freezes.-When water is cooled down to $0^{\circ} \mathrm{C}$. it changes into ice, and the jce which is formed takes up more room than the water does. In forming ice, the water therefore expands. That this is really the case we can prove by filling a small bottle with water and inserting a tightlyfitting cork, which will not allow air to enter. If the corked

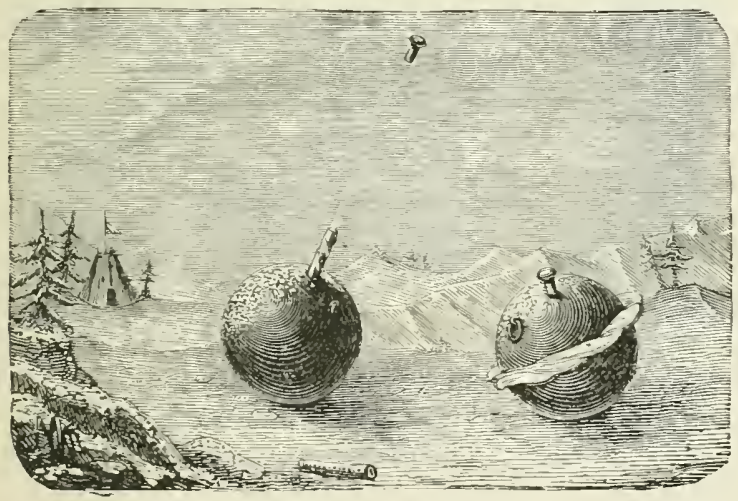

FIG. 27.- Bombs bave been filled with water and burst by the expansion of the water during freezing.

bottle is now placed into a mixture of ice and salt and is left in this freezing mixture (as a precaution the bottle containing the freezing mixture and the flask should be covered with a duster), after a time a slight explosion is heard. When 
the bottle is uncovered and examined it is either found that the cork has been driven out, or, if the bottle was not strong enough to bear the strain, it will be cracked, and perhaps some ice may be found protruding from the neck or rent. The explosion is louder if a smaller cast-iron cylinder with a top which screws in is used. This experiment has been tried on a large scale. Large bomb-shells have been completely filled with water, securely plugged, and left out a whole night during very cold weather. In the morning some were found cracked all round the middle, with a large belt of ice sticking out through the crack all round, and from others the plug had been forced out and a rod of ice was found sticking out where the plug had been inserted.

Not only do we learn from such experiments as these that water expands in forming ice, but also that the force with which the expansion takes place is very great, being strong enough to break a bomb-shell. When water turns into ice, the latter

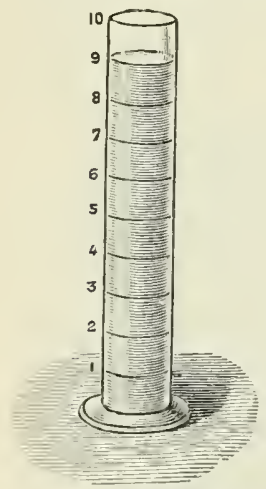

FIG. 28.-If the water in the jar were frozen the ice formed would fill the jar. occupies more room than the water from which it was produced; in fact, every 10 cubic inches of water produces about I I cubic inches of ice. Hence, if the cylinder shown in Fig. 28 were filled with water up to the number 9 , the water would, if converted into ice, fill the vessel to the top. It is because of this expansion of water that we often have water-pipes bursting during frosty nights. The bursting of the pipe takes place when freezing occurs, but is only discovered when the thaw takes place. This has given rise to a belief among some people that thawing causes the pipes to burst, but this is quite wrong.

How ice is formed at the top of a pond. - Let us now try to apply what has been learnt about the peculiar way in which water behaves when it is cooled, and see what happens when the water of a pond is gradually cooled on a frosty night. As the temperature of the water at the surface gets lower and lower, the water there gets smaller and consequently denser. The surface water therefore sinks, and its place is taken by warmer water from below. The same cooling and sinking of the surface water continues until 
the temperature of the whole of the water is $4^{\circ} \mathrm{C}$., at which temperature it has its maximum density, and consequently when the water at the bottom of the pond reaches this temperature it remains where it is. After the temperature of the water at the surface has reached $4^{\circ} \mathrm{C}$, any further cooling causes it to expand and get lighter, and this result continues until $\mathrm{o}^{\circ} \mathrm{C}$. is

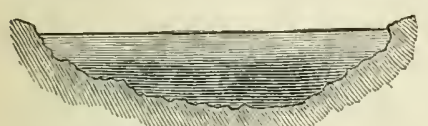

WATER BEFORE FREEZING HAS COMMENCED

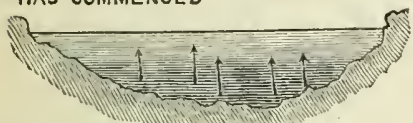

WATER BELOW A TEMPERATURE OF $4^{\circ} \mathrm{C}$ RISING TO THE TOP

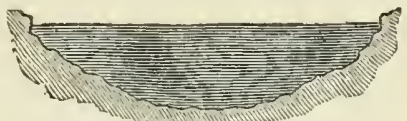

ALL THE WATER AT $4^{\circ} \mathrm{C}$

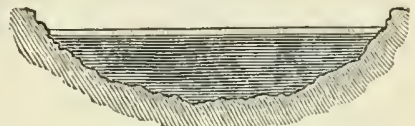

ICE AT SURFACE. WATER AT TEMPERATURE OF $4^{\circ} \mathrm{C}$

FIG. 29. - Stages in the freezing of a pond of water.

reached. The water at the surface is then changed into ice, which, being considerably lighter than water, remains on the surface. Ice is, moreover, a very bad conductor of heat, so that the temperature of the water below the ice only gets cooler very slowly and the thickness of the ice only increases very gradually.

This condition of things prevents several disastrous consequences which would of necessity result if ice were denser than water. If ice were denser than water it would sink to the bottom of the pond at the moment it was formed, and as the frost continued the ice would spread throughout the mass of the water, and not only would this cause the destruction of all the water animals in the pond, but the heat of summer would probably be insufficient to completely melt it.

Effects of heating water. Summary of results.-After ice has been changed into water at $0^{\circ} \mathrm{C}$, each successive addition of heat has two effects. First, the temperature is raised, and secondly, the size or volume of the water is altered. While, however, the temperature rises regularly, the alterations in size are not regular. As you have found, the size of the water gets smaller and smaller to begin with for every degree increase of temperature. This is continued until the temperature of $4^{\circ} \mathrm{C}$. is 
reached, at which temperature the water has a smaller size than at any other, or it is at its maximum density. From $4^{\circ} \mathrm{C}$. onwards, the temperature and volume of the water increase together as the water is more and more heated, and this holds true until a temperature of $100^{\circ} \mathrm{C}$. is reached, when the water is changed into steam as the water boils. When once the water has commenced to boil, no matter how vigorous the boiling, the temperature remains at $100^{\circ} \mathrm{C}$., or, as it is called, the boiling point of water, so long as any water is left.

Graphic representation of the changes of volume and temperature accompanying changes of state of water.-These changes of volume and temperature are of such importance that you

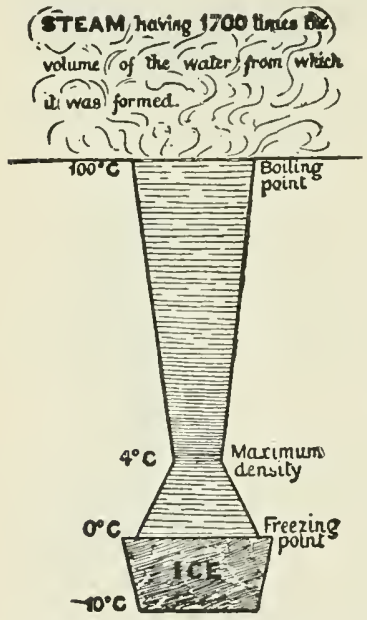

F1G. 30.-Water expands whether it is heated or cooled from a temperature of $4^{\circ} \mathrm{C}$. It also expands sud. denly when it freezes and when it is changed into steam. should endeavour to thoroughly understand them. It will help you to do so, and also to remember them more easily, if you represent the observations graphically. One way of doing this is shown in Fig. 30. The changes in temperature are marked on the left hand side of the diagram. The width of the shaded portions of the illustration represents the volume at the various temperatures. Beginning at the bottom of the figure, you are supposed to start with a lump of ice at ten degrees below zero centigrade (chat is, $-10^{\circ} \mathrm{C}$.), and to gradually warm it. Until the temperature reaches $0^{\circ} \mathrm{C}$. the ice behaves like most other solids, and regularly expands as it is warmed. When the temperature of $\mathrm{O}^{\circ} \mathrm{C}$. is reached, though the heating goes on steadily, the temperature does not alter. The heat is used up in changing the ice into water, and the volume of the water as shown by the width of the shaded portion of the figure is less than that of the ice. When all the ice is changed into water the further addition of heat causes the increase of temperature up to $4^{\circ} \mathrm{C}$., but as the width of the shaded part shows, the volume gets 
smaller until this temperature is reached. From $4^{\circ} \mathrm{C}$. to $100^{\circ} \mathrm{C}$. the diagram shows temperature and volume increasing together. The temperature remains at $100^{\circ} \mathrm{C}$. until all the water is changed into steam, and the size of the steam is 1,700 times greater than that of the water at $100^{\circ} \mathrm{C}$., from which it was formed. Thus a pint of water would make into $212 \frac{1}{2}$ gallons of stean.

To be Remembered.

The temperature of $4^{\circ} \mathrm{C}$. $\left(39^{\circ} \mathrm{F}\right.$. $)$ is known as the point of the maximum density of water, because at this temperature a given volume of water weighs more than at any other temperature.

When water is changed into ice it increases in volume.-Ice is consequently lighter than water and floats upon it. If this were not so, a pond would begin to freeze at the bottom, and would, during a long frost, become frozen right through.

Ice is lighter than water. - Io cubic centimetres of water at $4^{\circ} \mathrm{C}$. weigh 10 grams; 10 cubic centimetres of ice weigh 9 grams. A cubic foot of water weighs 62 lbs.; a cubic foot of ice only weighs 57 lbs. A cubic foot of water weighs more at $4^{\circ} \mathrm{C}$. than at any other temperature.

\section{Summary of effects of heating ice :}

Up to $0^{\circ} \mathrm{C}$. ice expands.

At $0^{\circ} \mathrm{C}$. ice contracts and forms water.

From $0^{\circ} \mathrm{C}$. to $4^{\circ} \mathrm{C}$. water contracts.

From $4^{\circ} \mathrm{C}$. to $100^{\circ} \mathrm{C}$. water expands.

At $100^{\circ} \mathrm{C}$. steam is formed.

Above $100^{\circ} \mathrm{C}$. steam expands.

\section{EXercise V'T.}

I. What is meant by the maximum density of water? At what temperature is water at its maximum density?

2. By what experiment could you prove that ro cubic centimetres of ice produce 9 cubic centimetres of watcr when melted?

3. How would you show that water expands in freezing?

4. Describe the changes which occur when the water in a pond freezes.

5. How is it that ice begins to form on the top of a pond during a frost?

6. If you had a uniform rod of ice 10 inches long, and you floated it upright in a jar of water, what length of the rod would be under water?

7. If you had a block of ice containing ro cubic feet, how many cubic feet of water would be obtained by melting it ? 


\section{LESSON VII.}

\section{HEAT AND TEMPERATURE.}

\section{PRACTICAL WORK.}

Things required.-Funnel, pipette or glass tube; india-rubber tubing to connect them and a clip. Tin canister and a can or beaker of about twice the diameter. IVide glass tubing or straight lamp glasses. Glass funnel. Corks and bent tubing as in Fig. 32. Thermometer. Balance and weights. Water. Mercury.

\section{What to do.}

Water-level.-Connect the neck of a large funnel with a glass tube by means of india-rubber tubing (Fig. 31). Pinch

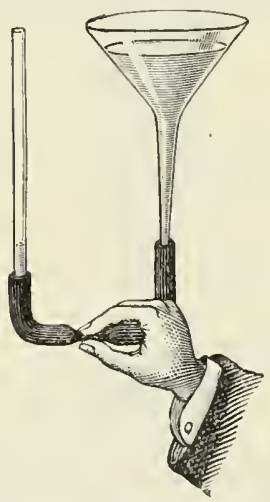

Fig. 3r.-Liquids fiow from high to lower levels when they can. the tubing, and pour water into the two glass vessels to different levels. Release the tubing, and notice that the water flows from the vessel in which the level was higher until the level is the same in each. There may be much more water in one vessel than in the other, but the flow stops when the level is the same in both vessels.

Heat-level or temperature.-Fill a tin canister about one-half full of warm (not hot) water, and place it in a larger canister or beaker about one-half full of cold water from the ordinary supply. Dip your fingers into the water in the two vessels every few minutes. After a short time you will find that each feels the same. The warm water becomes colder and the cold water becomes warmer, until they are both of the same temperature or heat level.

Rise and fall of water-lezel.-Connect two pieces of wide glass tubing of the same diameter with an india-rubber tube, 
as in Fig. 32. Pinch the india-rubber tube. Pour water into one of the glass tubes until the column is about 4 inches high, and into the other tube until it is half this height. Release the india-rubber, and when the flow of water has ceased measure the length of each column; it will be found to be 3 inches.
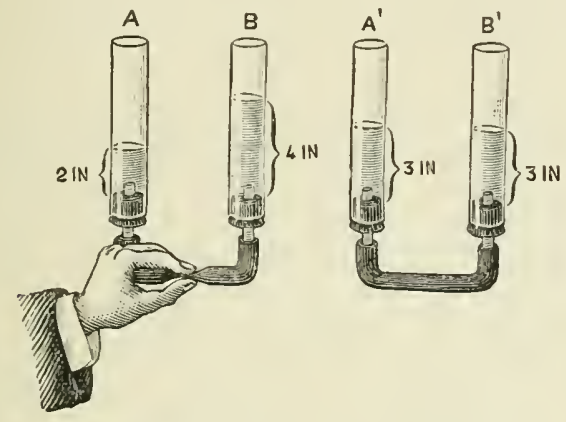

FIG. 32.-When the liquid in $A$ and $B$ is allowed to flow it comes to rest as shown in $A^{\prime}$ and $B^{\prime \prime}$. The rise of level in $A$ is equal to the fall in $B$.

Repeat the experiment with water at any convenient heights in each of the tubes, but let the levels be different. Write down your observations in columns, as shown below :

\begin{tabular}{|c|c|c|c|c|}
\hline $\begin{array}{c}\text { LEVEL OF } \\
\text { WVTER IN } \\
\text { TUBE } A \text {. }\end{array}$ & $\begin{array}{l}\text { LEVEL OF } \\
\text { WATER IN } \\
\text { TUBE } B \text {. }\end{array}$ & $\begin{array}{l}\text { LEVEL IN } \\
\text { TUBES AFTER } \\
\text { MIXING. }\end{array}$ & $\begin{array}{l}\text { FALI. OF } \\
\text { LEVEI. }\end{array}$ & $\begin{array}{l}\text { RISE OF } \\
\text { LEVEL. }\end{array}$ \\
\hline $\begin{array}{l}\text { Example- } \\
2 \text { inches. }\end{array}$ & 4 inches. & 3 inches. & $\mathrm{I}$ inch. & 1 inch. \\
\hline
\end{tabular}

You will notice that the fall of level in one tube is equal to the rise of level in the other tube in each case. Now, by using the measures already made, construct another table, thus : 


\begin{tabular}{c|c|c}
\hline $\begin{array}{c}\text { LEVEL OF } \\
A .\end{array}$ & $\begin{array}{c}A+B \\
2\end{array}$ & $\begin{array}{c}\text { LEVEL OF AFTER } \\
\text { MiXiNG. }\end{array}$ \\
\hline & $B$. & \\
\end{tabular}

The third and fourth columns will be found to be the same, showing that, when using tubes of the same diameter, the level of water after mixing is equal to half the sum of the two levels before mixing. If any of the water leaks out during the experiment, the level after mixing will, of course, not be half way between the two first levels.

Rise and fall of heat-level or temperature.-Put a certain mass of warm water, that is, water at a high heat-level, in a beaker, and an equal mass of cold water in another beaker. Observe the temperature of each by means of a thermometer. Pour the cold water into the hot. It will be found on stirring them together with the thermometer (taking care not to break the thermometer), that the temperature of the mixture is midway between the two original temperatures.

Mix warm mercury at a temperature of say $50^{\circ} \mathrm{C}$. with an equal mass of mercury at the temperature of the room. Notice that the resulting temperature is midway between the temperatures of the two quantities of mercury.

The observations made in these two experiments can be set down in tables of the same kind as were used for water levels, thus :

\begin{tabular}{|c|c|c|c|c|}
\hline $\begin{array}{c}\text { TEMPERATURE } \\
\text { OF } \\
\text { WARM WATER. }\end{array}$ & $\begin{array}{c}\text { Temperature } \\
\text { OF } \\
\text { Cold Water. }\end{array}$ & $\begin{array}{c}\text { TeMPERATURE } \\
\text { OF } \\
\text { MIXTURF. }\end{array}$ & $\begin{array}{c}\text { FALL OF } \\
\text { TEMPERATURE } \\
\text { OF } \\
\text { Hor WVATER. }\end{array}$ & $\begin{array}{c}\text { Rise OF } \\
\text { TEMPERATURE } \\
\text { OF } \\
\text { COLD WATER. }\end{array}$ \\
\hline $\begin{array}{c}\text { Example - } \\
60^{\circ} \mathrm{C} .\end{array}$ & $\mathrm{I} 4^{\circ} \mathrm{C}$. & $37^{\circ} \mathrm{C}$. & $23^{\circ} \mathrm{C}$. & $23^{\circ} \mathrm{C}$ \\
\hline
\end{tabular}


You will probably find that the temperature of the mixture will not be exactly midway between the temperatures of the hot and cold water, because a little heat will be lost while the liquids are mixing.

From your observations construct a table like the one below, to show that the heat-level, or temperature, produced by mixing equal masses of the same liquid at different temperatures, is equal to half the sum of these temperatures :

\begin{tabular}{c|c|c|c}
\hline $\begin{array}{c}\text { Temperature of } \\
\text { Water } A .\end{array}$ & $\begin{array}{c}\text { Temperature of } \\
\text { Water } B .\end{array}$ & $\frac{A+B}{2}$. & $\begin{array}{c}\text { Temperature } \\
\text { OF Mixture. }\end{array}$
\end{tabular}

REASONS AND RESULTS.

Distinction between heat and temperature.-It is important to understand clearly the difference between heat and temperature, in order to prevent an incorrect and confusing use of these words. A few simple examples will serve to illustrate the distinction. Suppose a master strikes a boy with a cane. The boy feels a pain, but the pain is not the cane; it is an effect produced by the cane. If the master strike his desk with his cane no pain is felt, but a noise is heard. You see, therefore, that the same cause may produce different effects. Just as the same amount of caning produces more effect upon some boys than upon others, so the same amount of heat has more effect in raising the temperatures of some substances than in raising the temperatures of other substances. Now, increase of temperature may for the present be regarded as an effect produced by heat. It is analogous to the level of a liquid, or the pitch of a musical note. A liquid may be at a high or low level, and a musical note may be high or low; and in the same way we may refer to the temperature of a body as high or low.

High and low temperatures. - A hot thing is said to be at a high temperature; and a cold one to be at a low temperature. If a hot flat iron be put upon a cold slate, the cold slate soon 
becomes heated, and the hot flat iron becomes cooler. Some of the heat of the hot iron is given up to the cold slate. Whenever a hot thing and a cold one are brought into contact there is a transference of heat from the hot one to the cold, until they are both of the same degree of hotness or coldness. Now, if in the last sentence the words "at a high temperature" are used for "hot," and "at a low temperature" for "cold," a definition of temperature can be obtained. Thus, if a body at a high temperature and one at a low temperature be brought into contact, heat passes from the former to the latter until they are both at the same temperature. Hence, temperature may be defined as a condition or state of a body which is changed by the gain or loss of heat.

Similarity of temperature and water-level.- It is well known that if two vessels containing water at different levels communicate with one another, as shown in Fig. 31, and one vessel is raised above the other, water at once flows from the vessel in which the water is higher towards the vessel in which it is lower. This is a consequence of a property possessed by all liquids which makes them, as we say, "seek their own level." This flow of water continues until the liquid in the two vessels is at the same level, no matter what is the size of the vessel. Water will flow from the large to the small vessel or from the small to the large, and the direction of flow is always towards the lower level. Evidently this is a similar state of things to that which we have in the case of a hot and a cold substance in contact. In one case there is a flow of water until the level is the same in the two vessels. In the other there is an exchange of heat until the temperature of the two bodies is the same. The higher liquid corresponds to the body with the higher temperature, and no matter what is the size of the body, if it has a higher temperature than another, heat passes from it to that body. It may therefore be said that temperature corresponds to water-level.

Changes of water-level in communicating vessels.-If two vessels of the same size are in communication with one another, so that water can flow freely from one to the other, then any amount of water placed in one of them is shared equally between the two. Suppose the communication to be stopped for a while, and water to be poured into one vessel to a level of eight inches, and into the other to a level of two inches. Upon 
permitting the liquids in the two vessels to mix, the high level in one would fall and the low level in the other would rise until the two levels were the same, namely, five inches. The liquid in one vessel would thus have its level reduced by three inches, and that in the other would have its level raised by three inches. With two vessels of the same size, the fall in one would always be equal to the rise in the other; and the final level would therefore be equal to the original levels added together and divided by two. Thus, if the levels before mixing were 8 inches and 2 inches, the level after the flow would be $\frac{8+2}{2}=5$ inches. Of course, this rule only applies when vessels of the same size are used.

Changes of heat-level produced by mixing hot and cold liquids. -It has been explained that temperature may be regarded as heat-level, so that a hot substance is at a higher heat-level than a colder one. Now suppose that a certain mass of hot water is put into one vessel and an equal mass of cold water into another. We shall then have equal masses of water at different heat-levels. If the two liquids are mixed together, the temperature, or heat-level, of the hot water will fall, and the temperature of the cold will rise, in a similar way to the fall and rise of the water-levels in the communicating vessels. The loss of level of one will be equal to the gain by the other, so that the temperature of the mixture will be midway between the two original temperatures. Thus, if the masses of water are equal, and the temperatures at first are $60^{\circ} \mathrm{C}$. and $20^{\circ} \mathrm{C}$, then the temperature of the mixture will be $40^{\circ} \mathrm{C}$. The tempera-

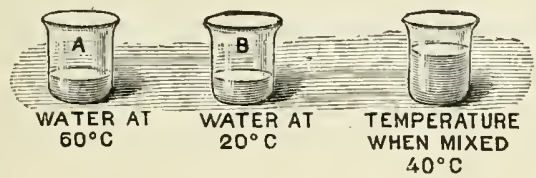

FIG. 33.-When equal quantities of a liquid at different temperatures are mixed, the resulting temperature is midway between the two first temperatures.

ture of the hot water would fall $20^{\circ} \mathrm{C}$. and the temperature of the cold water would rise $20^{\circ} \mathrm{C}$. As in the case of the waterlevel example, the temperature after mixing is equal to the original levels added together and divided by two. 
The actual temperature of the mixture would be slightly less than the calculated temperature, because some heat would be lost while the liquids were being mixed. The loss may be regarded as a leakage of heat, and it would of course reduce the heat-level of the mixture in the same way that a leak in the water-level apparatus would cause the level after mixing to be less than it would be if the apparatus were perfect.

\section{TO BE REMEMBERED.}

Temperature is a condition of hotness or coldness ; it is analogous to the level of a liquid, or the pitch of a musical note.

Bodies are at different temperatures when heat tends to pass from one to the other.

Liquids at high and low levels, in vessels of the same size, come to a level midway between the two original levels if they are are free to flow.

Equal masses of water at high and low heat-levels (temperatures) come to a temperature midway between the two if the hot and cold water are mixed.

\section{EXERCISE VII.}

I. A cook sometimes speaks of the "heat" of an oven. What word should be used instead of "heat," and why?

2. Will boiling water cool a flat-iron which has just been taken off the fire? Which is at the higher temperature, the water or the iron?

3. A hot slate is pressed against a cold one and the two are left in contact. What will be the condition of the slates after a little while?

4. When heat passes into a thing, how is its temperature affected?

5. If 2 lbs. of turpentine at a temperature of $50^{\circ} \mathrm{C}$. are mixed with $2 \mathrm{lbs}$. of turpentine at a temperature of $10^{\circ} \mathrm{C}$, what will be the temperature of the mixture? 


\section{LESSON VIII.}

\section{THE MEASUREMENT OF HEAT.}

\section{PRACTICAL WORK.}

Things required.-Straight lamp-glass and tube connected with rubber tubing, as in Fig. 34. Scale for measuring heights. Wine glass. Large vessel of cold water. Boiling water. Thermometer. Balance and weights. Several beakers.

\section{What to do.}

Rise and fall of water-level in communicating vessels of unequal size.-Fit up an arrangement to illustrate water level, but with one tube much larger than the other, as in Fig. 34. Clip the india-rubber, and put some water in each of the tubes, nearly filling the smaller one. Measure the level of the water in each tube, then unfasten the clip and let the water mix. Measure the final level, and from the results find the fall of level in the narrow tube and the rise in the wide tube. You
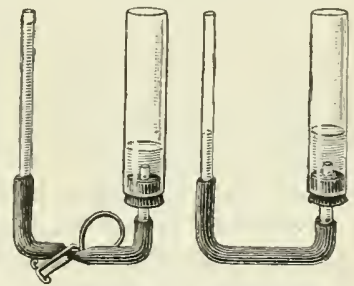

Fig. 34.-The rise and fall of tevel produced when the liquid is allowed to flow depends upon the size of the tubes as well as the difference of level of the water. will notice that the fall is much greater than the rise.

Rise and fall of temperature when unequal musses of hot and cold water are mixed.-Place a wine glass full of hot water, that is, water at a high heat-level or temperature, by the side of a large beaker of water at a lower temperature. Determine the temperature of each by means of a thermometer. Pour the hot water into the cold, and stir it up. Observe the temperature of the mixture, and from your results find the fall of temperature of the hot water and the rise of temperature of the cold water. You will notice that the fall is much greater than the rise.

Heating effect.- Put equal masses (about 100 grams) of cold water into two large beakers of the same size. Observe 
the temperature. Pour into one beaker 50 grams of boiling water and into the other 200 grams of warm water at about $70^{\circ} \mathrm{C}$. Which produces the greater heating effect, the large amount of warm water or the smaller amount of boiling water? Make several other experiments of the same kind to show that the heating effect depends upon the mass of water used as well as its temperature.

\section{REASONS AND RESULTS.}

Changes of water-level in communicating vessels of unequal size - It has been explained in the previous lesson that when water at different levels in vessels of the same size is allowed to n:ix the level after the flow has ceased is midway between the two levels at the beginning. If, however, instead of having two tubes of the same size communicating with one another, as in Fig. 32, tubes of unequal sizes are fitted up, as in Fig. 34, then it is easy to understand that the level produced by mixing water at different levels will not be midway between the original heights. Suppose that the water in the narrow tube nearly fills it, and that the wide tube is only about half full. Then, when the water is allowed to flow, the fall of level in the narrow tube will be much more than the rise of level in the wide tube. In the same way, suppose the wide tube is nearly filled with water and the narrow tube is only about half filled. Then, when the water is allowed to flow, the rise of level in the narrow tube will be much more than the fall of level in the wide one. You see, therefore, that the level produced by the mixture of water at different levels depends upon the volume of water in the communicating vessels as well as upon their levels.

Mixture of unequal masses of hot and cold water.-Hot water is analogous to water at a high level, and cold water to water at a lower level. The mixture of a small mass of hot water with a large mass of cold water is therefore similar to the mixture of a small amount of water at a high level with a larger amount at a lower level. If a wine glass full of hot water is poured into a large vessel of cold water you know it will not produce much heating effect. The temperature or heat-level of the hot water will fall very considerably, but the temperature of the cold water will only rise slightly. In a similar way, if a large mass of hot water is mixed with a small mass of cold water, the 
temperature of the cold water rises much more than that of the hot water falls.

Heating effect of water depends upon its mass and temperature. - This has already been partly explained, and you know it is true though you may not have thought about it. Suppose you have two basins, each containing equal amounts-about a cupful-of cold water. If a teaspoonful of boiling water is poured into one of the basins it warms the cold water slightly. If, however, warm water is poured into the other basin, so as nearly to fill it, the mixture of water in this basin will be warmer than the mixture in the other basin. A small amount of very hot water is thus not able to produce so much heating effect as a much larger amount of warm water. In other words, the heating effect of water depends upon the mass as well as the temperature. It will be explained in another lesson that the effect also depends upon the substance with which the water is mixed.

\section{To BE REMEMBERED.}

When water at different levels, in communicating tubes of unequal diameter, is allowed to mix, then ( $I$ ) a large fall of level in the narrow tube only causes a small rise of level in the wide tube; and (2) a small fall of level in the wide tube causes a large rise of level in the narrow tube.

When unequal masses of water at different temperatures are allowed to mix, the smaller mass undergoes the greater change of temperature.

In fact,

$$
\begin{gathered}
\text { Rise of } \\
\text { temperature }
\end{gathered} \times \begin{gathered}
\text { mass of } \\
\text { cold water }
\end{gathered}=\begin{gathered}
\text { Fall of } \\
\text { temperature }
\end{gathered} \times \begin{gathered}
\text { mass of } \\
\text { hot water. }
\end{gathered}
$$

In the measurement of heat, the mass as well as the temperature of the substance heated must be taken into account.

\section{Exercise VIII.}

I. When water at different levels in two separate ressels is allowed to $\mathrm{mix}$, is the fall of level always equal to the rise?

2. Which has the higher temperature, a red-hot tack or a bowl of boiling water? Which has the greater quantity of heat?

3. If a pint of hot water at a temperature of $90^{\circ} \mathrm{C}$. is mixed with a pint of water at a temperature of $30^{\circ} \mathrm{C}$., what will be the temperature of the mixture?

4. Why is it necessary to take into account both the mass and the temperature of a substance when measuring the quantity of heat in it? 
5. Can quantities of heat be measured with a thermometer?

6. About how much cold milk do you think you would need to put in a cup of boiling milk in order to make it luke warm?

\section{LESSON IX. \\ QUANTITY OF HEAT.}

PRACTICAL WORK.

Things required.-Beakers. Balance and weights. Thermo. meter. Hot and cold water. Flask. Tripod or retort stand. Laboratory burner. Duster.

\section{What to do.}

Quantity of heat.-Weigh about $200 \mathrm{gms}$. of cold water into a beaker, and observe its temperature. Put the same mass of water into another beaker; heat it to about $50^{\circ} \mathrm{C}$. Now place the beaker of hot water on your table, with a thermometer in it, and observe its temperature. When the temperature has fallen, to say $45^{\circ} \mathrm{C}$., take hold of the beaker with a duster, and quickly pour the hot water into the cold. Stir up the mixture with the thermometer, and observe the temperature after mixing. Record your observations as below :

Mass of cold water, - $\quad$ - $\quad$ - $\quad$ - $\quad$ - ......gms.

Temperature " - - - - $\quad$ - ..... C.

,$\quad$ of mixture, -

Number of degrees through which the temperature of the cold water was raised, - ..... ${ }^{\circ} \mathrm{C}$.

Mass of hot water, - $\quad$ - $\quad$ - $\quad$ - $\quad$ - ......gms.

Temperature of hot water, $\quad$ - $\quad$ - ..... ${ }^{\circ} \mathrm{C}$.

Number of degrees through which the tem-

perature of the hot water fell, - $\quad \ldots . .{ }^{\circ} \mathrm{C}$.

Tabulate the gain and loss that occur, as shown below:

Gain.

Mass of cold water

$x$ its rise of temperature
Loss.

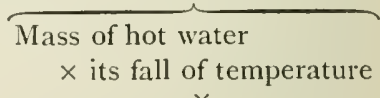


The gain will be found to be slightly less than the loss. This is not really the case, and it only appears so because the amount of heat required to raise the temperature of the glass of the beaker containing the cold water has not been taken into consideration.

Repeat the experiment, using unequal masses of hot and cold water. Notice that in each case the mass of hot water $x$ the fall of temperature, is approximately equal to the mass of cold water $x$ the gain of temperature. The difference shows the amount of heat absorbed by the glass of the cold beaker.

The amount of heat gained by I gram of water when its temperature is raised $\mathrm{I}^{\circ} \mathrm{C}$., or lost when its temperature falls $\mathrm{I}^{\circ} \mathrm{C}$., is adopted as the unit quantity of heat.

Determination of number of units of heat gained by water.Weigh out into a flask 100 grams of water. Take the temperature. Support the flask on a tripod, or retort stand, and heat it over a laboratoryburner for a few minutes. Again take the temperature of the water. Calculate the number of units of heat it has received from the burner. Let it stand aside

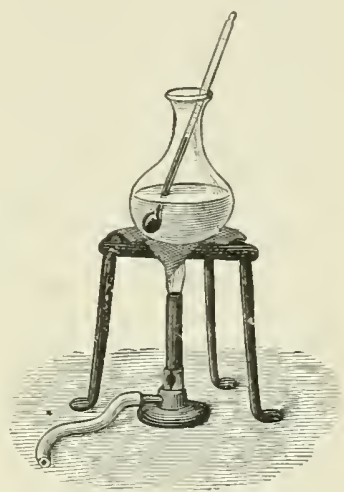

FIG. 35.-Arrangement for finding the number of units of heat absorbed by water in a certain time.

for to minutes and again record the temperature. How much heat has it lost?

\section{REASONS AND RESULTS.}

Quantity of heat in water at different temperatures.-Quantity of heat may be measured by heating effect, so that we can say that the quantity of heat in a vessel of water depends upon the mass of the water and its temperature. If, for the sake of simplicity, we imagine that water at $0^{\circ} \mathrm{C}$. contains no heat, then it may be said that the quantity of heat in 100 grams of water at $40^{\circ} \mathrm{C}$. is twice as much as in 100 grams at $20^{\circ} \mathrm{C}$. When equal or unequal masses of water at different temperatures are mixed, the quantity of heat lost by the 
hot water is the same as the quantity gained by the cold water. The fall of temperature multiplied by the mass of hot water is equal to the rise of temperature multiplied by the mass of the cold water.

Unit quantity of heat.-Now that it has been shown that we may correctly speak of quantities of heat, it is time to consider how such quantities of heat are measured. As in all other cases of measurement, a unit or standard quantity is required with which to compare quantities of heat. The unit quantity of heat generally adopted is the amount of heat necessary to raise the temperature of one gram of water through one degree centigrade. This unit is called a calorie or therm. The amount of heat required to raise the temperature of 2 grams of water through $I^{\circ} \mathrm{C}$. is thus 2 units or 2 calories. Similarly, if I gram of water at $0^{\circ} \mathrm{C}$. is heated in a test-tube over a burner until its temperature is $I^{\circ} \mathrm{C}$., it will have received from the burner $\mathrm{I}$ unit of heat, or I calorie. When this I gram of water reaches a temperature of $3^{\circ} \mathrm{C}$. it will have received 3 units of heat. If the tube contains 10 grams of water at $0^{\circ} \mathrm{C}$, and its temperature is raised to $12^{\circ} \mathrm{C}$, it will have received io times 12 units of heat, the number of units being equal to (mass in grams) $x$ (increase in temperature in degrees centigrade).

It will thus be seen that the number of units of heat taken up by any mass of water as its temperature rises, or the amount given out by any mass of water, the temperature of which is falling, may be found by multiplying the number of grams of water used by the number of degrees, as measured by a centigrade thermometer, through which the temperature rises or falls. This rule may be written as follows :

Number of heat-units $=$ Mass of water in grams $\times$ number of degrees centigrade through which its temperature rises or falls.

Example 1.-Ten grams of water at $20^{\circ} \mathrm{C}$. are heated until the temperature of the water is $70^{\circ} \mathrm{C}$. How many heat-units have been expended in the process?

Here the temperature has been raised from $20^{\circ} \mathrm{C}$. to $70^{\circ} \mathrm{C}$, or through $50^{\circ} \mathrm{C}$. of temperature.

The mass of the water is 10 grams. Hence

Number of heat-units used up in raising the temperature
of the water 
Example 2. - The temperature of 100 grams of water falls from $90^{\circ} \mathrm{C}$. to $30^{\circ} \mathrm{C}$. How many units of heat are given out?

Number of degrees through $\}=90-30=60$ degrees.

. which the temperature falls

Mass of water $=100$ grams. Hence

$\left.\begin{array}{c}\text { Number of heat-units given } \\ \text { out by the water in cooling }\end{array}\right\}=100 \times 60=6,000$ heat units.

Calculation of the number of units of heat in water.-When equal masses of hot and cold water, the temperatures of which are known, are mixed together, and the temperature of the mixture is observed, the hot water gives out the same number of heat-units in cooling down to the temperature of the mixture as the cold water takes up in being warmed up to the temperature of the mixture. This is only exactly true, however, if no heat is lost in warming the ressel containing the mixture. But since the vessel is also warmed, to be strictly correct, we ought to say that, supposing no heat to be lost in any way, the number of units of heat given out by the hot water, in cooling to the temperature of the mixture, is the same as that taken by the cold water and the vessel containing it in being warmed up to the temperature of the mixture.

Making use of what has already been learnt, namely, that the number of heat-units given out by a given mass of warm water in cooling through a certain number of degrees, or the number of heat-units taken up by a given mass of cold water in being warmed through a certain number of degrees, can be obtained by multiplying the mass of the water in grams by the number of degrees of rise or fall in temperature, it can be easily shown that the statement in the beginning of the paragraph is correct. Suppose the results obtained by mixing equal masses of hot and cold water were as follows :

Temperature of the mixture $=42 \frac{1}{2}^{\circ} \mathrm{C}$.

Nass of cold water

$$
=200 \mathrm{gms} \text {. }
$$

Temperature of cold water

$$
=15^{\circ} \mathrm{C} \text {. }
$$

Number of degrees through which the temperature of the cold water was raised

$$
=27 \frac{1}{2}^{\circ} \mathrm{C} \text {. }
$$

Gain of heat by cold water $=200 \times 27 \frac{1}{2}$ units.
Mlass of hot water

$=200 \mathrm{gms}$.

Temperature of hot water

$$
=70^{\circ} \mathrm{C} \text {. }
$$

Number of degrees through which the temperature of the hot water was lowered $=27 \frac{1}{2}^{\circ} \mathrm{C}$.

Loss of heat of hot water $=200 \times 27 \frac{1}{2}$ units. 
If unequal masses of hot and cold water are used, and, as before, it is assumed that no heat is lost to the vessel, the same equality of loss and gain of heat can be shown to be true. The following example illustrates the method of calculation :

Example 3.-120 grams of cold water at $20^{\circ} \mathrm{C}$. are mixed with 200 grams of warm water at $80^{\circ} \mathrm{C}$., and the temperature of the mixture is found to be $57 \frac{1}{2}^{\circ} \mathrm{C}$. In this case

Number of degrees through which the temperature of the cold water was

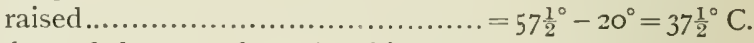

Number of degrees through which the temperature of the hot water was lowered ............................ $=80^{\circ}-57 \frac{1}{2}^{2}=22 \frac{1}{2}^{\circ} \mathrm{C}$.

Therefore the gain of heat by the cold

vater............................. $=\mathrm{I} 20 \times 37 \frac{1}{2}=4,500$

heat-units.

The loss of heat by the warm water $\ldots \ldots . .=200 \times 22 \frac{1}{2}=4,500$ heat-units.

\section{To be Remembered.}

The quantity of heat in any given amount of water depends upon (1) the mass of the water, (2) the temperature.

The unit quantity of heat is the amount of heat required to raise the temperature of one gram of water $1^{\circ} \mathrm{C}$., or which is given out by one gram of water in falling through a temperature of $1^{\circ} \mathrm{C}$. It is called a calorie or therm.

The number of heat-units taken up or given out by water when its temperature rises or falls is determined by multiplying the mass of the water in grams by the number of degrees centigrade through which its temperature rises or falls.

\section{EXERCISE IX.}

1. What is meant by the "unit quantity of heat"?

2. How would you calculate the number of heat-units given out by 200 grams of water when its temperature falls from $90^{\circ} \mathrm{C}$. to $40^{\circ} \mathrm{C}$. ?

3. Will a thermometer show any difference when placed in a cup of boiling water and a tub of boiling water?

4. Does a bucket of boiling water contain the same quantity of heat as a cup of boiling water? If not, how do the two differ?

5. How could you prove that quantity of heat depends upon mass as well as temperature? 


\section{LESSON X.}

\section{HEAT CAPACITY.}

PRACTICAL WORK.

Things required.-Three glass cylindrical vessels of different diameters but equal heights. Two similar cylindrical vessels of equal diameter. Tea-cups. Balance and weights. Mercury. Test tubes. Small flasks. Hot water. Thermometer. Thin cake of bees-wax. Retort stand. Metal balls of same mass. Laboratory burner.

What to do.

The same amount of water may produce different changes of level.-Arrange three glass cylinders of different diameters but equal heights in a row, and pour a cupful of water into each of them in succession. Notice that the same quantity of water fills the cylinders to different heights; in other words, the change of level produced by a certain quantity of water depends upon the capacity of the vessel into which the water is poured. (Fig. 37.)

The same quantity of heat may produce different changes of temperature. - Weigh out equal masses of water and turpentine at the same temperature in two beakers of the same size. Pour equal quantities of hot water at the same temperature into the cold water and turpentine. Observe the rise of temperature produced in each case. Though the equal amounts of hot water contain the same quantity of heat, the rise of heat-level (temperature) of the turpentine will be found to be more than the rise of temperature of the cold water; in other words, the capacity of turpentine for heat is less than the capacity of water for heat.

Comparison of rates at which water and mercury gain or lose heat.-Weigh out equal masses of cold water and mercury at the same temperature in two test tubes or flasks. Support the two vessels side by side at the same distance above a flame, or in a large beaker of boiling water. Let them remain for a few minutes; then observe their temperatures. The rise 
of temperature of the mercury will be found to be greater than

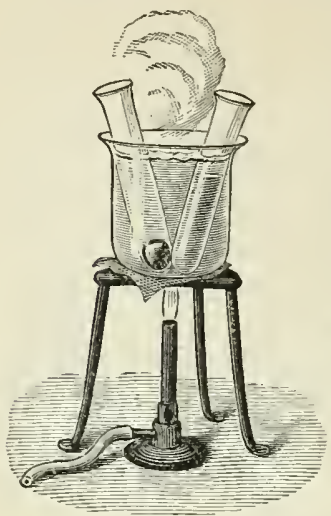

Fig. 36.-Equal masses of water and mercury do not become hot at equal rates, though they both have the same opportunity.

the rise of temperature of the water; in other words, mercury gets hotter than water under the same conditions. (Fig. 36.)

Blacken two small beakers or flasks of the same size, on the outside, by holding them in a fish-tail gas burner or over a candle flame. Into one put a convenient mass of water at a known high temperature, and into the other an equal mass of mercury at the same high temperature. Into each insert a thermometer. Allow both to cool, and notice that the mercury cools much more rapidly than the water.

Different heating effects of substances at the same temperature.Obtain balls of different metals of, say, lead, iron, tin, bismuth, with hooks attached; also a cake of bees-wax about $\frac{1}{4}$ inch thick, and arrange it on the ring of a retort stand, as in Fig. 38. Then suspend the balls from a wire support (as shown) in a bath of oil heated to about $150^{\circ} \mathrm{C}$., and drop them together on to the cake of wax; notice the iron ball melts through first, then the tin, followed by the lead, and last of all the bismuth.

\section{REASONS AND RESULTS.}

Relative capacity for heat.-So far we have only considered the amount of heat in water, and you have seen that it depends upon the mass of the water and its temperature. You may think, therefore, that as any mass of water at a certain temperature contains a certain quantity of heat, the same mass of another substance at the same temperature contains the same quantity of heat. This, however, is not the case. A hundred grams of water at a temperature of $50^{\circ} \mathrm{C}$. always contain 5000 units of heat, but Ioo grams of turpentine, mercury, lead, iron or any other substance at the same temperature as the water, namely $50^{\circ} \mathrm{C}$, do not contain this number of units of heat. The quantity of heat in a substance thus not only depends upon the mass and the temperature, but also upon the substance itself. 
Analogy between fluid level and heat capacity. - If three jars of different diameters but equal heights are obtained, and a cup of water is poured into each, you know that the water will be at different levels, as shown in Fig. 37. The same amount of water thus produces different changes of level, according to the vessel into which it is poured. In the narrow jar, which is a vessel of small capacity, the rise of level produced by the cup of water is much more than in either of the other jars, which are capable of holding much more water, and are, therefore, said to have larger capacities.

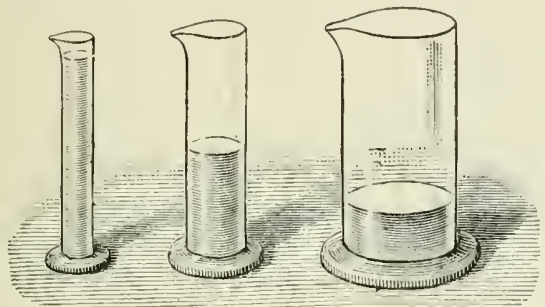

FIG. 37. -The same amount of water produces different levels in jars of different capacities.

Now, just as the same quantity of water produces different levels in vessels of different liquid capacities, so the same quantity of heat produces different heat-levels, or temperatures, in equal masses of substances of different heat capacities. If some hot water is poured into a cup containing cold water, the cold water rises to a certain degree of warmth; but if the same mass of hot water is poured into a cup of cold turpentine of the same mass and temperature as the cold water, the mixture of water and turpentine becomes warmer than the mixture of hot and cold water because turpentine has less capacity for heat than water.

Capacity of water for heat.-Of all known substances, water has a greater capacity for heat than any other body. Consequently a larger amount of heat is required to raise the temperature of a given mass of water through any number of degrees than is needed by an equal mass of any other substance.

Thus, suppose a pound of water be put into one flask and a pound of mercury into another, and that these flasks are then heated for five minutes by two laboratory burners, which as far as we can tell, give out the same quantity of heat. The 
temperature of the two liquids as the commencement of the experiment is, say $15^{\circ} \mathrm{C}$. If at the end of the experiment the temperature of the water was $20^{\circ} \mathrm{C}$. that of the mercury would probably be about $180^{\circ} \mathrm{C}$, and in order to raise the water to this temperature (if that were possible by this means) much more heat would be required. Similarly, and for the same reason, in cooling through any number of degrees of temperature a definite mass of water will give out a larger amount of heat than an equal mass of any other substance will in cooling through the same number of degrees.

Results in nature of high capacity of water for heat.-The results in nature of this great capacity for heat which water possesses are very important.

Though water takes a large amount of heat to warm it and is consequently heated by the sun's rays only slowly, yet when it cools it parts with its heat just as slowly. The effect of this on the climate of islands is very marked. The winter temperature is never very low, and the climate never very severe, because the water surrounding the country not only acts

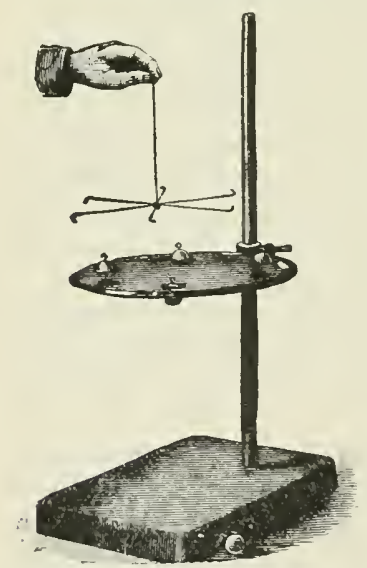

Fig. 38. - Though the balls were at the same temperature, they melt through the cake of wax at different rates.

like a great-coat, and keeps the land warm, but also acts as a great storehouse, slowly giving up heat to it. Similarly, the summer temperature is never unbearably hot because the surrounding water takes so long to warm, and being always cooler than the land, keeps the temperature of the latter from getting very hot.

Illustration of different amounts of heat in substances at the same temperature.-If balls of lead, iron, tin, and bismuth are heated to the same high temperature in hot oil and placed together on a cake of bees-wax, they melt through at different rates.

Though all the balls are at the same temperature when dropped on to the wax, the rate at which they melt through the wax depends chiefly upon the amount of heat they give out, so 
that since the iron gets through first it had most heat to give out, or its capacity for heat, or heat-storing power, is greatest of all the metals taken. The experiment teaches, therefore, that the different metals can hold different quantities of heat. Though these bodies were at the same temperature, the amounts of heat they took up from the oil differed because of their different capacities for heat, and in the same way the amount of heat they are able to give to the wax also differs in the same proportion.

This experiment also serves to illustrate the difference between the terms "quantity of heat" and "temperature." All the balls were heated in the same bath of oil and must therefore have had the same temperature. But though the masses of iron, tin, lead, etc., have the same temperature as shown by a thermometer, the quantity of heat they take from the oil is not the same. A thermometer, then, can only indicate the heat intensity, or hotness of a body, or as we say, its temperature ; it will not measure the quantity of heat in a body.

Another homely example which will show that temperature and quantity of heat are not the same, is the following: Suppose that from a bucket of boiling water a small beakerful is taken, and then the temperature of the water in each vessel is quickly observed. The temperatures will be the same. Suppose now that small pieces (of equal size) of butter or some other substance which easily melts are dropped one by one into the beaker and bucket. Which water will melt the greater number of pieces of butter? That in the bucket. But since it requires a certain quantity of heat to melt a piece of butter, you will at once see that the water in the bucket had a greater quantity of heat in it than the water in the beaker, though both had the same temperature.

\section{To be Remembered.}

The same amount of liquid rises to different levels in similar vessels of different capacities.

The same amount of heat produces different temperatures when added to equal masses of substances of different capacities for heat.

The temperature of a substance is analogous to the level of a liquid in a vessel ; the capacity for heat is analogous to the fluid capacity of the vessel.

II. 
The heat capacity of water is greater than that of any other substance.

Water takes longer to get hot and longer to become cool than an equal mass of any other substance.

Equal masses of different substances often contain different quantities of heat, though the temperature may be the same.

\section{Exercise $X$.}

1. How could you show that the same quantity of heat produces different effects upon the temperature of equal masses of water and turpentine at the same temperature?

2. If an iron ball is made red hot and then put into boiling water, what would be the highest temperature that wonld be shown by a thermometer standing in the water?

3. Suppose you had three balls made of lead, iron, and tin, each of the same mass, and after you had made them as hot as boiling water you dropped them upon a tub of butter. Which ball would sink deepest into the butter and which would sink least?

4. If two flasks containing equal masses of water and mercury at the same temperature were placed at the same distance from a fire, which would first become hot?

5. If I $\mathrm{lb}$. of hot water and I $\mathrm{lb}$. of turpentine at the same temperature were put aside to cool, which would first become cold?

\section{LESSON XI.}

RELATIVE CAPACITIES FOR HEAT.

PRACTICAL WORK.

Things required. - Balance and weights. Thermometer. Beakers, including a small thin one. Retort stand or tripod. Laboratory burner. Lead shot. Iron tacks Small copper nails, or copper wire cut into small pieces. Glass beads. Mercury. Test-tubes.

What to do.

Relative heat cupacities of vater and iron.-Counterpoise a thin beaker and place in it 50 or 100 grams of cold water. 
Observe the temperature. Pour into the beaker an equal quantity of hot water, at a temperature of about $70^{\circ} \mathrm{C}$. Observe the temperature of the mixture.

Weigh out the same quantity of cold water as before, and observe its temperature. Put into a testtube an equal mass of iron tacks. Stand the test-tube, with the thermometer surrounded by the tacks, in a beaker of water, and boil the water. A loose plug of cottonwool may be used to keep the tacks dry (Fig. 39). Observe the temperature of the tacks, and when the water has been steadily boiling for some time take out the thermometer, cool it under a tap, and dry it. Take hold of the testtube with a duster, quickly pour

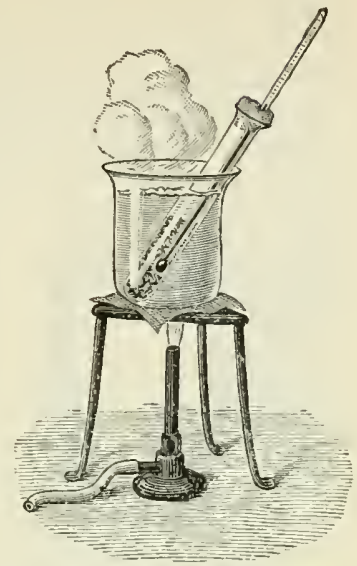

FIG. 39.-A method of heating a substance to the temperature of boiling water. the tacks into the cold water, and observe the temperature of the mixture. Record your observations thus :

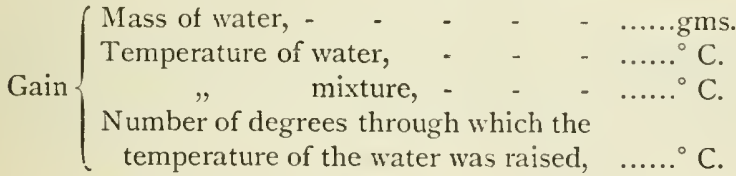

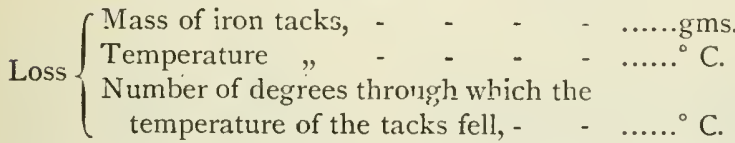

Compare the effect of the tacks in raising the temperature of the cold water with that of the same mass of hot water at the same temperature:

IOo gms. of water at ..... C. raised the temperature of 100 gms. of water at $\ldots . .{ }^{\circ} \mathrm{C}$. through ...... ${ }^{\circ} \mathrm{C}$.

$100 \mathrm{gms}$. of tacks at $\ldots . .{ }^{\circ} \mathrm{C}$. raised the temperature of 100 gms. of water at $\ldots . .{ }^{\circ} \mathrm{C}$. through $\ldots . .{ }^{\circ} \mathrm{C}$.

Heat capacity of copper.-Cut 100 grams of thin copper wire into pieces, and repeat the preceding experiment with them 
instead of iron tacks. Compare, as before, the heating effect of the copper with that of the same mass of water.

Heat capacities of rarious substunces.-Repeat the preceding experiments, using, instead of the tacks and the copper, I00 grams of lead shot; also roo grams of glass beads, mercury, sand, or any other substances available.
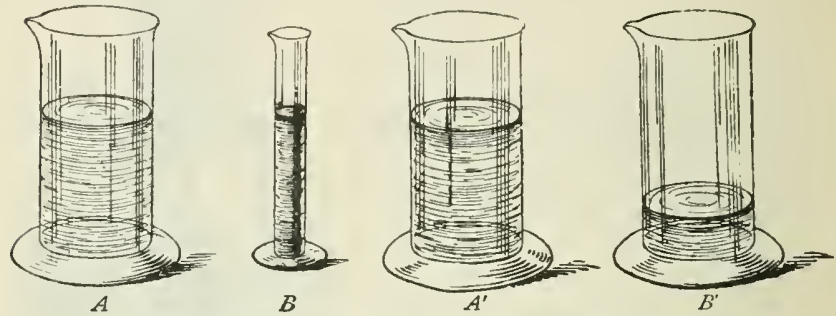

Fig. 40.- The quantity of water in $A$ is greater than that in $B$, though the level is the same. $A^{\prime}$ and $B^{\prime}$ have equal capacities for water, but the levels produced when the water from $A$ and $B$ respectively are poured in them are different.

Arrange the substances in a table, from that substance that gives up most heat to that which gives up the least.

\section{REASONS AND RESULTS.}

Comparison of capacities of bodies for heat and capacities of vessels for water.-Just as all vessels have not the same capacities, or storing powers, for water, so equal quantities of different substances have not the same capacities for heat or heat-storing powers. The same amount of water does not raise the level of the water in vessels of different capacities to the same amount ; nor does the same amount of heat raise the temperatures of equal masses of bodies having different capacities for heat through the same number of degrees of temperature.

Again, if the levels of water in two vessels-one wide and the other narrow-be the same, and the water they contain is transferred into two equal vessels, the levels of the water in the sccond pair of vessels is by no means the same. The level is higher in that vessel which contains the water from the wider vessel (Fig. 40).

Similarly, suppose cqual masses of lead and water arc heated to the same high temperaturc, say $100^{\circ} \mathrm{C}$, and the lead is put into one mass of water at a lower temperature, say $20^{\circ} \mathrm{C}$, and 
the hot water is mixed with another equal mass of water at $20^{\circ} \mathrm{C}$. When the resulting temperatures in the two cases are determined, it is found that the temperature of the cold water into which the water was poured is higher than that of the equal mass of cold water into which the lead was plunged.

It may thus be shown that equal masses of lead and water at the same high temperature do not give out the same amount of heat when cooled, because they contain unequal amounts. Water at $100^{\circ} \mathrm{C}$. contains a larger quantity of heat than an equal mass of lead at $100^{\circ} \mathrm{C}$., because the capacity of the water for heat is greater than the heat capacity of the lead used.

Or, if $\mathrm{I} \mathrm{lb}$. of water at the temperature of the air is mixed with $1 \mathrm{lb}$. of iron at $100^{\circ} \mathrm{C}$, the resulting temperature is not so high as that obtained by mixing $1 \mathrm{lb}$. of water at $100^{\circ} \mathrm{C}$. with I lb. of iron at the atmospheric temperature. This evidently means that $1 \mathrm{lb}$. of water at $100^{\circ} \mathrm{C}$. contains more heat than I lb. of iron at $100^{\circ} \mathrm{C}$., or the capacity of iron for heat is less than that of water. In the same way, similar experiments with water and mercury show that the capacity of mercury for heat is less than that of water.

Relative capacities for heat.-When equal masses of water, tacks, copper wire, sand, and mercury at the same high temperature, that of boiling water for instance, are each in turn stirred up with equal masses of cold water at a convenient lower temperature, it is found that the heating effect of the hot water is greater than that of any one of the other substances.

BEFORE

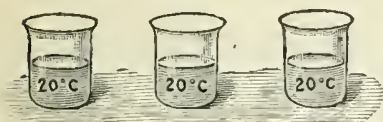

BEAKERS CONTAINING 200 GMS OF WATER

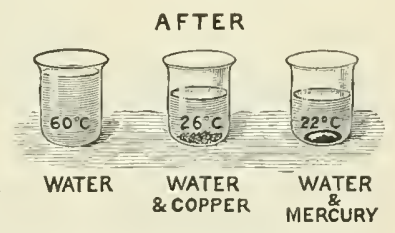

Fig. 4I.-Equal masses of different substances at the same temperature contain different quantities of heat.

For instance, let three beakers, each containing 200 grams of cold water at $20^{\circ} \mathrm{C}$, be taken; into the first 200 grams of hot water at $100^{\circ} \mathrm{C}$. are poured, into the second 200 grams of small pieces of copper wire at $100^{\circ} \mathrm{C}$., and into the third an equal quantity of mercury at $100^{\circ} \mathrm{C}$. On stirring and observing the temperature of the mixtures they will be nearly as repre- 
sented in Fig. 41, not allowing for the heat absorbed by the beakers.

Thus, though the water, copper, and mercury all have the same high temperature, and are equal in mass, the hot water will have about twenty times the heating effect of the hot mercury, and the hot copper will raise the temperature of the cold water about three times as much as the mercury.

How can this be explained? It is evident that the hot water has more heat stored up in it than the copper, and that the copper holds more than the mercury, though all have the same temperature. This again shows that water has a greater power of storing up heat than mercury, copper, or any other substance, or, as it is more correct to say, the capacity of a given mass of water for heat is greater than that of the same mass of any other substance. The experiments also teach that the copper must have a greater capacity for heat than the mercury.

In each case the temperature of the mixture formed is observed, namely, tacks and water, copper wire and water, and so on, and then by subtraction the number of degrees through which each has raised the temperature of the water into which it was put is calculated. A series of numbers is obtained showing the relative capacities for heat of each of the bodies experimented with. The substances, arranged in the order of their capacities for heat, stand thus :

Tacks

Copper Wire

Mercury

Lead.

Water is taken as the standard substance in the measurement of capacity for heat. The number of calories required to raise the temperature of I gram of a substance through $r^{\circ} \mathrm{C}$., or given out by the substance when its temperature falls through $\mathrm{I}^{\circ} \mathrm{C}$., is called the specific heat of the substance. This will be more fully explained in the next lesson.

\section{TO BE REMEMBERED.}

The amounts of heat ausorbed (or given out) by equal masses of different materials when heated (or cooled) through the same number of degrees of temperatule are generally different.

Any mass of water at a given high temperature has nore heat in it than an equal mass of any other substance at the same high temperature. 
The greater the capacity for heat of a body the larger the number of heat-units does it give out in cooling through a given number of degrees of temperature.

\section{EXERC1SE XI.}

I. What experiments would you perform to show that when hot and cold water are mixed the former gives up as many heat-units as the latter gains?

2. How would you show that water has a greater capacity for heat than copper wire or sand?

3. How would you compare the capacities for heat of iron tacks, quicksilver, and paper-fasteners?

4. What do you understand by capacity for heat? How would you show that different bodies have different capacities for heat?

5. What will be the temperature of the mixture of $\mathbf{I} \mathrm{lb}$. of water at $70^{\circ} \mathrm{C}$. with I lb. at $30^{\circ} \mathrm{C}$. ? Could you obtain the resulting temperature in the same way if you mixed $1 \mathrm{lb}$. of lead at $70^{\circ} \mathrm{C}$. with a pound of water at $30^{\circ} \mathrm{C}$. ? Give a reason for your answer.

\section{LESSON XII.}

\section{SPECIFIC HEAT.}

PRACTICAL WORK.

Things required.-Thin beaker, or thin metal vessel, for use as a calorimeter. Balance and weights. Thermometer. Steam heater (Fig. 43). Copper wire cut into small pieces. Laboratory burner. Retort stand.

What to do.

Water equivalent of calorimeter.-Determine, by weighing, the mass in grams of the thin beaker, or of a small cylindrical vessel made of thin copper or brass, and known as a calorimeter. Observe the temperature of the air, and consequently of the beaker or vessel. Pour into the vessel a convenient quantity of warm water at a temperature of from $35^{\circ} \mathrm{C}$. to $40^{\circ} \mathrm{C}$. Enough to half fill the vessel is a convenient amount. Notice with a thermometer, which you should carefully use as a stirrer, that, on pouring warm water into the cold vessel, 
the temperature of the water falls. When its temperature becomes stationary, which it will soon do, record it again.
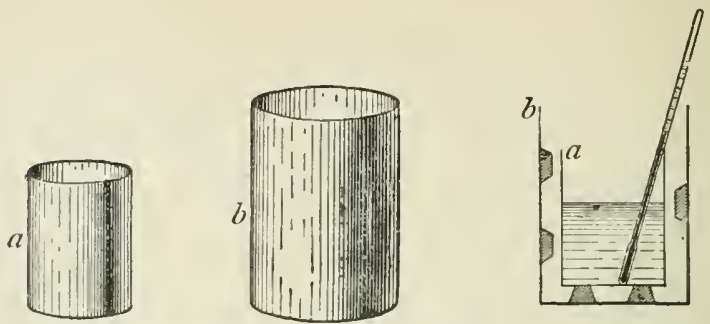

FIG. 42. - The calorimeter $a$ is placed on pieces of cork in the small can $b$ in order to prevent loss of heat during an experiment.

Determine the mass of the vessel and water together. Subtract the previously determined mass of the vessel, and the result will give you the mass of the water used. Record your results as follows:

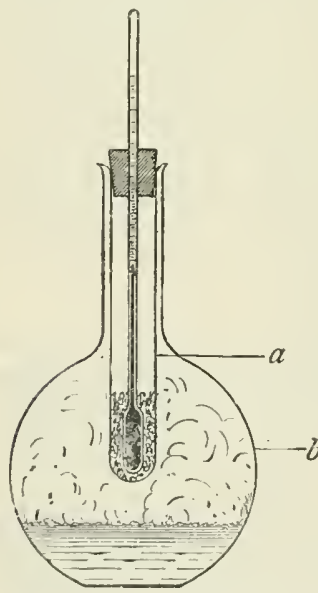

Fig. 43. $-\Lambda$ test-tube $a$, containing the substance of which the specific heat is to be foumd, and a thermometer are heated by. the steam from water boiling in the flask $b$.
Mass of ressel, Temperature of vessel, - $\quad-\quad \ldots .{ }^{\circ} \mathrm{C}$.
Mass of water,

Resulting temperature, - - $\quad$ - ..... C.

Heat-units given up by hot water, calories. Rise of temperature of vessel, $\quad-\quad$ -....$^{\circ} \mathrm{C}$.

The number of heat-units required to raise the temperature of the vessel through a certain number of degrees is thus obtained, and from the result the number of heatunits required to raise the temperature of the vessel through onedegree can be calculated. The result is called the water equivalent or water value of the ressel uscrl, and has to be taken into consideration when exact measurenicnts of heat quantity are made. 
Method of measuring the specific leat of a solid.-Determine, by weighing, the mass of the beaker or copper vessel of which you have found the number of units of heat absorbed by it for a rise of temperature of $1^{\circ} \mathrm{C}$. Pour in enough water to onethird fill it. Again weigh. Put a thermometer into the water and leave it to take the temperature of the water. When the temperature is stationary, record it. Weigh out about 50 grams of short pieces of copper wire. Heat the copper in a steam-heater (Fig. 43), and record the temperature of the copper with a second thermometer. Quickly introduce the hot copper into the cold water, stir, note the rise in temperature of the water, and, when constant, record.

Set down your observations thus:

Mass of vessel and water, grams.

Therefore mass of water in calorimeter,

Water equivalent of calorimeter, -

Total water,

Temperature of mixture,

", water, - - -
Therefore rise of temperature, -
uantity of heat gained by water and calorimeter (mass $\times$ temperature), - ...... calories.

Mass of copper, grams

Temperature of copper before mixing, - ...... C.

Therefore its fall of temperature,

50 grams of copper the temperature of which fell ...... degrees gave out ...... calories gained by cold water and calorimeter ;

therefore

I gram of copper the temperature of which falls ...... and degrees would give out ...... calories;

I gram of copper the temperature of which falls $I^{\circ}$ would give out ...... calories.

The result thus obtained is the specific heat of copper. 


\section{REASONS AND RESULTS.}

Specific heat.-It will be remembered by the student that the specific gravity or relative density of a substance is found by comparing the mass of any volume of the substance with the mass of an equal volume of water at the same temperature. In a similar way, the specific heat of a substance may be found by comparing the quantity of heat in a given mass of a substance with the quantity in the same mass of water at the same temperature. Relative density refers to quantity of matter; relative heat capacity or specific heat refers to quantity of heat. This analogy will give an idea as to what is meant by specific heat, but to be more precise it is necessary to consider unit mass, whether we are dealing with density or specific heat. In density, the mass of the unit volume of a substance is measured; in specific heat the quantity of heat in unit mass is usually compared. Specific heat may be defined as "the ratio of the number of calories required to raise the temperature of a given mass of a substance through a certain number of degrees of temperature, compared with that required to raise the temperature of an equal mass of water through the same number of degrees." This definition is analogous to the definition of specific gravity. Specific heat is also as "the number of calories required to raise the temperature of a unit mass of a substance through I ${ }^{\circ} \mathrm{C} . "$ - which definition is analogous to the definition of density.

Determination of specific heat.-Suppose Ioo grams of water at a temperature of $15^{\circ} \mathrm{C}$. are placed in a thin beaker or a small copper can, which is called a calorimeter when it is used to measure heat. Also, suppose 100 grams of copper are heated in a vessel held in the steam from boiling water, and that the temperature is $100^{\circ} \mathrm{C}$. Now let the copper be quickly placed into the cold water; it warms the water, and the temperature of the mixture will be found to be about $22^{\circ} \mathrm{C}$. The increase of temperature of the water is from $15^{\circ} \mathrm{C}$. to $22^{\circ} \mathrm{C}$; that is, $7^{\circ} \mathrm{C}$. As the amount of water, the temperature of which is raised through this number of degrees, is 100 grams, the number of units of heat, or calories, absorbed is $7 \times 100$, that is, 700 . But the amount of heat lost by the copper is the same as that gained by the water, if we do not consider the heat absorbed by the calorimeter. We may therefore say that 100 grams of copper lost 700 units of heat, or calories, in falling from a 
temperature of $100^{\circ} \mathrm{C}$. to a temperature of $22^{\circ} \mathrm{C}$.; that is, through $78^{\circ} \mathrm{C}$. One gram of copper would of course only give up one hundredth of this amount, so it would lose $\frac{700}{100}$, or 7 units of heat, in cooling through $78^{\circ} \mathrm{C}$. In cooling through a single degree of temperature, the heat given up by a gram of the copper is therefore $\frac{7}{78}$, or 0.09 ; that is, about one-tenth of a unit of heat. The number thus found is the specific heat of copper, for it shows the quantity of heat given up by I gram of copper when its temperature falls $\mathrm{I}^{\circ} \mathrm{C}$.

Any problem or experiment in specific heat may be thought out step by step in this way. All you have to consider is the number of units of heat gained or lost by the water in the calorimeter. Then the substance causing the gain or loss must have lost or gained the same quantity of heat. Knowing the mass of the substance, you can calculate what effect I gram of it would produce alone, and then you can also calculate the quantity of heat I gram would give up or absorb when its temperature falls $I^{\circ} \mathrm{C}$. The final result is the specific heat of the substance used.

Water equivalent of a calorimeter--Everyone knows that when hot water is put into a cold vessel it loses some of its heat. You may have noticed that your mother pours a little hot water into the teapot and empties it away before she puts in the tea. This is to make the teapot warm, so that when the hot water is afterwards poured upon the tea none of the heat shall be used up in raising the temperature of the teapot. If you bear this simple fact in mind, it is easy to understand why, in exact determinations of specific heat, the heat absorbed by the calorimeter must be taken into consideration. The way to find how much heat the vessel absorbs when its temperature is raised $\mathrm{I}^{\circ} \mathrm{C}$. is to pour a known quantity of warm water into it and observe the rise of temperature produced in it. Suppose the temperature of 30 grams of warm water at $35^{\circ} \mathrm{C}$. fell to $33^{\circ} \mathrm{C}$. when the water was poured into the vessel. The number of units of heat given up was equal to the mass of water $\times$ the fall in temperature; hence it was $30 \times 2$, or 60 calories. If the temperature of the calorimeter to begin with was $13^{\circ} \mathrm{C}$., then its rise of temperature was from $13^{\circ} \mathrm{C}$. to $33^{\circ} \mathrm{C}$, that is, $20^{\circ} \mathrm{C}$. As 60 calories are used to raise the temperature of the calorimeter through $20^{\circ} \mathrm{C}$, the number of calories absorbed when the temperature is increased $\mathrm{I}^{\mathrm{C}} \mathrm{C}$. is $\frac{60}{20}$, or 3 calories. 
This value is termed the water equivalent of the calorimeter, because it shows the amount of water to which the calorimeter is equivalent. In specific heat experiments the water value, or water equivalent, of the calorimeter should be added to the mass of the water used.

\section{To BE ReMEMBered.}

Relative capacity for heat is analogous to relative density; it is the number of units of heat absorbed (or given out) by a substance in comparison with the number of units which would be absorbed (or given out) by an equal mass of water which underwent the same change of temperature.

Specific heat is analogous to specific gravity. It may also be regarded as the number of calories required to change the temperature of unit mass of a substance $I^{\circ} \mathrm{C}$.

The quantity of heat in a substance depends upon (I) the mass. (2) the temperature, (3) the specific heat of the substance.

In determining specific heat it should be borne in mind that Gain of heat by water and $=$ Loss of heat by substance.
calorimeter

Or

\section{Mass of water $\times$ rise of ten $-=$ Mass of substance $\times$ fall of tem- perature perature $\times$ specific heat.}

The water equivalent of a calorimeter is the number of units of mass of water to which the calorimeter is equivalent as regards heat capacity.

\section{EXercise XII.}

I. What is the unit quantity of heat? Describe exactly how you would do an experiment which would tell you which of two pieces of metal gives out the greater quantity of heat when each of them falls $I^{\circ} \mathrm{C}$. in temperature.

2. What do you understand by the "specific heat" of a substance? 50 grams of mercury at $56^{\circ} \mathrm{C}$. are poured into 60 grams of water at $15^{\circ} \mathrm{C}$. and the temperature of the mixture becomes $16^{\circ} \mathrm{C}$. Find the specific heat of mercury.

3. 50 grams of water at $100^{\circ} \mathrm{C}$. are mixed with 50 grams of water at $20^{\circ} \mathrm{C}$.; what should the resulting temperature be? Is it actually so in practice? Give reasons for your answer.

4. In the last question, if the 50 grams were not water but iron, how would it affect the result?

5. 35 grams of copper (specific heat .09) at $17^{\circ} \mathrm{C}$. are mixed with 80 grams of water at $100^{\circ} \mathrm{C}$. Find the resulting temperature.

6. How many units of heat are required to raise the temperature of Io grams of water from $10^{\circ}$ to $75^{\circ} \mathrm{C}$. ? How many to raise the 
temperature of ro grams of copper (specific heat .09) through the same number of degrees?

\section{LESSON XIII}

\section{HEAT ABSORBED IN THE FUSION OF ICE.}

\section{PRACTICAL WORK.}

Things required. - Glass tubing. Thermometer. Beaker. Laboratory burner. Sand-bath. Balance and weights. Ice. Wax.

\section{What to do.}

Melting point of wax. - Melt a little paraffin wax in a beaker, and immerse the bulb of a thermometer in the liquid. When the thermometer is taken out, a thin film of liquid paraffin will be seen upon it. Let the bulb cool, and notice the temperature when the wax assumes a frosted appearance, which shows that it is solidifying. When the wax on the bulb has become solid, place the thermometer in a beaker of water and gently heat the water. Observe the temperature at which the wax becomes transparent again. The average of this result and the preceding one is the melting point of paraffin wax.

$$
\text { Melting point of ice.-Put }
$$
some small pieces or shavings of clean ice into a beaker and thrust a thermometer into them. Record the tempera-

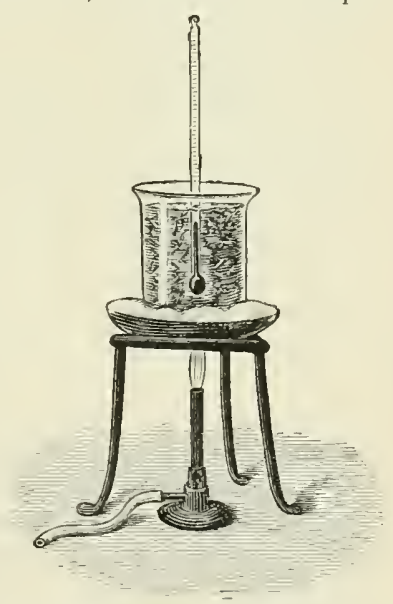

FIG. 44.-The temperature of the ice and water remains at $0^{\circ} \mathrm{C}$. until all the ice is melted. ture indicated. Pour in a little water, stir the misture, and again record the temperature. 
Place the beaker on a sand-bath and warm it gently. Notice the reading of the thermometer so long as there is any ice unmelted.

In all these cases the reading of the thermometer is the same, or the temperature of melting ice is constant.

Heat requirea to melt one gram of ice.- IVeigh about 200 grams of warm water into a beaker and observe the temperature. Put a few small pieces of ice into the water, stir them round with the thermometer, and, as soon as they have melted, again observe the temperature of the water. Now make another weighing, and find out by subtraction the mass of the ice added. Record the observations as shown below :

Mass of water, -

Temperature of water,

Fall of temperature, "when the ice had melted, ...... ${ }^{\circ} \mathrm{C}$.

Mass of water and mass of melted ice, - ......gms.

Therefore mass of ice added, - - - - ......gms.

The loss and gain of heat may be shown in two columns thus :

Loss.

The temperature of ......gms.

of water fell through $\therefore$ C.

Quantity of heat lost $=$ mass of water $x$ fall of temperature $=\ldots \ldots$
Gain.

......gms. of ice were melted to water at $0^{\circ} \mathrm{C}$.

The temperature of......gms. of water at $0^{\circ} \mathrm{C}$. was raised to ...... ${ }^{\circ} \mathrm{C}$., that is, through ...... $\mathrm{C}$.

Quantity of heat used = mass of water (melted ice) $\times$ rise of temperature $=\ldots$...

You see how much heat was expended, and you also see that only a part of it was used in heating the melted ice from $0^{\circ} \mathrm{C}$. to the final temperature. The difference between the two results gives you the amount of heat expended in melting the mass of ice used. Find from this the amount of heat required to just melt I $\mathrm{gm}$. of ice.

\section{REASONS AND RESULTS.}

Melting points.-When a solid is heated, the first effect of the heating is ustrally to make it get larger. But if the heating is 
continued long enough, when the solid reaches a certain temperature, which differs for different solids, melting begins. The solid changes into a liquid. The temperature at which the melting takes place is called the melting point. Thus, when a lump of lead is heated its temperature rises, it gets larger, and as the heating is continued it is converted into a silverylooking liquid. IVax, ice, and iron are other examples of solids which melt. But ice, wax, lead, and iron differ very widely in the temperatures at which they begin to melt, as the following table shows:

$\begin{array}{lcccccc}\text { Ice melts at } & - & - & - & - & 0^{\circ} \mathrm{C} \text {. } \\ \text { Beeswax } & " & - & - & - & - & 65^{\circ} \mathrm{C} \text {. } \\ \text { Lead } & " & - & - & - & - & 330^{\circ} \mathrm{C} \text {. } \\ \text { Cast-iron } & " & - & - & - & -1200^{\circ} \mathrm{C} \text {. }\end{array}$

So long as any of the solid remains unmelted, the temperature does not rise above the melting point. You can easily satisfy yourself that this is true in the case of ice. If you obtain some small pieces of clean ice, and thrust a centigrade thermometer into them, you will notice that the thermometer records a temperature of $0^{\circ} \mathrm{C}$. Or, if you put some of the ice into a beaker, and pour in some water, you will find after you have stirred the ice and water together for a little while, provided you have put enough ice to be sure that it does not all melt, that the thermometer still records a temperature of $0^{\circ} \mathrm{C}$. And even if you put the beaker, with the ice and water in it, over a laboratory burner and warm it gently, you will still find that, so long as there is any ice unmelted, the thermometer still reads $0^{\circ} \mathrm{C}$. It is very evident, then, that the temperature of melting ice is always the same, and remains the same as long as there is any ice unmelted.

Latent heat.-The experiments which have just been described are of the very greatest importance. You must not leave them until you understand what they mean. It is certain that when the mixture of ice and water is heated over a laboratory burner heat is being continually given to the mixture. Yet the temperature as recorded by the thermometer gets no higher. The question arises, what becomes of this heat, as it has no effect upon the temperature of the mixture? You know that the ice is gradually melted, and if the heating is continued long enough it is all changed into water. As soon as this has happened, every 
further addition of heat raises the temperature of the water. These considerations lead us to conclude that the heat previously given to the mixture is all used up in bringing about the change of ice into water. Further, it is found that not only in the case of ice, but when any solid is turned into a liquid, there is no increase in temperature, even while heat is being added to it, until the whole of the solid has been changed to a liquid.

This amount of heat which is necessary to change a solid into a liquid is spoken of as latent heat. The word latent comes from a Latin word, meaning "lying hidden," and refers to the fact that the heat used up in changing a solid to the liquid condition has no effect upon a thermometer, but appears to be hidden away in the liquid.

How the latent heat of water is measured.-A convenient way to find out how many units of heat are required to melt a gram of ice, is to mix together some warm water and ice, the mass and temperature of both being known, and then record the temperature of the mixture at the instant the last piece of ice disappears. The facts which in this way are observed are as follows :

Mass of warm water in grams.

Mass of ice in grams.

Temperature of warm water.

Temperature of the ice.

Temperature of the mixture after the ice has finally disappeared.

Number of degrees through which the temperature of the water falls.

In such an experiment a certain number of heat-units would be lost by the water, and a certain number gained by the ice and by the water into which the ice is changed as it melts.

The loss of heat is at once calculated by knowing that the temperature of a certain number of grams of water has fallen through an observed number of degrees, and if these numbers are multiplied together the result shows the number of units of heat lost by the warm water.

The gain of heat consists of two parts: first, the unknown number of units of heat necessary to melt the number of grams of ice which were taken. Secondly, the number of units of heat 
required to raise the temperature of the mass of water at $0^{\circ} \mathrm{C}$. (formed by melting the number of grams of ice which were taken) up to the temperature of the mixture. This number of units of heat can be found by multiplication.

You also know that the total loss of heat by the warm water is equal to the total gain of heat by the ice. Consequently it should be plain, that the difference between the two known results, obtained as described, tells the number of units of heat used up in melting the quantity of ice taken. Dividing this by the number of grams of ice gives us the number of heat units required to convert $\mathrm{I}$ gram of ice at $\mathrm{o}^{\circ} \mathrm{C}$. into a gram of water at $0^{\circ} \mathrm{C}$.

An Actual Experiment.-The following results of an experiment will enable you to understand exactly the method of calculation :

Mass of water,

Temperature of water, - - - $\quad 56^{\circ} \mathrm{C}$.

Fall of temperature, , after ice had all melted, $6^{\circ} \mathrm{C}$.

Mass of water and melted ice, Therefore mass of ice added, -

Loss.

The temperature of $200 \mathrm{gms}$. of water fell through $50^{\circ} \mathrm{C}$.

Units of heat lost $=200 \times 50$ $=\mathrm{I} 0,000$.

$$
\begin{array}{ll}
-\quad & -\quad 56^{\circ}-6^{\circ}=50^{\circ} \mathrm{C} . \\
-\quad & -\quad 320 \mathrm{gms} . \\
-\quad & -120 \mathrm{gms} .
\end{array}
$$

GAIN.

(a) 120 gms. of ice were melted to water at $0^{\circ} \mathrm{C}$.

(b) The temperature of 120 gms. of water at $0^{\circ} \mathrm{C}$. was raised to $6^{\circ} \mathrm{C}$.

Units of heat required to do this $=120 \times 6=720$.

Heat required to melt $\mathrm{I} 20 \mathrm{gms}$. of ice $=\mathrm{I} 0,000-720=9280$ calories.

Heat required to melt $\mathrm{r} \mathrm{gm}$. of ice $=\frac{9280}{120}=77^{\circ} 3$ calories.

Latent heat of water.-The number of units of heat which are required to change the state of a gram of ice, converting it from the solid to the liquid condition without raising its temperature, is called the latent heat of water or the latent heat of fusion of ice. To melt I gram of ice requires 80 heat-units. That is to say, as much heat as would raise the temperature of a gram of water through $S 0^{\circ} \mathrm{C}$, , or would raise that of So grams of water through $\mathrm{I}^{\circ} \mathrm{C}$., is used up in changing a gram of ice into 
a gram of water at the same temperature. Similarly, to melt I lb. of ice requires as many heat-units as are necessary to raise the temperature of I $\mathrm{lb}$. of water from $0^{\circ} \mathrm{C}$. to $80^{\circ} \mathrm{C}$, or as much heat as is wanted to raise that of 80 lbs. of water through $I^{\circ} \mathrm{C}$.

Should you endeavour to perform an experiment to prove the above statement, you must remember that the thermometer and beaker you use will give out or take in some heat, which will, unless allowed for, prevent an exact result being obtained.

Natural consequences of latent heat of water.-Just as it is necessary, before a pound of ice can be changed into a pound of water, to give it an amount of heat which would raise the temperature of a pound of water through $80^{\circ} \mathrm{C}$., so before a pound of water can be changed into a pound of ice, precisely the same amount of heat must be taken from it. This is why it takes so many cold nights to cover a pond with ice, for not until every pound of water at the surface has had this large amount of heat taken from it can it change into ice. For just the same reason, it takes a very long time to completely melt the snow in the roads and the ice on the ponds, even after a thaw has set in.

\section{TO BE REMEMBERED.}

The melting point of a solid is the temperature at which the solid changes into a liquid. So long as any of the solid remains unmelted the temperature remains the same.

Latent heat is the number of heat-units necessary to bring about a change of state of unit mass without a change of temperature.

The latent heat of water is the number of heat-units required to change one gram of ice into one gram of water at $0^{\circ} \mathrm{C}$. ; and its value is So.

This number is obtained by mixing known masses of warm water and ice and recording the temperature of the mixture at the instant the last piece of ice disappears.

As a natural consequence of the latent heat of water, ponds require many frosty nights to freeze them over; and a thaw takes many days to become complete.

\section{EXERCISE XIII.}

1. How would you ascertain the melting point of beeswax? What do you mean by the melting point of a solid?

2. A thermometer is placed into a mixture of pounded ice and water which is gently heated over a laboratory burner. What changes in temperature are noticed $i$ 
3. What do you mean by (1) latent heat, (2) latent heat of water?

4. How would you proceed to determine the latent heat of water? What is its value in heat-units?

5. What are some of the consequences in nature of the latent heat of water?

6. When a mixture of ice and ice-cold water is held over a flame, the water does not get any warmer if it is kept well stirred. What becomes of the heat which is being given to the water?

7. Though ice melts at a temperature of $0^{\circ} \mathrm{C}$, yet ice, or snow, in winter does not change into water as soon as the sun shines upon it. How do you account for this?

\section{LESSON XIV.}

CONVECTION. HEAT ABSORBED IN THE CONVERSION OF WATER INTO STEAM.

\section{PRACTICAL IVORK.}

Things required.-Cochineal or other colouring matter. Short piece of candle. Lamp glass. Card. Saucer. Bent tubing. Wide-mouthed bottle without bottom. Test-tube fitted as in Fig. 46. Laboratory burner. Thermometer. Apparatus shown in Fig. 45 .

[Experiments to show that heat is absorbed when a liquid turns into a vapour have been described in Lesson $I$. It may be well to refer back to that lesson before proceeding with this one.]

\section{What to do.}

Convection currents in water.-Heat water into which some solid colouring matter (like cochineal, crystals of magenta, or fragments of litmus) has been thrown, in a round-bottomed flask over a small flame, and observe and sketch the convection currents (Fig. 47).

Direction of air currents.-Open the door of a warm room slightly. Hold a lighted candle $(a)$ near the top, $\langle b\rangle$ near the bottom, $(c)$ near the middle. Notice the direction of the air currents. The warm air flows out at the top, and cold air enters at the bottom. 
Convection currents in air.-Place a short piece of candle in a saucer, light it, put a lamp glass over it, and pour sufficient water into the saucer to cover the bottom of the lamp glass. Watch how the light of the candle is affected. Next cut a strip of card less than half the height of the lamp glass, and nearly as wide as the internal diameter of the top. Insert the card into the lamp glass so as to divide the upper part into halves. Now light the candle again, and see whether it will burn with the divided chimney over it. Test the direction of the currents of air at the top of the chimney by holding a smoking taper or smouldering brown paper over it (Fig. 50).

Ventilation of a mine.-Fit a box with chimneys and glass face as in Fig. 51. Show that when a candle is burning below one of the chimneys air rises above it and descends in the other chimney.

Circulation of water.-Fit up apparatus as shown in Fig. 45. $A$ is a 6-oz. wide-mouth corked bottle, with the bottom knocked

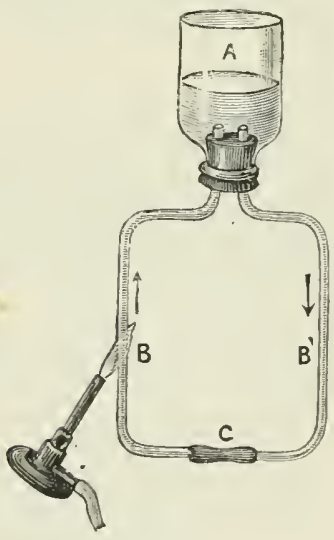

FiG. 45.-Arrangement to show circulation of water produced by hot water rising and colder water sinking. out (a small gas jar will do, or an ordinary lamp glass may be used). A well-fitting cork with two holes is inserted, through which the bent glass tubes $B$, $B^{\prime}$ pass, as shown. They are united at the bottom by a short piece of india-rubber tubing, $C$. Pour water into $A$ until it just covers the open ends of the tubes. Now pour in about a teaspoonful of ink. Apply a small flame at $B$. Notice what happens

Temperature of boiling water. -Boil water slowly in a flask and take its temperature with a thermometer. Make the water boil more vigorously either by increasing the size of the flame or putting two flames underneath. Take the temperature again. What becomes of the heat when a larger flame is used?

Heat absorbed in the conversion of water into steam.-To a test-tube of about one inch diameter fit a cork through which 
passes a short glass tube bent at a right angle. About half an inch from the open end inside the test-tube a hole is blown in the side of the glass tube (Fig. 46). Boil water in the test-tube, and, when steam is issuing freely, place a weighed calorimeter containing water, the mass and temperature of which have been observed, so that the end of the tube from which steam is issuing is immersed in the water. The calorimeter may be wrapped in cotton wool and placed in an outer vessel if desired and the flame screened by

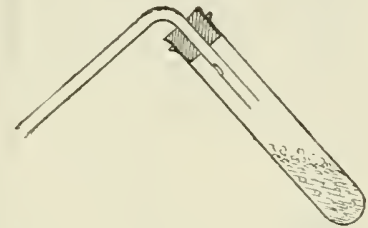

FiG. 46.-A simple arrangement for producing steam and determining the quantity of heat given out by steam when it becomes water.

a note-book. After the temperature has risen to about $40^{\circ} \mathrm{C}$. remove the calorimeter-do not remove the test-tube from the flame-and observe the temperature. Then weigh the calorimeter and water again to find the mass of steam condensed. The observations may be written down thus :

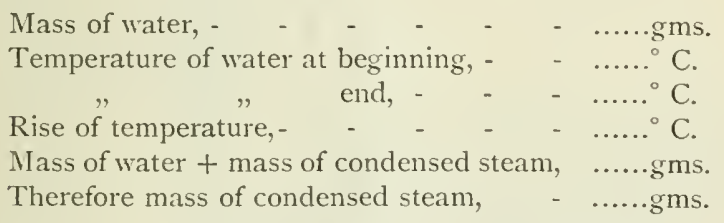

As in the last lesson, the changes of temperature can be arranged under two heads :

Gain.

The temperature of ......gms. of water was raised through ...... ${ }^{\circ} \mathrm{C}$.

The quantity of heat used $=$ mass of water $\times$ rise of temperature.

=......calories.
Loss.

.....gms. of steam were condensed to water at $100^{\circ} \mathrm{C}$. The temperature of ......gms. of water at $100^{\circ} \mathrm{C}$. fell to ..... ${ }^{\circ} \mathrm{C}$., that is, through ...... $\mathrm{C}$.

The quantity of heat thus given up $=$ mass of condensed steam (water) $\times$ fall of temperature.

$=\ldots .$. calories. 
You thus see the quantity of heat gained, and how much of the gain was due to the temperature of the condensed steam falling from $100^{\circ} \mathrm{C}$. to the final temperature. The remainder shows you the amount of heat given up by a certain mass of steam in condensing into water. Find the amount of heat given up by $\mathrm{I} \mathrm{gm}$. of steam in condensing to form I $\mathrm{gm}$. of water. This is called the latent heat of steam, or the latent heat of vaporisation of water.

\section{REASONS AND RESULTS.}

Process by which liquids are heated.-The process by which water and other liquids are heated may be easily studied by heating water, into which some solid colouring matter (like

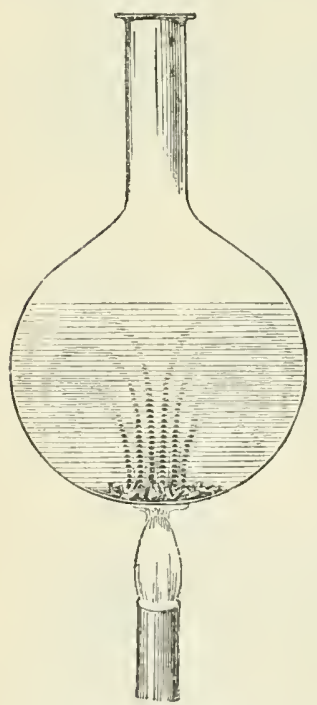

Fig. 47.- Hot particles of water rise and cold parricles descend to take their places. cochineal, aniline dye, litmus, etc.) has been thrown, in a round-bottomed flask over a small flame as in Fig. 47. The water nearest the flame gets heated, and consequently expands and gets lighter. It therefore rises, and causes a warm ascending current of coloured water. But something must take the place of this water which rises, and the cold water at the top being heavier than the warm water, sinks to the bottom and occupies the space of the water which has risen. This water in its turn gets heated and rises, taking heat with it to another part of the fluid, and more cold water from the sulface sinks. There are thus upward currents of heated water and downward currents of cool water, until by-and-by the whole of the water is hcated. These currents are known as convection currents, and the process of heating in this manner is called convection. Eventually the whole of the water gets so hot that the bubbles of vapour which are formed near the source of heat arc not condensed again in their upward passage through the liquid, and coming to the surface they cscape as steam. The 
liquid is then said to boil. The temperature at which bubbles of this sort get formed throughout the liquid is quite definite, and is called the Boiling Point.

Gases are similarly heated by the process of convection, which may be thus defined: Convection is the process by which fiuids (liquids and gases) become heated by the actual movement of the particles of the fluid.

Applications of heating by convection.-Heating buildings by hot water.-One of the commonest ways of heating large buildings is by means of hot-water pipes, and the action of this

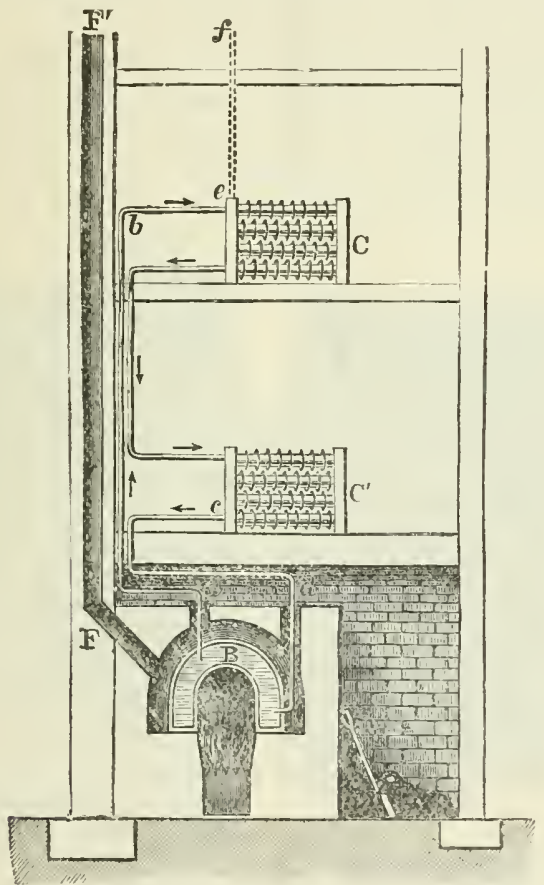

FIG, 48.-Circulation of water used to warm a house. Warm water rises and cold water sinks to take its place.

system is due to the facts you have just learnt. In Fig. 48 we have the condition of things in such a building very simply represented. We will suppose, to begin with, that the boiler $B$, 
the pipes $a b$, etc., and the coils $C, C^{\prime}$, are nearly full of cold water and that the fire below the boiler is lighted. Heat passes through the bottom of the boiler by the process of conduction, and heats the layer of water near it, which, expanding, rises and passes up the tube $a b$ to the top of the building, where it gives out its heat to the rooms. The place of this water which has thus risen is taken by cold water fron the other pipe, terminating just past $d$. This in its turn gets warmed and rises, and its place is taken by the water which has become cold by its passage through the pipes in the various rooms. There is thus no difference in this case from what you have seen to be true in the flask of water being heated from below.

Ventilation.-The ventilation of ordinary dwelling rooms is easily possible because of the way in which gases become heated by convection. The air in a room becomes warm and rendered impure at the same time. Consequently there is a tendency for the impure air to rise, and if a suitable place near the ceiling is made for it to get out, as well as a place near the floor for the

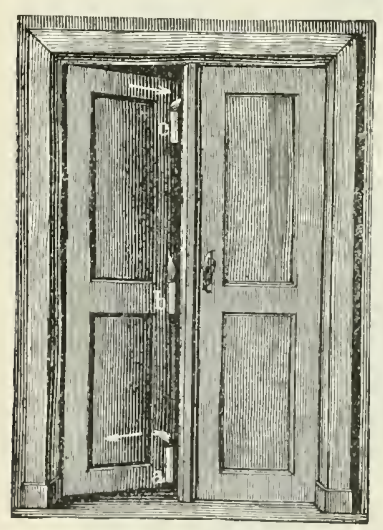

Fig. 49.-Currents of air move from warmer to colder points.

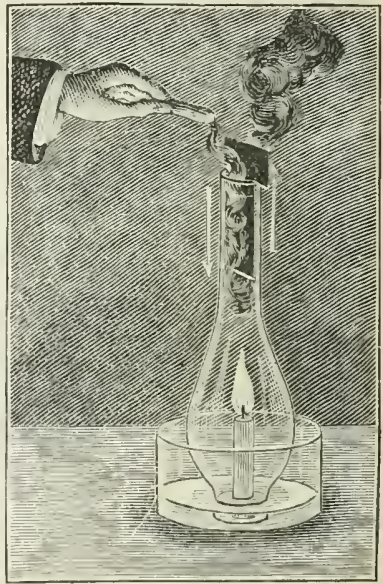

FIf. 50. - The smoke shows that a current of warm air is ascending and a current of colder air is descending.

colker, purer air from outside to enter, we shall have a continuous circulation of air set up which will keep the atmosphere of the room pure and sweet. 
The existence of these currents can easily be proved. Thus, if the door of a room is opened and a lighted candle is held Ist near the top, 2nd near the bottom, 3 rd at the middle of the opening, the light is affected as shown in Fig. 49.

Another experiment is to place a short piece of candle in a saucer, light it, put a lamp glass over it, and pour sufficient water into the saucer to cover the bottom of the lamp glass (Fig. 50). In this case the light of the candle is affected and eventually goes out. But if you cut a strip of card less than half the height of the lamp glass, and nearly as wide as the internal diameter of the top, and insert the card into the lamp glass so as to divide the upper part into halves, and then light the candle again, it will be seen to continue to burn with the divided chimney over it. The direction of the currents of air at the top of the chimney can be shown by holding a smoking taper or smouldering brown-paper over the chimney.

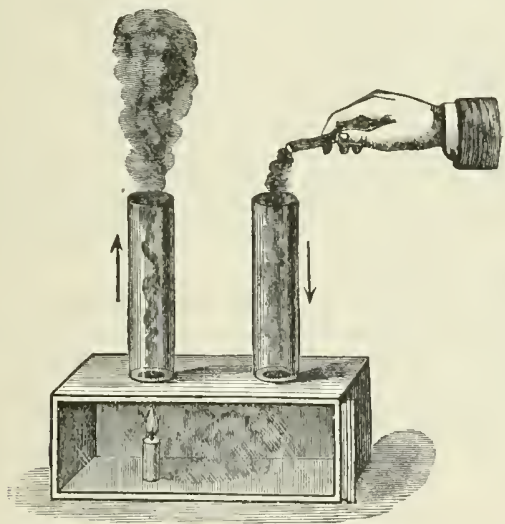

FIG. 5r.-Warm air ascends one chimney and cold air descends the other to take its place.

Small mines are often ventilated by keeping a fire burning at the bottom of one of the shafts. The warm air thus produced rises up one shaft and cold air descends down the other shaft to take its place. Fig. 5 I shows a simple arrangement for producing this effect on a small scale.

Latent heat of steam.-When once water has started to boil, its temperature gets no higher than the boiling point. So 
long as there is any water left, no matter how much it is heated, its temperature remains the same if it is contained in an open vessel. After what has been stated about the latent heat of water, you should have no difficulty in understanding the reason for this. After water has been heated to the boiling point, $100^{\circ} \mathrm{C}$, heat is absorbed, or used up, in bringing about the change from the liquid state to that of vapour. It requires a great many more heat-units to convert one gram of water at a temperature of $100^{\circ} \mathrm{C}$. into a gram of steam at the same temperature, than it does to change a gram of ice at $0^{\circ} \mathrm{C}$. into a gram of water at $0^{\circ} \mathrm{C}$. To bring about the latter change requires an expenditure of 80 heat-units, but to convert a gram of water at $100^{\circ} \mathrm{C}$. into a gram of steam, without changing its temperature, requires no fewer than 536 heat-units, that is, nearly seven times the quantity of heat. This number, 536, represents the latent heat of steam, or as it is sometimes called, the latent heat of vaporisation of water. Expressed in another way, we may say that it requires as much heat as would raise the temperature of 536 grams of water through $1^{\circ} \mathrm{C}$., or as much as would raise the temperature of $53 \frac{3}{5}$ grams of water through $10^{\circ} \mathrm{C}$. to simply bring about the change of one gram of water at $100^{\circ} \mathrm{C}$. into one gram of steam at the same temperature. A liquid is never changed into a vapour without some absorption of heat. This is true whether the change takes place quietly as in evaporation, or rapidly as in boiling.

Some familiar instances of the heat absorbed when a liquid is changed into a vapour.-If you sprinkle some liquid such as ether or alcohol upon your hands and wave them about, you notice your hands get cold. This is because the heat necessary to bring about the change from liquid to vapour is taken from the hands.

A dog cools himself by letting his tongue loll out. This is because the evaporation which takes place from the large surface of tongue exposed causes heat to be taken from the tongue itself, and to consequently cool it.

In tropical countries, where the land gets very hot during the day, evaporation takes place so rapidly after sunset that the water sometimes becomes so much cooled by the extraction of the heat required to bring about the change from liquid to vapour, that the water freczes.

You will probably yourself have noticed that not only is the 
dust laid by watering the roads in summer, but the air is pleasantly cooled by the evaporation of the water.

Just as a large quantity of heat is required to convert water into steam, so a large quantity is given up when steam becomes water. It is for this reason that a scald from the steam of boiling water is worse than a scald from the boiling water itself.

Determination of the quantity of heat required to convert water into steam.-All that is needed is to condense some steam, by passing it into water, and to find the number of units of heat given up. Then, if the number of grams of steam condensed is known, the number of units of heat given up by one gram of steam can easily be calculated. A convenient way to do the experiment is to put a known quantity of cold water into a thin beaker or calorimeter. Then let a tube, from which steam from boiling water is issuing, dip into the water in the calorimeter. The temperature of the cold water is first raised by the condensation of the steam into water at $100^{\circ} \mathrm{C}$, and then by the cooling of the hot water formed. Suppose the temperature to begin with was $10^{\circ} \mathrm{C}$. and the mass of the water Ioo grams. And suppose the steam raised the temperature to $40^{\circ} \mathrm{C}$., that is, through $30^{\circ} \mathrm{C}$; then the number of units of heat gained by the water would be $30 \times 100$, that is 3000 calories. If 5 grams of steam were found to have condensed into water, then the heat given up by this water in falling from $100^{\circ} \mathrm{C}$. to $40^{\circ} \mathrm{C}$., that is, through $60^{\circ} \mathrm{C}$., would be $5 \times 60$ or 300 calories. If these 300 calories are subtracted from the 3000 gained by the cold water, the gain due to the condensation of the steam is found to be 2700 calories. As this quantity represents the number of units of heat given up by 5 grams of steam, the number of units given up by I gram is $2700 \div 5$, or 540 calories. This is therefore approximately the latent heat of steam. The same facts can be expressed thus :

Number of units of heat gained by cold water, - 3000

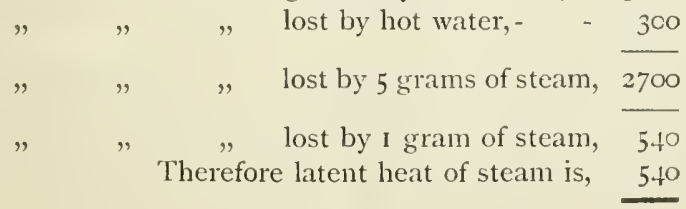




\section{TO BE REMEMBERED.}

Liquids and gases are heated by convection. The upward warm currents and the downward cold currents are known as convection currents.

Convection is the process by which liquids and gases become heated by the actual movements of their particles.

Heating buildings by hot water is a practical way of making use of convection currents.

Ventilation is possible because of the convection currents set up in rooms as the air becomes heated.

The latent heat of steam, or the latent heat of vaporisation, means the number of heat-units required to change a gram of water at $100^{\circ} \mathrm{C}$. into a gram of steam at the same temperature. The latent heat of steam is 536. Hence, it requires as much heat to change a gram of water at $100^{\circ} \mathrm{C}$. into a gram of steam at the same temperature as would be necessary to raise the temperature of 536 grams of water through $\mathrm{r}^{\circ} \mathrm{C}$.

\section{EXERCISE XIV.}

I. Describe the changes in volume which take place as the temperature of a piece of ice is gradually raised until the ice becomes water, and the water is converted into steam.

2. What are convection currents? Describe the manner in which a liquid becomes heated.

3. Describe an experiment to show convection currents.

4. Explain how convection currents are used to warm buildings by hot water.

5. How could you show the direction of air currents entering and leaving a room?

6. Describe an experiment to illustrate how a small mine can be supplied with fresh air.

7. What do you mean by the latent heat of steam? How many units of heat are required to change I gram of water at $100^{\circ} \mathrm{C}$. into steam at the same temperature?

8 . Give some common instances which show that heat is always absorbed when a liquid is changed into vapour.

9. Why is a scald from the steam of boiling water more serious than one from the water itself?

I0. Suppose you had two bottles, each containing a pint of cold water. If ten ounces of boiling water werc added to one, and ten ounces of steam were condensed in the other, which would become the warmer of the two, and why?

Ir. Why is it necessary, when distilling water, to keep cold water constantly flowing around the tube in which the steam is condensed? 
INCREASE OF MASS ACCOMPANIES BURNING. 93

\section{LESSON XV.}

INCREASE OF MASS ACCOMPANIES BURNING.

PRACTICAL WORK.

Things required.-Watch glass and iron tacks. Laboratory burner, sand-bath, and tripod or retort stand. Basin of water. bottle, glass rod, glass plate, and muslin bag. Crucible. Balance and box of weights. Magnesium ribbon or powder. Copper filings or powder.

\section{What to do.}

Increase of mass when magnesium is burnt.-Weigh a crucible and its lid with a piece of magnesium, which, folded lightly, is placed in the crucible. Heat it strongly in a burner, taking care to let no fumes escape (Fig. 52). To do this keep on the lid, and only raise it a little when the flame is removed.

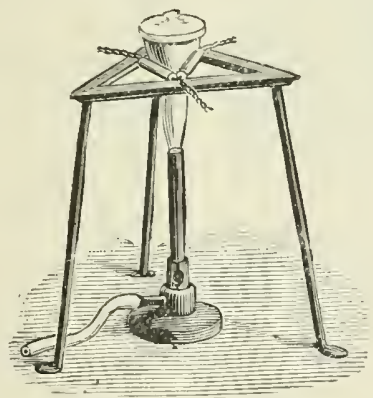

Fic. 52.-How to heat magnesium powder or ribbon in a crucible.

The magnesium is seen to burn brightly in places, but, if care is taken, no fumes are lost. When finished, the whole mass should be in the form of a white powder. Allow to cool, and weigh the crucible with the lid and powder. Subtract the mass of the crucible and lid to find the mass of the powder. It will almost certainly be found to be more. 
Increase of mass when iron rusts.-Carefully weigh a watch glass with some iron filings or tacks in it. Because iron rusts best when damp, add a few drops of water to the iron in the watch glass, and allow it to stand for a day or two. At the end of this time warm the watch glass gently, so as to evaporate any water left. When the rusty iron is quite dry, weigh the watch glass and its contents again. Its mass will be found to be more after the rusting has taken place; evidently, therefore, the iron in getting rusty has gained in mass.

Air absorbed during rusting.-Place some iron filings in a muslin bag and tie the bag to a piece of glass rod. Moisten

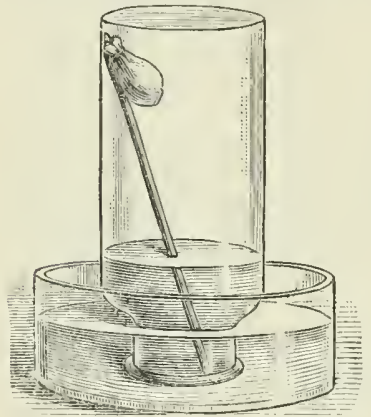

FIc. 53.-As the iron filings in the muslin bag become rusty they use up part of the air in the bottle. well and place it in a bottle of air inverted over water. If necessary, put something on the bottle to keep it upright (Fig. 53). Examine after a few days. It will be seen that the water has risen in the bottle, showing that some part of the atmosphere has been abstracted by the iron in rusting.

Alteration of air when iron rusts in it.-Tightly place your hand or a card under the mouth of the jar so as to allow no water to escape ; set the jar upright and plunge a burning taper into it. Note that the flame is extinguished; do not throw away the water.

\section{REASONS AND RESULTS.}

Properties of the atmosphere already learnt.-In several of the previous lessons different properties which the atmosphere, or air around us, possesses have been described, and before the rusting of iron is more closely studied, it will be best to bring together here what has already been learnt about the atmosphere. You have seen that it is a transparent gas, which, like every other kind of matter, possesses mass. Because of its mass, the atmosphere exerts a pressure in every direction equal to the weight of 15 lbs. On every square inch of the surface of 
the earth. This pressure is measured by an instrument called a barometer. The air generally contains some invisible water vapour, the actual amount depending upon its temperature. The quantity of water vapour present at any time is measured by a hygrometer.

Effects of heating metals in air.-Some of the effects of heat upon substances have already been observed and described. It has been seen that solids may be melted into liquids, and liquids converted into vapours, by heat. WV now come to another kind of effect produced when substances are strongly heated in the air. If a piece of platinum wire or platinum foil is held in the smokeless flame of a laboratory burner it becomes red-hot; but when it is taken out of the flame it quickly resumes its ordinary colour, and no change can be seen to have taken place. But, if a piece of magnesium wire is held in a flame, it catches alight and burns brilliantly away, leaving a white ash. Platinum and magnesium thus behave very differently when heated. Many metals, like iron, copper, and lead, become covered with a film or tarnish when they are heated in the air, but if they are heated in closed tubes without air they do not change in this way. It thus seems that the tarnish is due to the absorption of something from the air.

But if something is taken from the air when a metal tarnishes, or when a metal like magnesium burns, the tarnished metal or the ashes of the magnesium, should weigh more than the original substance. Observations show that this is actually the case. If a piece of magnesium is weighed and then burnt in a crucible, the white ash which remains behind will weigh more than the metal did. In a similar way copper may be proved to increase in mass when it is tarnished by being heated. On the other hand, platinum, which does not tarnish in this way, does not increase in mass when heated. As air seems responsible for the effects described, it is evidently well worth investigation.

Chemical properties of air.-You have now to study what are called the chemical properties of air, and to do this it is necessary to carefully consider the changes which different substances undergo when exposed to the atmosphere. It is best to begin with those cases which appear to be simplest. Everyone has noticed that when iron is exposed to damp air it becomes rusty. It is instructive to try to find out what takes place during the rusting of iron, and what rust really is. Does 
the iron lose or give up something when it rusts? Or, does it, on the contrary, take up or gain something? These questions can be best answered by properly arranged experiments.

Iron gains in mass during rusting.-If a known mass of iron is allowed to rust by contact with damp air, you can easily show by weighing it after the rusting has taken place that it has increased in mass.

The result of this experiment is very important. If the weighings are carefully made, the iron is always found to gain in mass when it rusts. You should therefore remember that always

\section{Iron gains in mass when it rusts.}

What causes the gain in mass?-The substance causing the increase of mass, when damp iron filings rust, could come from the water or moisture on the iron or from the air. If the iron is allowed to rust in a closed space, and the experiment is arranged so that if anything is taken from the air the loss can be detected, it can be decided whether the water or the air causes the rusting. Figure 53 shows a convenient way of doing this. Some iron filings are placed loosely in a muslin bag and the bag is tied to a piece of glass rod. The bag of filings is well moistened and arranged in a bottle of air inverted over water in a basin, in the manner shown by the illustration. The apparatus is then left undisturbed for a day or two. When it is examined after this time the water is seen to have risen in the bottle. Why is this? It is quite clear that there is less air in the bottle now than there was before the iron had become rusty. Some part of the air has, therefore, been used by the iron as it rusted, and this part of the air has joined with the iron to help to make the rust on the outside of it.

Air as well as iron undergoes change.-When iron rusts the change which it has undergone is visible. No difference can, however, be seen between the character of the air left in a bottle in which iron has rusted and ordinary air. But there is a very great difference. As a flame is extinguished by the gas left in a bottle in which iron has rusted, you know that it cannot be ordinary air, for a taper will burn quite easily in air. But before the rusting of the iron took place in it, the air was ordinary air. Hence, it is clear that there are two kinds of gases in air. When iron rusts it takes out of the air that 
part of it which helps burning, and, moreover, the iron and the part of the air concerned in burning combine together to form iron rust. The part of the air left in the bottle will not let things burn in it. It should be very carefully remembered that

Iron in rusting gains in mass, taking some material from the air, and this material is the part of the air which causes substances to burn in it.

TO BE REMEMBERED.

Substances increase in mass when tarnished by being heated in air. Magnesium increases in mass when burnt.

When iron rusts it increases in mass.

A gas from air is used up when iron rusts, and this gas causes the increase of mass.

The gas which remains will not let a taper burn in it.

There are two kinds of gases in air : one used up when iron rusts, and another in which a light is extinguished.

\section{EXERC1SE XV.}

I. How would you show that iron gains in mass during rusting?

2. Describe an experiment to show that iron in rusting takes something out of the air.

3. Write down all that you have learnt about air.

4. Why does iron gain in mass during rusting?

5. How could you show that air in which iron has rusted is different from ordinary air?

6. How could you prove that the ashes of a piece of burnt magnesium are hearier than the magnesium was to begin with?

7. If the inside of a bottle had iron filings spread over it, and the bottle were corked up and left in a warm room for a few weeks. what would you expect to see if the cork was then withdrawn while the mouth of the bottle was held under water? 


\section{LESSON XVI. \\ THE RUSTING OF IRON.}

PRACTICAL WORK.

Things required.-The jar in which the rusting of iron took place in the last lesson. Graduated vessel. Taper. Muslin bag, iron filings, and glass rod. Crucible and copper filings. Pipe-clay triangle. Laboratory burner. Balance and box of weights.

\section{What to do.}

l'olume of air use $l$ up in nusting.-Measure in a graduated vessel the quantity of water in the bottle from the experiment in the last lesson. This is equal to the quantity of gas which has been used up and has joined with the iron. Also measure the quantity of water the bottle holds. This gives us the volume of air the bottle originally held.

Change produced in air by iron rusting in it.- - Repeat the experiment of allowing iron to rust in an enclosed rolume of air, as described in the last lesson. After the iron has been left for a day or two and there is no further rise of the water, mark the level of the water in the jar by a narrow strip of gummed paper on the outside. Carefully introduce another muslin bag of iron which is not rusty. This can be done by using a large enough basin of water and pushing the bay through the water, being careful to allow no more air to get into the bottle. Examine the bottle after another day or two. There is no further rise in the level of the water and the iron is not rusty. Evidently the gas which is left after iron has rusted in air, and which extinguishes the flame of a taper, will not allow more iron to rust in it, though it is colourless and transparent, like ordinary air.

Rusting of copper in air.-Put some copper filings into a crucible, and, by weighing, determine the mass of the crucible and its contents. Support the crucible on a pipe-clay triangle and heat it strongly with a laboratory burner for some time, occasionally lifting the lid to admit fresh air. Notice as the 
heating is continued the copper changes in colour. Allow the crucible to cool. When it is cold determine the mass of the crucible and its contents. It will have increased in mass.

\section{REASONS AND RESULTS.}

What proportion of the air is taken by iron in rusting? - You have seen that iron takes something out of air when it rusts, and you may have supposed that all the air in a bottle would be used up if iron were allowed to rust in it for a long enough time. But this is not true. Only a certain proportion of the enclosed air is taken out of it when iron rusts. Suppose some damp iron filings are allowed to rust in an enclosed amount of air, contained in a bottle inverted over a basin of water. The amount of water which rises up in the bottle can be measured by means of a graduated vessel. A moment's thought will tell you that as this water gradually takes the place of the material which the iron used out of the air, its volume must be the same as the volume of the material so taken out of the air: The amount of water the bottle holds when full can be easily found, and the result shows the volume of air in the bottle to begin with. If observations of this kind are made, it will be found that, when the bottle is full, it has five times more water in it than it has after the iron has rusted. Even if the experiment is repeated several times with bottles of different sizes the result is always the same. It is always found that one-fifth of the volume of the air in the bottle to begin with is taken by the iron and its place occupied by water.

Chemical composition of the air.-It is now possible to state some definite conclusions concerning the composition of the air. That part of the air which helps substances to burn, and is taken out of the air by iron in rusting, may be called the active part of the air. That part which is left by the iron and will not allow a taper or candle to burn in it may be called the inactive part. The observations just described show, then, that air is made up or composed of I volume of the active part to 4 volumes of the inactive part, in every 5 volumes. In other words, in 100 pints of air there are 20 pints which will unite with iron to make iron rust, or which will assist a candle to burn, and 80 pints of the inactive part which will not assist burning. 
The inactive part of the air.- The gas which is left in a bottle of air after iron has rusted in the air will not allow a candle or taper to burn in it. This is one reason why it is called the inactive part of the air. The inactive part of air does not affect damp iron at all; and the iron does not rust when put into it. The name by which this gas is known to chemists is Nitrogen, and the effect of the presence of the gas in air is that the activity of the active part is toned down or weakened. Nitrogen not only refuses to allow things to burn, or be consumed, in it, but it will not itself burn, that is, it is incombustible. There are other substances present in the air besides the active and inactive parts which have been referred to, but their amounts are comparatively small, and they may here be left out of consideration.

Other metals combine with the active part of air.-When copper is heated in air, it gradually blackens and increases in

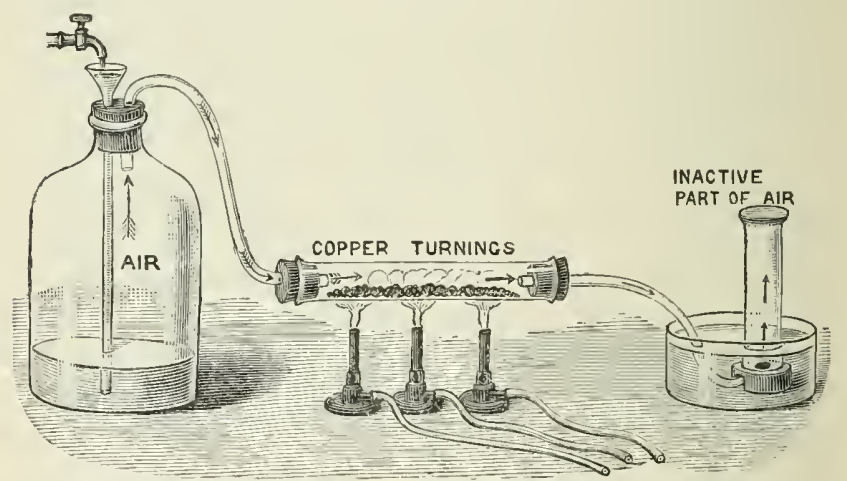

Fig. 54.- When air passes over hot copper it is deprived of its active part, and the inactive part may be collected as shown.

mass. When hot, copper has the power of combining with the active part of the air in just the same way as the iron does gradually when cold, and it is reasonable to conclude that the black substance formed is copper rust, though it is not generally known by that name.

That copper only combines with the active part, and leaves the inactive part, can be shown by a suitable experiment, though not so easily as in the case of iron. Some copper turnings are placed in a hard glass tube like that shown in Fig. 54, onc 
end of which is connected with an aspirator full of air, and the other by means of a well-fitting cork with a tube which dips under water in a trough. Then a bottle full of water is inverted in the trough of water exactly over the end of the small tube, which dips into it, and is connected with the hard glass tube containing the copper. The copper is heated strongly and air is forced over it by making water take the place of the air in the aspirator. As the air passes over the heated copper, the active part of the air joins with the copper to form the black copper rust, and the inactive part passes on alone into the inverted bottle in the trough. That the inactive part, nitrogen, collects in the bottle is indicated, though not proved, by the fact that it puts out the flame of a taper. If this gas is, in the same way, passed over some more heated copper it has no effect on it; the copper does not blacken. Moreover, if the amount of air which has come out of the aspirator is measured, and also the amount collected in the bottle, it is found that in passing over the copper the air loses one-fifth of its volume.

To be ReMeMbered.

When iron rusts in an enclosed amount of air it always takes up. one-fifth of the volume of the air. This part, which is also concerned in burning, may be called the active part. The remaining four-fifths which will not allow substances to burn in it, and in which iron will not rust, may be called the inactive part.

The inactive part of the air is called nitrogen. It weakens the activity of the active part.

Other metals besides iron combine with the active part of the air. Thus, when copper is heated in air, it takes out the active part, becoming changed into a black substance-a kind of copper rust.

\section{Exercise XVI.}

1. What proportion of the air is taken by iron in rusting? How would you prove your answer by an experiment?

2. What fraction of the volume of the air in a bottle is unable to support combustion? What is another name for this inactive part of air?

3. Describe very carefully what occurs when copper is heated in the air. Is there any increase of mass? If so, why?

4. How many pints of the active part of air would there be in 100 pints of air, and how many of the inactive part?

5. Sketch and describe the apparatus by which you could prove the propurtion of nitrogen in air by passing air over heated copper. 
6. An iron I lb. weight is allowed to rust. Will it weigh more or less than I lb. when it is rusty? If the rust is cleaned off, will the weight be a true I lb.? If not, how will it be wrong, and why?

\section{LESSON XVII.}

THE ACTION OF PHOSPHORUS ON AIR.

PRACTICAL WORK.

Things required.--Red and yellow phosphorus. Test-tube. fitted with a good cork or india-rubber stopper. Slate, tile, or an old saucer. Basin of water. Apparatus shown in Fig. 57. Strip of gummed paper,

What to do.

Read the caution on p. 105 .

The burning of phosphonis.-Place a little phosphorus

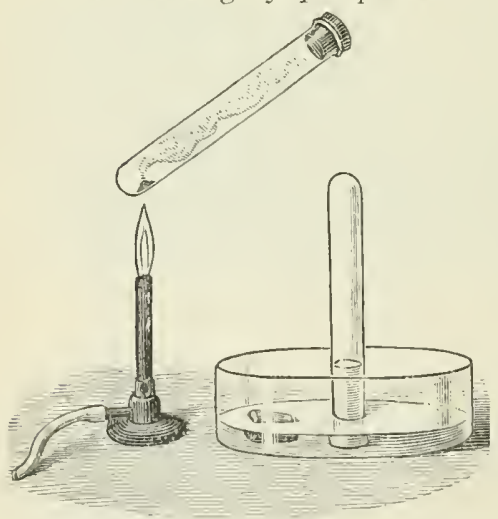

FIG. 55. - After the phosphorus has burned in the corked test-tube, the tust-tube is uncorked under water, and water enters to take the place of the air used up. and make it burn. When it will burn no longer, take away the test-tube and let it cool for five or ten minutes. upon a slate, tile, or an old saucer. Apply a light to it. It catches on fire and burns brightly. As it burns, dense white clouds are formed.

Volume of air used up when phosphorus burns. -Place a little red (or yellow) phosphorus in a test-tube fitted with a good cork. Fix the stopper firmly in the test-tube. Hold the test-tube slantingly, by means of a testtube holder, over a flame for a minute or two, so as to heat the phosphorus 
Then hold the mouth of the test-tube well under water, and carefully take out the stopper. Water rises inside the tube to take the place of the air used up. Sprinkle a little water on the outside of the tube, in order to cool the air inside. Mark the level to which the water rises, by means of a strip of gummed paper.

Lift the test-tube out of the water, and find, by means of a measuring jar, the volume of water required to fill it to the level of the bottom of the cork when inserted as it was in the experiment. Find also the volume required to fill the tube up to the level of the edge of the gummed paper, which marks the level to which the water rose.

By subtracting this rolume from the whole volume, the volume of air used up by the phosphorus can be determined. Record your measures thus:

Tolume of air in test-tube

Volume of air left afterburning phosphorus ..... , cub. cms.

" , used by

Proportion of air used to total rolume of air ......

Another way to find the volume of air used up when phosphorus burns.-Place a little red phosphorus in a long narrow test-tube, or a glass tube about eight inches in length, sealed at one end. Melt the tube near the open end and draw it out to a slender thread, being sure to keep the phosphoms well below the level of the flame while you do so, or it will catch alight. Break off the slender thread near the middle, and hold the broken end in a flame until it is well sealed up. Hold the test-tube in a test-tube clip over a

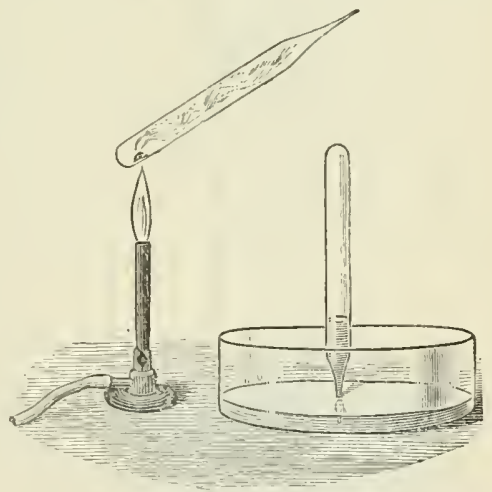

Fig. 56.-After the phosphorus has burned in the sealed tube the narrow end of the tube is broken of under water, and water enters to take the place of the air used up. flame, so as to heat the phosphorus. After it will not burn any more, take the test-tube away from the flame. 
When the tube is thoroughly cool, dip the pointed end well under water, and break off the end with a pair of pincers. Notice that the water rises up the tube to take the place of the gas used by the phosphorus in burning.

When the water has stopped rising, lower the tube until the level is the same inside as outside, and stick a strip of gummed paper upon the tube to mark this level. Now place a finger over the open end, and lift the tube out of the water.

Shake the water from the tube into a measuring glass, or hold the open end over a measuring glass and heat the other part, when the water will be driven out. Observe the volume of water that was in the tube ; this shows the volume of air used.

To find the volume of residual air, break off the tapering end of the tube, and fill the tube

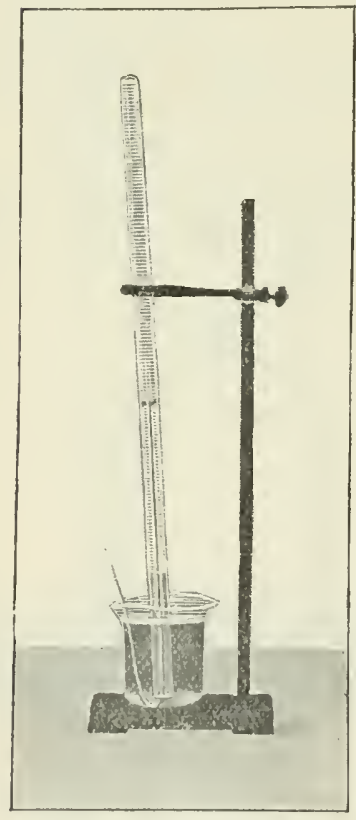

Fic: 57.-The slow combustion of a piece of phosphorus in the tube uses up one-fifth of the volume of enclosed air. with water to the edge of the gummed paper which marked the level of the water inside. Then pour this water into a measuring glass. It will be found to be four times more than the water previously measured.

Volume of air used up by phosphorus in slow combustion. -Obtain a glass tube about 18 inches long and $\frac{3}{1}$ inch in diameter, closed at one end. Fill the tube with water, and then stand it on one side.

Pour a little water into a small test-tube, and then drop a small piece of phosphorus into it. Put the small test-tube into a larger one containing hot water. The phosphorus melts. Bend one end of a piece of thin copper wire about 18 inches long into a small loop, and push the loop into the melted plosphorus in the test-tube. Remore the large test-tube of hot 
water; allow the small test-tube to cool; the phosphorus becomes hard again and the wire loop is imbedded in it.

Take the wire with the phosphorus upon it, out of the test-tube and quickly insert it in the long tube of water. Let about three inches of the wire remain out of the tube and bend it double so that the wire can rest on the tube. Place a finger on the open end of the tube, and then invert the tube in a jar, or beaker of water, as in Fig. 57. Now let the water run out of the tube. You thus obtain a piece of phosphorus in a certain volume of air. White fumes are slowly produced and water from the beaker or jar rises up the tube.

Let this action go on until the next lesson; you will then see that about one-fifth of the air originally in the tube has been used up and water has taken its place.

To test this accurately, take out the phosphorus and put it in water for safety. Place a finger or a disc of card on the open end of the tube, and lift the tube out of the jar with the water it contains. Stand the tube upright, take away the disc or finger, and test the remaining gas with a lighted taper. The taper is extinguished, showing that the residual gas is the inactive part of air. Pour the water from the tube into a graduated jar, and observe its volume ; then fill the tube with water, and find the volume of the whole space in the tube by pouring the water into the graduated jar. Compare the first observation, which represents the volume of active air used by the phosphorus, with the second, which shows the whole volume of air enclosed. The active part of air will thus be found to be one-fifth the volume of air enclosed.

\section{REASONS AND RESULTS.}

\section{Warning! Care is necessary in dealing with phosphorus.}

Different kinds of phosphorus.-There are two kinds of phosphorus, one called yellow phosphorus, and the other red, or amorphous, phosphorus. Yellow phosphorus catches on fire very easily; the warmth of the hand is quite enough to inflame it. For these reasons it is always kept under water. It is generally bought in the forms of sticks, which, when freshly manufactured, are of a yellow waxy colour. This phosplorus can easily be cut with a knife, but the cutting should always be 
done under water. However small the piece, it must never be touched with the bare fingers but always lifted by smalt tongs or forceps. If this precaution is not taken, the warmth of the fingers may cause the phosphorus to catch on fire and, as it is difficult to shake it off when once alight, the burn which it causes is very severe and dreadfully painful. In all experiments with yellow phosphorus these warnings must be borne in mind. The red or powder form of phosphorus is not so inflammable as the yellow kind, but it must be used with care.

Phosphorus readily burns in the air.-It is only necessary to touch a piece of dry phosphorus with a hot wire to make it catch on fire and burn. It burns with a dazzling bright flame, and at the same time dense clouds of white fumes are formed, which spread throughout the room. These facts are noticed until all the phosphorus has disappeared.

What happens when phosphorus burns in this way? Is the change anything like that when iron rusts? Does the phosphorus gain or lose in mass? These and several other questions present themselves, and they must be answered in this lesson.

Change produced in air by burning phosphorus.-.-To decide whether phosphorus in burning causes the same change in air as iron does when it rusts, it is best to burn some phosphorus in an enclosed amount of air in a way similar to that which has already been described for an experiment with damp iron. One way to do this is to place a little phosphorus on a cork or basin which floats on the surface of water, under a bell jar, or a stoppered bottle having no bottom. After the experiment is over, and the fumes have disappeared, the water is seen to have risen in the jar, indicating that there is less gas in the jar than before the phosphorus was burnt in it.

From what you have already learnt, you can understand at once that phosphorus in burning takes out the active part of the air and leaves the inactive part behind. So far, then, the changes which occur when phosphorus burns are very like those when iron rusts. Some differences will be studied a little later.

The fraction of the air which disappears as a result of the burning of the phosphorus in a stoppered jar, can be measured easily enough after the jar has been raised a little, so that its mouth is still under water, but it no longer rests on the bottom of the basin. As in the case of the rusting of iron, one-fifth of the air is taken out of it by the phosphorus in burning. 
Another way is to burn a little phosphorus in a sealed tube having a pointed end, and then by breaking off the end of the tube under water, the volume of water which takes the place of the air used can be found, and its proportion to the whole volume of the tube can be determined.

That the gas left behind is really the inactive part, which is called nitrogen, can be proved by quickly pulling out the stopper of a jar in which phosphorus has been burnt, and intro-

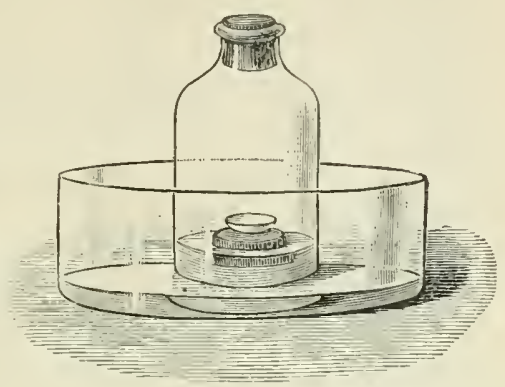

Fig. 58.-Phosphorus uses up one-fifth of the air in the bottle when it burns, and water rises to take the place of the air used.

ducing a lighted taper. The flame is at once extinguished.

Phosphorus slowly takes out the active part of the air without being lighted.- IVe have seen that iron slowly takes the active part of the air and combines with it to form rust. And this happens without heating the iron. Will ordinary phosphorus do the same when it is not alight? This question, too, is easily answered by a simple experiment. When a piece of clean phosphorus is exposed to an enclosed quantity of air over water, the rapid changes described in the last paragraph take place slowly. The only difference in the two cases is the rate at which the active part of the air is taken out. Burning phos. phorus combines, with the active part very quickly; ordinary phosphorus but slowly. Still, given time enough, ordinary phosphorus will remove all the active part of air, and at the end of the experiment it will be found that again one-fifth of the air has disappeared.

\section{TO BE, REMEMBERED.}

Phosphorus readily burns in the air; in doing so it takes out the active part and combines with it to form a white snow-like powder.

Phosphorus can also, like iron, slowly take out the active part of the air without being lighted.

When phosphorus is burnt in an enclosed volume of air, onefifth of the volume is used up, and four-fifths remain. 


\title{
EXERCISE XVII.
}

I. Write down all you know about phosphorus.

2. Describe carefully what occurs when phosphorus is burnt in an enclosed quantity of air.

3. How would you show that phosphorus will slowly take out the active part of the air without being lighted?

4. How could you prove that air contains gases having different properties?

5. In what way is the rusting of iron similar to the slow burning of phosphorus?

6. A piece of phosphorus is burnt in a stoppered bottle containing 100 c.c. of air. The stopper of the bottle is then taken out under water. How many cubic cms. of water enter the bottle?

7. Is the same proportion of air used up whether a large or a small piece of phosphorus is burnt in a stoppered bottle of air?

\section{LESSON XVIII.}

CHANGES PRODUCED BY BURNING PHOSPHORUS IN AIR.

\author{
PRACTICAL WORK.
}

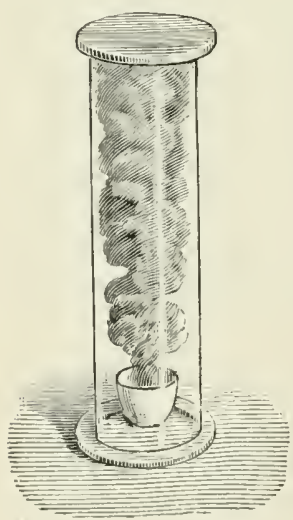

Fitg. 59.-Arrangement for collecting the white powder produced by burning phosphorus.
Things required.-Large test-tube, with well-fitting cork. Phosphorus. Litmus paper or blue litmus solution. Vinegar. Acids. Soda. Wire. Apparatus shown in Fig. 6o. Taper.

\section{What to do.}

White powuder produced wihcn phosphorus burns.-Carefully dry a wide glass cylinder and a small crucible. Cut off (under water) a piece of phosphorus about half as big as a pea, and dry it between blotting paper or filter paper. Using a pair of tongs, place the phosphorus in the crucible, touch it with a hot wire, and quickly put the cylinder over it, as in Fig. 59. A white 
powder is deposited upon the sides of the cylinder. When the phosphorus has ceased to burn, lift up the cylinder and pour a little water into it. The white powder dissolves with a slight hissing noise. Add a little blue litmus to the water; the colour is changed to red.

Use of litmus paper.-Dip a blue litmus paper into water. No distinct change of colour is observed.

Dip a blue litmus paper into vinegar, lemon-juice, and weak solutions of other acids, such as hydrochloric and sulphuric acids. Notice that each liquid turns a blue litmus paper red.

Dip a reddened litmus paper into a weak solution of soda. Notice that it has just the opposite effect to the acids and turns the reddened litmus blue again.

Lime-water test.-Burn a little phosphorus in a test-tube as in Lesson XVII. When the test-tube is cool, take out the cork and shake up the residual gas with a little clear limewater which has been poured into it. No change in the lime-water will be observed.

Increase of mass when phosphorus burns.-Procure a hard glass tube, having the shape of $B A$ in Fig. 6o, and loosely pack asbestos fibre into its drawn-out end. When this is

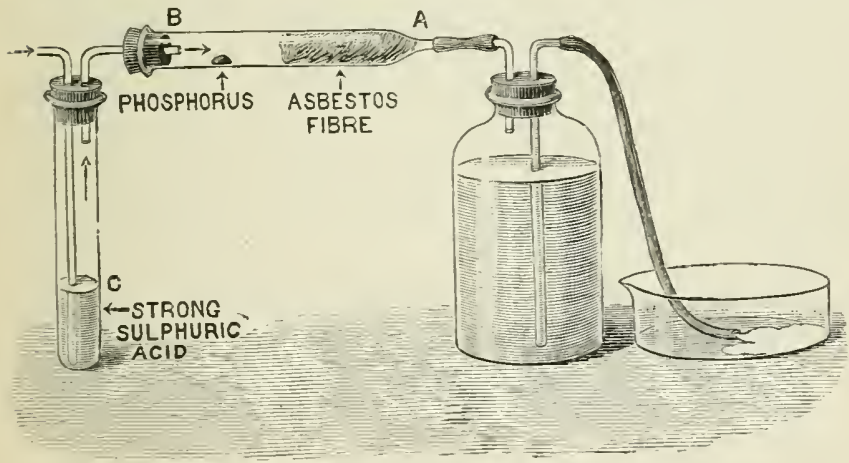

Fig. 60.-Experiment to show that the fumes produced by burning phosphorus in a current of air are heavier than the phosphorus used.

done determine the mass of the tube by weighing. Place a small piece of dry phosphorus, the mass of which is about one-fifth of a gram. in the tube, and after putting it in weigh 
the tube and its contents again, so that the exact mass of the phosphorus may be known. Attach the narrow end $A$ of the tube to an aspirator. As the water runs out of the bottle a current of air is drawn through the tube, and, in order to dry the air, it is first made to pass through the test-tube $C$, containing strong sulphuric acid, to absorb the moisture from the air which passes through the tube. Slightly warm the phosphorus; it soon catches fire. When this happens, remove the burner and allow the phosphorus to continue to burn. The fumes which are formed are stopped by the asbestos fibre. A quantity of red deposit is also found (this is really another form of phosphorus), but may be got rid of by strongly heating it.

When the apparatus is cool, disconnect the tube $B A$ from the test-tube and aspirator, and again weigh. It will be found that a decided increase of mass has occurred.

\section{REASONS AND RESULTS.}

Properties of the substance formed when phosphorus combines with the active part of the air.- IVe have as yet only noticed that the substance which is formed when phosphorus unites or joins with the active part of the air is a white snow-like powder; this corresponds to the rust formed when iron is exposed to air. With a little care, the quick disappearance of the white material which forms the fumes of burning phosphorus can be prevented. All that need be clone is to burn a piece of dry phosphorus in a dry vessel. In these circumstances, the white fumes settle down on the inside of the vessel in the form of a snow-like solid. But the white powder has so great an attraction for water that as soon as the vessel is opened it extracts the moisture from the air, and, first becoming moist, is quickly replaced by drops of liquid. If water is put into a test-tube or other vessel in which dry phosphorus has bcen burned, the white powder rapidly dissolves with a hissing noise, like that noticed when water comes in contact with hot iron.

Properties of a solution of the white powder produced by burning phosphorus. - Pure watcr, as everyonc knows, is tasteless. There are, however, many liquids, such as vinegar and lemonjuice, which have a sharp acid taste. If a very small quantity of an acid is put into a glass of water, it is almost impossible for a 
person to know by tasting whether any has been added or not. A piece of blue litmus paper is a more delicate means of testing this. If the paper is dipped into pure water, no particular change is observed in its colour. But if it is dipped into water only very slightly acid, it is turned red. When a piece of blue litmus paper is dipped into a solution of the white powder produced by burning phosphorus it is immediately reddened, thus showing that the solution is acid. A solution of soda acts in exactiy the opposite way and turns reddened litmus paper blue again.

Gain of mass when phosphorus burns.-If a piece of phosphorus is put into a closed vessel of air, and the whole is weighed before and after the phosphorus has been burnt, you would expect the mass to be the same in both cases. To begin with, there would be the bottle, the air in it, and the phosphorus; after the phosphorus had burned, there would be the bottle, the white powder, and the inactive part of air. As phosphorus uses up the active part of air in burning, and as, after burning, the bottle only contains the white powder and the inactive part of air, evidently the white powder weighs more than the phosphorus.

To determine exactly the increase in mass when phosphorus burns, a piece of phosphorus is weighed and placed in a tube through which a current of dry air is caused to pass. The phosphorus is set alight by warming it, and the white fumes are prevented from passing out of the tube by some asbestos fibre placed in it. If the mass of the tube and asbestos fibre is determined to begin with, and then another weighing is made when the phosphorus has been consumed, it is found that the tube with the asbestos fibre increases in mass, and that the white powder which causes the increase weighs more than the piece of phosphorus used. If the mass of the phosphorus to begin with is one-fifth of a gram, the mass of the powder produced would be nearly one-half a gram.

\section{To be ReMEMBERED.}

When phosphorus combines with the active part of the air it forms a white powder which dissolves in water with a hissing noise.

By dissolving the white powder in water a solution is obtained which turns blue litmus paper red and is thus shown to be acid.

The inactive part of air, which remains after burning phosphorus, does not produce any effect upon lime-water. 
Phosphorus in combining with the active part of the air increases in mass.

\section{EXERCISE XVIII.}

I. What do you know of the substance formed when phosphorus combines with the active part of the air?

2. If a small piece of phosphorus is put into a dry bottle and made hot, what would you observe?

3. How could you show that phosphorus in combining with the active part of the air increases in mass?

4. How could you obtain a small quantity of the white powder formed by burning phosphorus?

5. Describe how you could test whether a liquid was acid or not without tasting it.

6. Pieces of blue litmus paper are dipped into (1) vinegar, (2) a solution of soda, (3) water in which the white powder produced by burning phosphorus has been dissolved. Describe the changes of colour which take place in the three experiments.

7. A piece of phosphorus is placed in a bottle, and the bottle is corked, suspended from one arm of a balance. and counterpoised. The phosphorus is then caused to burn by heating the bottle. Will any change of mass be noticed?

\section{LESSON XIX.}

\section{THE BURNING OF A CANDLE.}

\section{PRACTICAL WORK.}

Things required.-Candle. Clear glass tumbler. Taper. Lime-water. Small pickle bottle. Basin of water. Copper wire. Cardboard disc.

\section{What to do.}

Moisture is formed when a candle burns.-Over a burning candle hold a clear cold tumbler, which has been carefully dried inside and out. Notice that the inside of the bottle becomes covered with mist, and, after a short time, drops of water are formed which run down the sides of the bottle.

Properties of the gas left after a candle has burnt in air.Wind a piece of copper wire round a small candle, as shown in Fig. 61, and light the candle. Push the top of the wire through a small hole in a disc of cardboard, and then lower the 
candle into a dry, clear glass bottle in such a manner that the top of the jar is covered by the cardboard disc. Observe that the flame of the candle becomes dimner and dimmer, and soon goes out altogether. Water collects on the inside of the jar as in the last experiment. Take out the candle and cover the jar with a greased glass plate.

To find out something about the gas left in the jar :

(i) Quickly insert a burning taper, or the relighted candle; it is at once put out.

(ii) Pour in a little fresh clear limewater, and shake it up in the jar; notice that it is turned milky.

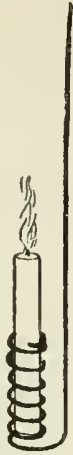

F1G. 61.-Method of supporting a candle for insertion in a bottle.

Volume of air used by a candle in burning.- Fix two or three small candles of different lengths upon the inside of the top of a tin canister. Float the lid upon the surface of water in a basin, or sink it to the bottom of the basin, if the candles project well above the surface while it is in that position. Light

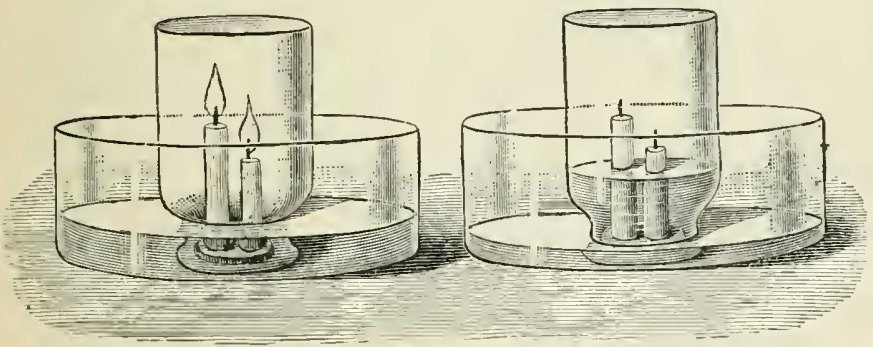

FIG. 62.-When the candles burn, a certain proportion of air is used up, and water rises into the inverted bottle to take its place.

the candles, and while they are burning, hold over them a wide-mouthed bottle, so that the mouth of the bottle is beneath the surface of the water. When the candles have gone out and the air in the bottle has become cool again, mark the place to where the water has risen, by means of a strip of gummed paper. Take out the bottle and find the 
volume of water which just fills it. Find also the volume required to fill it to the edge of the gummed paper. Subtract this volume from the preceding one, and thus obtain the volume of air used.

\section{REASONS AND RESULTS.}

The burning of a candle-You have now learnt several facts about the burning of phosphorus in air, and it will be desirable

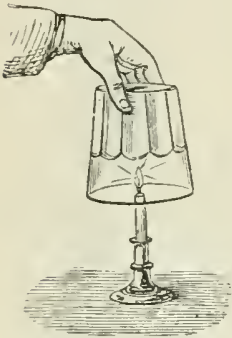

FIG. 63.-Moisture is formed when a candle burns. before proceeding farther to study the burning of some more common combustible substance, such, for instance, as a candle.

In what respects is the burning of a candle similar to the burning of phosphorus and does it differ from it in any way? You have already learnt when studying ventilation ( $\left.p .8_{4}\right)$, that a candle will not continue to burn very long in an enclosed quantity of air. Unless the air is renewed in some way the candle goes out. This gives us a convenient starting-point for the inquiry. Why does the candle go out, and what changes take place when the candle is burning?

Water is formed when a candle burns. - When a clear glass bottle, which has been carefully dried inside and out, is held over a burning candle, it is soon noticed that drops of liquid besin to collect on the inside of the bottle and after a time they run down the sides. In some way or other, then, the burning of the candle causes a liquid to be produced. If a sufficient quantity of this liquid is collected, it can be proved to be water by tasting it, or by determining its density, or its boiling and freezing points. Water is the only liquid which boils at $100^{\circ} \mathrm{C}$. and freezes at $0^{\circ} \mathrm{C}$.

Another substance besides water is formed when a candle burns. -If a candle is burnt in a clear glass bottle in the way slown in Fig. 61, the gas which is Ieft behind can easily be examined. Experiments with this gas show that, like the inactive part of the air, it will not allow things to burn it. lisut besides this it is found that the gas tums lime-aider milliy. The gas left after phosphorus has been burned in a similar jar, has not this property of making lime-water milky; and you can thus be 
quite sure there is something else in the cylinder, besides the inactive part of the air already described. Hence, when a candle burns, it not only forms water, but also a colourless gas which turns clear lime-water milky.

A candle uses up the active part of the air in burning.-Just as it is possible to show, by burning phosphorus in a jar inverted over water, that phosphorus takes out the active part of the air as it burns, so the same fact can be made clear in the case of a candle by a similar experiment. This is a very old experiment. It was shown to the students of Oxford University as long ago as 1670 . The lecturer describes the experiment thus : ${ }^{1}$

"Let a lighted candle be so placed in water that the burning wick shall rise about six fingers' breadth above the water; then let a glass vessel of sufficient weight be inverted over the candle. Care must be taken that the surface of the water within the glass shall be equal in beight to that without, which may be done by including one leg of a bent syphon within the ressel, while the other opens outside. The object of the syphon is that the air enclosed by the ressel and compressed by its immersion into the water may escape through the hollow syphon. When the air ceases to issue the syphon is immediately withdrawn so that no air can afterwards get into the glass. In a short time you will see the water gradually rising into the vessel while the candle still burns."

When this experiment is performed, as you already know, at a certain stage the canclle goes out. It is then found that the water has risen and filled a part of the jar. A similar result has been noticed in so many lessons that you are thus given reason to believe it is because the candle has used up the active part of the air.

TO BE REMEMBERED.

When a candle burns in air water is formed, and also a gas which turns lime-water milky.

The active part of air is used by a candle in burning.

It can be shown by burning substances in an enclosed quantity of air over water that one-fifth of the enclosed air is used.

Exercise XIX.

I. How would you show by experiment that when a candle is burnt in air two new substances are formed?

1 See Perkin and Lean's Introduction to the Stndy of Chemistry, p. I60. 
2. What experiment can be done to show that a candle in burning takes out one-fifth part of the air?

3. A lighted candle is stood upright in water, and a bottle is placed over it with the neck under the surface of the water. Describe what would happen.

4. A piece of phosphorus is burnt in one bottle of air and a candle in another bottle. A little clear lime-water is then poured into each bottle. What changes would you observe?

5. If two bottles were given you, in one of which phosphorus had been burnt, and in the other a candle, how could you decide which bottle was used for the phosphorus?

\section{LESSON XX.}

THE BURNING OF A CANDLE-CONTINUED.

\section{PRACTICAL IVORK.}

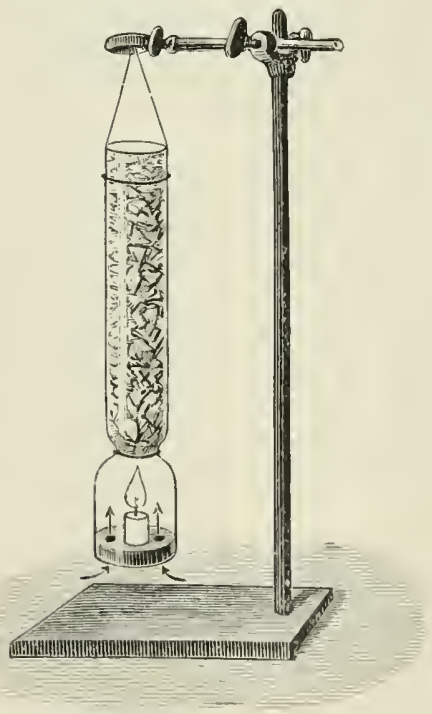

Fug. 64. - Lamp glass containing caustic soda to absorb the substances produced when a candle burns.
Things required.-Lamp glass, of the form shown in Fig. 64. Small piece of wire gauze. Caustic soda in lumps. Wide tubes. Copper wire. Balance as in Fig. 65, and box of weights. What to do.

Gain of mass when a candle burns.-Obtain a lamp glass like the one shown in Fig. 64. At the narrow part arrange a tray of coarse wire gauze. On the shelf so formed put pieces of caustic soda. Fit a large cork, with several holes through it, into the bottom of the lamp glass. Through one hole in the cork insert a candle. By weighing, find the mass of the whole 
apparatus. Witıdraw the cork, light the candle, and reinsert the cork. After the candle has burnt for a few minutes, blow out the flame, and when the apparatus is cool make another weighing. It will be found that the apparatus has increased in mass.

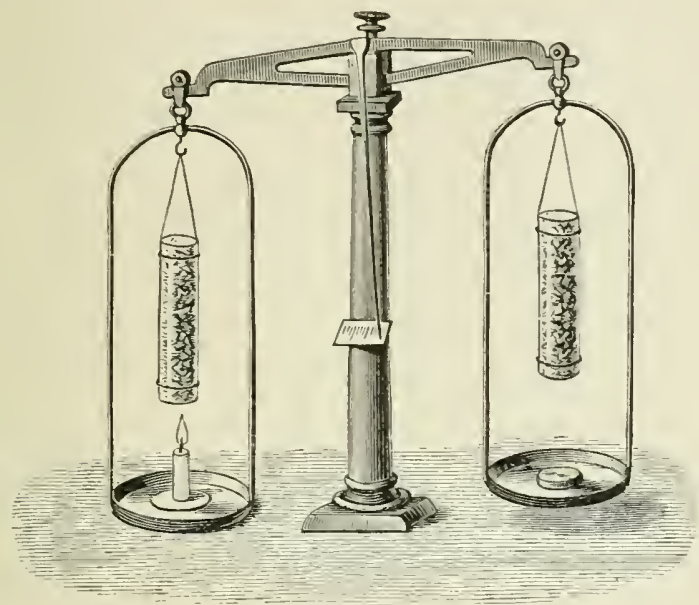

Fig. 65.-The tubes suspended from each arm of the balance contain caustic soda. When the candle in the left-band pan burns, the substances formed are absorbed by the caustic soda aoove it, and their mass is seen to be greater than that of the candle used.

A second method.--On each arm of a balance, as shown in Fig. 65, hang similar wide tubes containing caustic soda, the mass of each of which is the same. The caustic soda is prerented from falling out by coarse wire gauze at the bottom of the tubes. On the right-hand pan of the balance place a flat cork upon which a candle is fixed, so that the candle is immediately under the wide tube. Counterpoise the candle by means of nails or metal foil. Now light the candle and allow it to burn for five minutes. Notice that the balance is no longer counterpoised. The candle side is the heavier.

\section{REASONS AND RESULTS.}

Nothing is lost when a candle burns. - You have seen that when iron rusts, or, as you know, when it takes out the active 
part of the air, it increases in mass. Similarly, you have learnt that phosphorus in burning combines with the active part of the air, and also increases in mass. This naturally leads to the consideration of the burning of a candle. Surely, in this case, the same cannot be true. The candle gradually gets shorter and shorter, and, you will perhaps think, must get lighter and lighter. Of course if a candle is weighed and then lighted, and after it has burnt for an hour is blown out and weighed again, its mass will be less than before. But this is taking no account of the things into which it is changed as it burns. The iron changes into rust as it combines with the active part of the air, and the rust, being a solid, stays where it is formed, and is easily shown by weighing to have a greater mass than the iron.

But the candle, in taking out the active part of the air, forms two invisible gases-steam, which on a cold surface condenses into water, and the gas which turns lime-water milky, - and it is not so easy to understand that these substances together have a greater mass than the part of the candle which has disappeared. Yet this is so ; and the increase can be shown by simple experiments. A white solid substance called caustic soda has the power of taking up and absorbing water vapour, and also the invisible gas which turns lime-water milky. By making use of caustic soda, it is easy to show that the two gases into which the candle is changed have a greater mass than the part of the candle which disappears.

The mass of the substances formed when a candle burns is greater than that of the candle burnt.-If an open tube, containing some lumps of caustic soda in it, is arranged above a burning candle, the smoke and the invisible gases which the candle forms in burning pass through the tube, and are stopped by the caustic soda. The mass of the substances produced by the burning of a candle can thus be determined by fincling the increase of mass of the caustic soda which absorbs them. If the mass of the candle at the beginning of the experiment has been found, the mass of the substances absorbed by the caustic soda will be greater than the mass of the candle at first.

First Experiment.-One way of performing the experiment is shown in Fig. 64. A wide glass tube with a narrow part near one end is fitted at the bottom with a good cork, through which several holes have been bored. Into one of these the candle is fixed; the others are required to supply 
air to the candle. Pieces of caustic soda are put in the upper part of the tube. Either they must be large enough not to fall through the narrow part of the tube, or else a tray of wire gauze must be arranged in the tube io support the pieces of caustic soda. The whole apparatus is first weighed, and its mass thus determined; the cork is then taken out, the candle lighted, and the cork quickly replaced. As the candle burns, air is drawn through the holes, as shown by the arrows. After the burning has gone on for, say five minutes, the flame is blown out and the tube allowed to cool. It is then weighed again, and its mass is found to be decidedly greater than before.

Second Experiment.-The experiment can be done in the manner shown in Fig. 65, which is only another way of showing the same thing. In this case the candle is placed on one pan of a balance, and above it is hung a wide tube containing pieces of caustic soda as before. A similar tube containing caustic soda to balance the first one is hung on the other arm, and the beam is made to hang horizontally by means of nails or metal foil. The candle is lighted and allowed to burn for some minutes and then blown out. After the tube has had time to cool it is found that the beam of the balance no longer hangs horizontally. The pan on which the partly burnt candle rests is lower than the other. This side is therefore heavier than the other, and the increase in mass is due to the addition of the active part of the air with which the candle combines in burning to form the invisible gases which are stopped by the caustic soda. It thus seems that what takes place when phosphorus, iron, and copper are heated in the air, takes place also when a candle burns; in other words, a candle, in burning, uses up the active part of the air, and this causes an increase of mass.

\section{TO BE REMEMBERED.}

Nothing is lost when a candle burns. This can be shown by collecting the substances formed as a candle burns, and then, by weighing, these substances are proved to have a greater mass than the part of the candle which has disappeared.

Caustic soda absorbs both the water and the invisible gas, which turns lime-water milky, formed as a candle burns.

\section{EXERCISE XX.}

I. What reasons can you give for the statement that nothing is lost when a candle burns? 
2. Describe an experiment which shows that the substances formed as a candle burns have a greater mass than the part of the candle burnt.

3. Write all you can about the burning of a candle.

4 A candle is lighted and lowered into a large bottle. The bottle is then corked. Will the bottle and its contents gain or lose in mass as the candle burns?

5. In what way is the burning of a candle similar to the rusting of iron?

6. What reasons can be given for the statement that, when a candle burns, an invisible gas is produced which is not the inactive part of air?

\section{LESSON XXI.}

\section{THE BURNING OF OIL AND GAS.}

\section{PRACTICAL WORK.}

Things required.- Small oil lamp and a wide bottle or cylinder into which it can be placed as in Fig. 66. Clean dry bottle. Glass and india-rubber tubing. Lime-water.

What to do.

Moisture and soot produced by flames.-Invert a clear dry

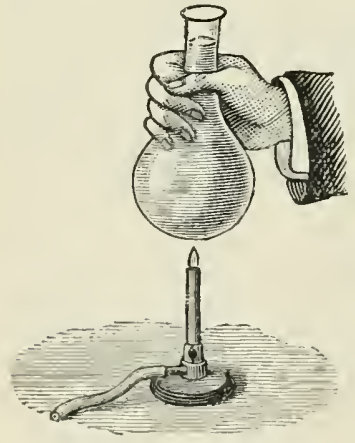
FIG. 66. - How to show that mouthed bottle or a wide glass moisture is formed when gas burns. lamp without a chimney. Notice that the inside of the bottle becomes wet. The black deposit which also occurs may obscure the water but will not hide it entirely.

Hold a flask of cold water over a small gas flame. Notice the deposit of moisture and soot upon the glass. If a laboratory burner is used no blackening will take place (Fig. 66).

Invisible changes caused by burning oil and gas.-Place a widebottle over the flame of a small oil cylinder completely over a small oil lamp. Notice that after a time the flame goes out. When 
this happens quickly remove the cylinder and corer it with a glass plate or a piece of card. Pour in a little clear fresh lime-water. Shake it up and observe the milkiness produced.

Bend a glass tube into the shape shown in Fig. 67, and to its long limb attach an india-rubber tube, and so connect the bent glass tube to the gas supply. Turn on the tap and light the gas at the end of the short limb. Turn the flame very low and insert the tube into a cylinder or bottle, and after it begins to get dins. turn

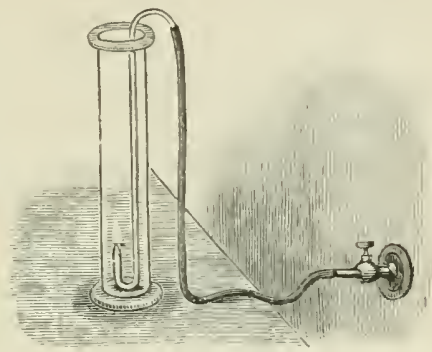

FIG. 67.-How to burn gas in a jar. off the gas, remove the glass jet from the cylinder, and cover it with a plate. Show that the gas left in the cylinder turns lime-water milky.

Into the bottom of a cylinder or bottle pour some clear lime-water. Hold a large wood splinter in a laboratory burner until it is burning fiercely, then hold it in the cylinder until it either burns dimly or goes out. Notice the limewater. Shake the cylinder and again notice the effect.

\section{REASONS AND RESLLTS.}

Some familiar combustible bodies. - Candles are not now commonly used for lighting our houses. Sometimes lamps are employed, and in large rooms ordinary coal-gas is usually the substance which is burnt. As every boy knows, lamps are supplied with oil. This oil rises up the wick of the lamp in the same way as water does up cotton threads, and this has already been studied. At the end of the wick the oil is burnt. Gas which is supplied to our houses in pipes, is made by distilling coal in iron retorts. In this way the gas is driven out of the coal and collected in the large cylindrical holders of metal, always seen at a gasworks, and called gasometers. It is from these gasometers that the gas passes into the gas pipes and so reaches the burners, where by turning on the tap it can be lighted and 
burnt. In this lesson the burning of oil and gas will be considered. Is this burning like that which occurs when a candle is lighted, and if not, what are the differences?

What products are formed when oil or gas is burnt?-By holding a clear dry bottle over the flame of a burning candle it is easy to prove that water is formed as the burning is continued, because the vapour becomes condensed on the inside of the cold glass. In exactly the same way, it is found that water is formed when the flame is due to the burning of either oil or gas. This, then, is one way in which these three kinds of burning resemble one another. As in the burning of a candle, so when oil and gas burn, water is formed.

But when a candle is burnt, a gas which turns lime-water milky is formed as well as water. Is this gas also produced when oil and gas are burnt? This question may be answered in the same manner as when studying the burning of the candle. An oil lamp, or a gas jet, or a splinter of wood, is allowed to burn for a few minutes in a glass jar, and is then removed and the jar covered with a glass plate. When lime-water is poured into the jar it is turned milky. We may consequently say that when a candle, a lamp, coal-gas and wood are burnt, two substances are formed, namely, water and an invisible gas which turns lime-water milky.

There is no loss in mass in these cases of burning.-To prove that nothing is lost when oil burns or a jet of coal-gas is lighted, an experiment must be made similar to that already described with a candle. The mass of the oil or gas used up, would have to be determined and also the masses of the water and the other substances produced by the burning. When this is carefully done, and none of the products of combustion are allowed to escape, the total mass of the substances formed is found to be greater than that of the oil or gas burnt. In every case which chemists have examined, the same thing is proved to hold true. In no kind of chemical change is there any loss of matter.

All substances in burning use up the active part of the air.-By burning phosphorus or a candle in an enclosed quantity of air over water, it has been seen in previous lessons that one-fifth of the air disappears, and on examining the gas which is left, it is found to be incapable of allowing things to burn in it, and is consequently known as the inactive part of the air. The active 
part combines with the phosphorus or the candle, and new substances with new properties are formed. This accounts for the disappearance of the active part. All these facts are found to be true, too, in the case of oil and coal-gas. By suitable means it can be shown that these also unite with the active part of the air and leave the inactive part behind. In fact, this is true in all cases of burning in the air. It does not matter what the substance which burns is like, if it burns in air it does so because it takes out the active part to unite with it to form new substances, and the inactive part is always left behind.

\section{To BE Remenbered.}

The burning of familiar combustible bodies such as oil and 'gas' is similar to that of the candle. The same substances are formed and they are recognised in the same way.

There is no loss in any of these cases of burning.

All substances burning in air use up the active part of the air.

\section{EXERCISE XXI.}

I. Name four common combustible substances.

2. In what ways does the burning of oil or coal-gas resemble the burning of a candle?

3. How would you show that a gas which turns lime-water milky is formed as coal-gas burns?

4 In what respects is the burning of a candle and of an oil lamp similar?

5. How could you show that a new gas is formed when coal-gas is burnt in a jar of air?

6. If two bottles were given you, one containing ordinary air, the other air in which a lamp had been burnt, how could you test which bottle contained the fresh air?

7. Are the substances formed when an ordinary gas-jet is lighted the same as those given off by the flame of a laboratory burner? 


\section{LESSON XXII.}

SEARCH FOR THE ACTIVE PART OF AIR.

\section{PRACTICAL WORK.}

Things required.-Pieces of lead. A porcelain crucible. Pipe-clay triangle. Tripod or retort-stand. Laboratory burner. Hard glass tube. Red lead. Red oxide of mercury or red precipitate. Splinters of wood.

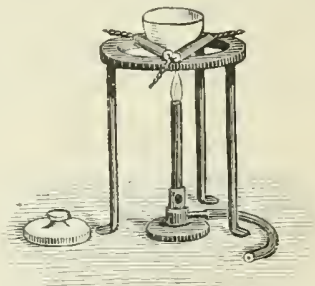

FIG. 68.-A way to produce lead rust.

What to do.

Changes produced by heating lead in air.-Heat a few pieces of clean lead in a crucible in the manner shown in Fig. 68. When the lead has melted, stir the liquid metal with a stout iron wire. Notice the formation of a powdery scum upon the lead. Observe that the colour of the powder is darker when hot. Let the crucible cool. Notice that it now contains a yellow powdery substance in addition to the unchanged lead. By strongly heating this powder its colour clıanges again, and it becomes red lead.

Gas produced by heating ret lead.-Place a little red lead in a hard glass tube and strongly heat the tube as in Fig. 69. Notice that the red lead undergoes a change of colour. Into the tube insert a glowing splinter. Observe that the splinter is rekindled. Why is this? 
Change produced by heating mercury rust.-Repeat the preceding experiment with some red oxide of mercury, ${ }^{1}$ and notice the formation of the silvery, mirror-like deposit of mercury, or quicksilver, round the cold upper part of the tube. Insert a glowing splinter of wood and watch it rekindle.

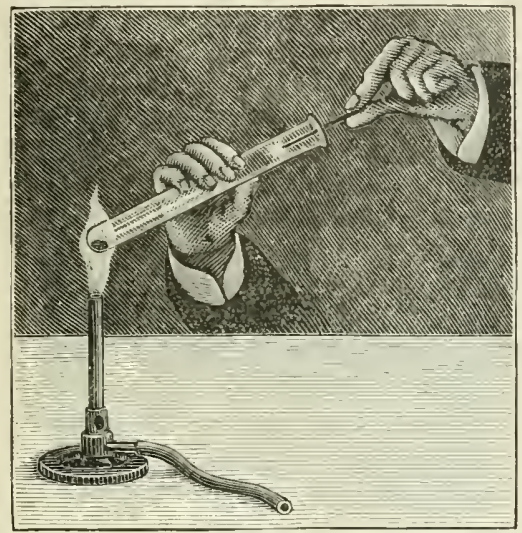

FiG. 69.-When red lead is heated, a gas is given off which will re-kindle a glowing splinter.

REASONS AND RESULTS.

Where to look for the active part of air.-It has been seen several times that many substances take the active part out of the air, and combine with it when exposed to it under suitable conditions. A candle does so when it burns, iron when it rusts, and copper and lead when they are heated in contact with the air. Since these substances take the active part out of the air, and unite with it to form fresh substances, it should not be difficult to make these or similar substances give up the part of the air which they take up, and to thus procure the active constituent of air by itself in a pure form. But a little more thought suggests that probably some of these substances would do better than others. It is quite certain that some are formed more easily than others. IVill those which are most easily formed be the best from which to get the active part? No. The reason is this. When a chemical change takes place very easily it generally

1 This is the chemist's name for the rust of mercury, or quicksilver. 
means that the substances taking part in the change have a great liking for one another, and when they combine together they form a compound which it is very difficult to separate into its parts again. The easiest way to set to work is, therefore, to first find some substance which only combines with the active part slowly and with difficulty, for the compound such a substance forms with the active part will most likely be a weak one and easily broken up again.

The compounds which lead forms with the active part of the air.-When the metal, lead, is heated in contact with the air, it soon melts into a silvery whitc liquid. If this molten metal is kept stirred with a stout iron wire it is observed to gradually undergo a change. The place of the silvery liquid is taken by a yellow powder which is much darker in colour when hot. If the heating is continued long enough, all the metal is changed into powder. As you know, this change is brought about by the combination of the lead with the active part of the air. The change takes place fairly easily, so that from previous reasoning you would conclude that it is probably difficult to get the active part again from this powder. And this is so. But it is found that when some of the yellow powder is heated for a long time at the temperature at which lead melts, that it slowly takes out still more of the active part of the air, and changes in colour, becoming red. The first powder obtained, which is yellow, is in some states called litharge; the second red powder is known as red lead. As you might suppose, it is easy to get the second lot of the active part of the air again from the red lead.

How the active part of air is obtained from red lead.-When red lead is heated, it changes in colour, and if the heat has not been great it regains its original red colour when allowed to cool. But if strongly heated, the red lead gives up some of the active part of the air which it contains, and is reconverted into litharge. The part of the active part of the air which it thus gives up on being heated is the sccond quantity referred to in the last paragraph, which is taken up slowly when the heating of lead is continued for a long time. If red lead is strongly heated in a tube, as in Fig. 69, and a glowing splinter of wood is pushed down the tube, the splinter bursts into flame and continues to burn brightly. If you think about this you will see that it is just what might have been expected. You have scen that the gas which makes up four-fiftlos of the air, which is referred to in 
the previous lessons as the inactive part, will not allow things to burn in it at all, or, it dilutes the active part of the air, which makes up the other fifth. Naturally, therefore, when the active part is obtained by itself it supports burning very strongly indeed.

Other ways of obtaining the active part of air.-Quicksilver, or mercury, when strongly heated in the air, slowly combines with the active part, and becomes gradually converted into a bright red powder, which is the rust of mercury. If some of this rust of mercury is heated in a hard glass tube, as in Fig. 69, it soon changes in colour ; and as the heating is continued it is noticed that a mirror-like deposit is formed round the top, cold part of the tube. When this deposit is rubbed with a penholder or pencil it runs together and forms little drops of quicksilver. Moreover, if a glowing splinter of wood is introduced into the tube it bursts into flame, as it does when held in a tube in which red lead is heated, showing that the active part of the air is being driven out of the red mercury rust. It is not difficult to understand that this change is just the reverse of what takes place when mercury itself is heated. The active part of the air, which hot mercury slowly combines with, is driven out of the red mercury rust when that is strongly heated. But this red powder, which is made by heating mercury for a long time, is very expensive, and it is too costly a plan to heat this powder to obtain a quantity of the active part of air in order to study its properties. Several other substances which do not cost much, easily give up the active part of air when heated.

The active part of the air is called oxygen.-As it will be more convenient in the future to speak of the active part of the air by the name chemists use for it, we may state here that it is always called oxggen, but the meaning of this name will be better understood later on.

In this lesson you have seen that two substances at leastmercury and lead-when strongly heated, have the power of taking hold of, or uniting with, the oxygen of the air and separating it from the inactive part with which it is mixed. Further, that when the substances which contain this active part, or oxygen, are further heated, they let go some, or all, of the oxygen they took from the air, thus enabling the properties of the gas alone to be studied. 
TO BE REMEMBERED.

In searching for the active part of the air, substances are heated which metals form when heated in the air.

Those substances which are formed with difficulty are split up most easily. Thus, red lead when heated gives off some of the active part of the air and is changed into litharge.

The red oxide of mercury is easily split up into mercury and the active part of air, when it is heated.

The active part of the air is called oxygen, and is easily recognised by its power of rekindling a glowing splinter of wood.

\section{EXERCISE XXII.}

1. Which metal rusts the quickest, iron, copper, or lead? How does the rust of a metal differ from the metal itself?

2. Why can the active part of air be more easily obtained from red lead than from iron rust?

3. What substances do you know which are made up of lead and the active part of the air?

4. What happens when red lead is heated?

5. Describe the changes you notice when lead is heated in an open crucible.

6. What is the chemist's name for the active part of the air ; how can this gas be obtained from red oxide of mercury?

\section{LESSON XXIII.}

\section{PREPARATION OF OXYGEN.}

\section{PRACTICAL, IVORK.}

Things required.- Test-tubes. A hard glass tube closed at one end, fitted with good cork or india-rubber stopper with one hole through it. Glass delivery tube. Trough of water and bottles. Glass plates. Retort stand. Laboratory burner. Potassium chlorate, manganese dioxide, sand. Splinters of wood.

\section{What to do.}

Oxygen from potassium chlorate.-Place a little potassium chlorate or chlorate of potish (which is the same thing) in a test-tube and heat it as in Fig. 69. Observe that the mass 
crackles, melts, and gives off a gas. Test by a glowing splinter of wood, and see that the gas behaves like oxygen, the actire part of the air.

Preparation of a small quantity of oxygen.-Powder some crystals of potassium chlorate, and mix the powder with a little manganese dioxide (sometimes called pyrolusite). Heat some of the mixture in a test-tube, as in the last experiment. Observe by putting in a glowing splinter that oxygen is given off. Notice that in this case there is no melting, and the gas comes off more readily. Repeat the last experiment, substituting sand for the manganese dioxide. The results are the same.

Preparation and collection of oxygen.-Into a hard glass tube, closed at one end, fit an india-rubber stopper, with one hole in it, through which a tube, bent as in Fig. 70, is passed. The other end of this tube, called the delivery tube, dips under water in a trough. Mix together some potassium chlorate and manganese dioxide (or sand), as in the previous experiments, and place the mixture in the tube. Support the tube and delivery tube as shown in the illustration. Fill several bottles with water and invert them in the trough. Gently warm the tube, and place one of the bottles of water over the end of the delivery tube. As the oxygen is driven off, it displaces the water and gradually fills the bottle. When the bottle is full of oxygen, cover its mouth with a groundglass plate, and lift it out of the trough. In this way fill five or six bottles with oxygen.

Caution.-Be careful not to take away the burner from under the hard glass tube before removing the delivery tube from the trough.

Physical character of oxygen.-Take one of the bottles and examine the gas inside as far as you can by looking at it. Then lift off the glass plate and smell the gas. Inhale a little and notice that it has no taste.

\section{REASONS AND RESULTS.}

Other substances besides rust give up oxygen when heated. -It was mentioned in the last lesson that several substances, much less expensive than the red rust of mercury, could be used for preparing oxygen. It has been found by experiment that a 
number of substances when heated give off a gas of the same kind as the active part of the air. The one most commonly used is a white crystalline solid called potassium chlorate or chlorate of potash. If a crystal of this substance is placed in a test-tube and heated in the flame of a laboratory burner, it first crackles, then melts, and by and by begins to give off bubbles of oxygen gas. It is easy to show that the gas given off is really oxygen, because when a glowing splinter of wood is inserted into the tube it is immediately rekindled, bursting into flame and burning brightly.

Oxygen is given off more easily if the potassium chlorate is mixed with manganese dioxide or sand.-To obtain all the oxygen from potassium chlorate requires a considerable amount of heat when the substance is heated alone. If, however, the chlorate of potash is first mixed with certain other substances, such as manganese dioxide or sand, it is found possible to obtain the oxygen with very much less trouble. The gas is given off at a much lower temperature, and more readily in every way. It is the custom, therefore, when it is desired to prepare considerable quantities of oxygen in the laboratory to use a mixture of potassium chlorate and manganese dioxide, which is often known as oxygen mixture.

Preparation and collection of oxygen.-The apparatus shown in Fig. 70 is very convenient for preparing oxygen from oxygen mixture. As the illustration shows, a tube closed at one end is fitted with an india-rubber stopper or a good sound cork, through which a hole has been bored. A small glass tube, conveniently bent, as the diagram shows, fits tightly into the hole, and is so arranged that its other end dips under water in a trough. A mixture of potassium chlorate and manganese dioxide is placed in the closed tube. You have seen that when this mixture is heated, a gas is given off. To collect this gas several bottles should be filled with water and inserted in the trough.

When these bottles are ready, the closed tube is gradually warmed with a laboratory burner, and after a little while one of the bottles is placed over the open end of the tube in the trough. The gas which passes down this delivery tube, being lighter than the water, of course rises up through it into the bottle. In this way the water is gradually pushed out of the bottle, and its place taken by the gas. 'This plan of collecting gases which do not clissolve, or dissolve only to a small extent in water, was 
devised by Priestley, the chemist who first obtained oxygen. It is called collecting over water. It is the plan which is generally adopted for collecting such gases as oxygen. When the bottle is full of the gas, and while its mouth is still under water, it is covered with a glass plate, which is held tightly to the mouth by the left hand, and the bottle lifted out and placed on the table with the right. The gas is now ready for testing.

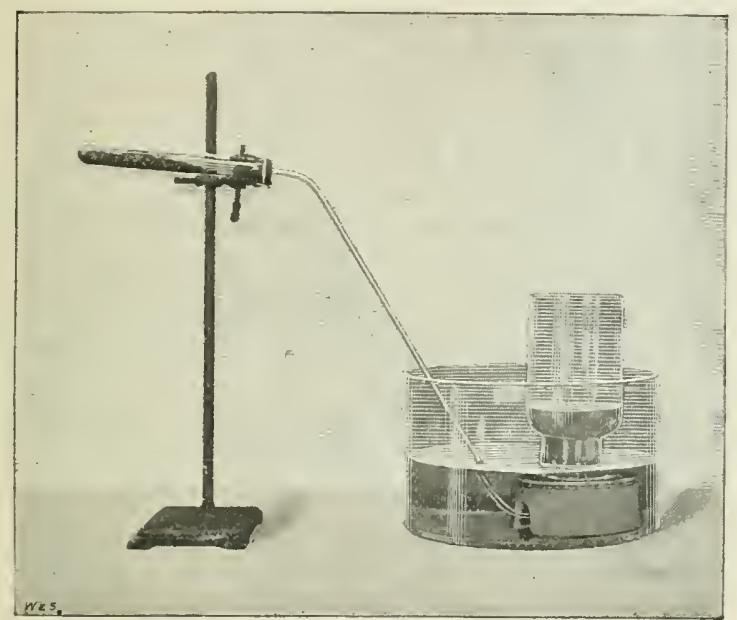

FIG. 70.-A convenient means of obtaining oxygen gas from a mixture of potassium chlorate and manganese dioxide.

Physical properties of oxygen.--If one of the bottles of gas collected as described is allowed to stand for a minute or two ${ }^{1}$ and then examined, several of the characters of oxygen can be made out. To begin with, oxygen is an invisible gas. It has neither smell nor taste. It has been found by making careful weighings of the same volumes of oxygen and air that oxygen is a little heavier than air. When made very cold and compressed very much it is changed into a liquid. All these are called physical properties of oxygen.

1 The first buttle or two are generally a little cloudy. This cloudiness is due to a substance which is not oxygen. It soon disappears if the bottle is allowed to stand.

II. 


\section{TO BE REMEMBERED.}

When potassium chlorate is heated in a test-tube it crackles, melts, and gives off bubbles of oxygen.

If manganese dioxide or sand is mixed with the chlorate of potash the oxygen is given off more readily and at a lower temperature. Such a mixture is called oxygen mixture.

Oxygen is generally obtained in quantities by heating oxygen mixture in a suitable vessel and collecting it over water.

oxygen is a gas with no colour, no taste, and no smell. It is a little heavier than air.

\section{EXercise XXIII.}

I. Write a list of the things you would require if you wished to obtain a few bottles full of oxygen.

2. Draw the apparatus you would use in preparing oxygen from oxygen mixture.

3. Describe carefully how oxygen is collected over water.

4. Write down the chief physical properties of oxygen.

5. Describe the appearance of chlorate of potash and of manganese dioxide.

6. If two bottles were given you, one containing oxygen and the other ordinary air, how could you find out which was which?

\section{LESSON XXIV.}

\section{CHEMICAL CONDUCT OF OXYGEN.}

\section{PRACTICAL WORK.}

Things required.-Four jars of oxygen prepared as in the last lesson. Deflagrating spoons. Charcoal, sulphur, phosphorus, and a watch-spring. Lime-water and blue litmus. Laboratory burner. Small dish to hold water for phosphorus.

What to do.

Substances when cold do not burn in oxygen.-Place a piece of charcoal in a deflagrating spoon, on the stem of which a disc is placed in such a position that it will cover the mouth of the bottle when inserted in it, while at the 
same time the spoon is at a convenient distance from the bottom of the bottle. Quickly plunge this into one of the bottles of oxygen. Nothing happens.

Make the same test with pieces of sulphur and phosphorus. Again observe that when at the temperature of the air, carbon, sulphur, and phosphorus do not combine with oxygen.

Combustion of various substances in oxygen.-Repeat each of the previous experiments, using a new bottle of oxygen each time, but first make the carbon red hot, and ignite the sulphur and phosphorus. Observe that in each case the burning is very much more intense

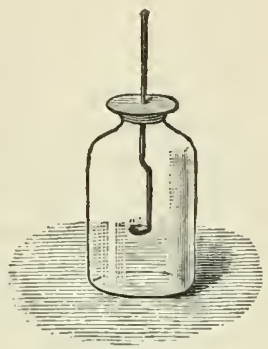

FIG. 71.-A deflagrating spoon, for burning a substance in a bottle of a gas. than in air. After the burning has finished, take out the deflagrating spoon and again cover the bottle used with a well-greased glass plate.

Obtain a piece of iron wire (a thin steel watch-spring will do), and dip one end into a little melted sulphur. Light the sulphur on the wire, and while the sulphur is still burning, place the wire into a jar of oxygen. Notice that the sulphur burns brightly, and then starts the burning of the iron, which continues with a brilliant shower of sparks.

Products of combustion in oxygen. - First, take the bottle in which the charcoal was burnt. Place a piece of moistened blue litmus paper in the bottle; it is turned red. Why? (If you forget, look back to p. 109). Pour in a little clear limewater. Notice that it turns milky.

Secondly, take the bottle in which the sulphur or brimstone was burnt. Notice the suffocating smell of the fumes. Shake up a little water in the bottle. The fumes dissolve. Put a piece of blue litmus paper into the water. It is turned red.

Thirdly, take the bottle in which the phosphorus was burnt. The dense white fumes soon disappear. Bear in mind what was said in Lesson XVIII. about the fumes formed when phosphorus burns in the air. Test the solution of the fumes with a blue litmus paper. The paper is immediately turned red.

Fourthly, take the bottle in which the iron was burnt. Notice the brown deposit on the sides of the bottle. Compare it with the rust of iron. Examine the lump of black material 
found on the bottom of the bottle, or still attached to the remainder of the watch-spring. Is it iron?

\section{REASONS AND RESULTS.}

Substances at the temperature of the air do not ignite in oxygen.-When pieces of cold charcoal, sulphur, and phosphorus are placed into jars of oxygen gas nothing happens. These observations show that for burning to take place, even in oxygen, we must assist it by heating the substance until it reaches a certain degree of temperature. For the same reason, it we wish paper, wood, or coal to burn, that is to unite with the oxygen of the air, we apply heat to them to cause them to do so. If this were not so, since, as you have learnt, the air contains one-fifth of its volume of oxygen, many substances would combine with this gas when simply exposed to the air. The temperature to which a substance must be heated before it will commence to combine with oxygen, or start burning, is often called the kindling temperature, or temperature of ignition.

When heated many substances readily combine with oxygen. - But if, before putting a piece of charcoal into oxygen, it is

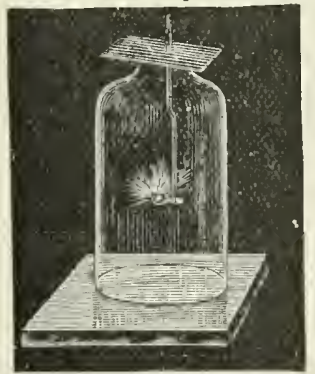

Iti, 72.-Sulphur burns more brilliantly in oxygen than in air. made red hot in the flame of a laboratory burner or a spiritlamp, it no sooner comes into contact with the oxygen than a change is noticed. The piece of charcoal begins to buin very brilliantly, bright sparks are given off, and the appearance is so brilliant that the burning puts the observer in mind of a firework. As the burning proceeds the piece of charcoal gets smaller and smaller. The char. coal seems to disappear and be lost, but from what you have alieady learnt you know that this cannot be so.

Similarly with sulphur, even when a piece is held in a flame, it only catches on fire with difficulty and soon goes out again if removed from the source of heat. But if while it is still alight it is transferred to a jar of oxygen a difference is at once 
observed. The flame gets larger and brighter and is of a beautiful lavender colour. It remains until all the sulphur, or all the oxygen, or both, have been used up.

The flame with which phosphorus burns in oxygen is dazzling in its brightness. In fact, the burning is so intense that it is painful to some eyes to watch it. This is particularly the case when the experiment is performed in a dark room.

Substances formed when charcoal, sulphur, and phosphorus burn in oxygen.-An examination of the contents of the jars in which the different cases of burning just described have taken place teaches many important facts.

Carbon.-First, what happens in a jar in which charcoal has been burnt? It has already been stated that the piece of charcoal gets smaller and smaller. An examination of the gas left in the bottle shows that it is not oxygen. It turns a moistened blue litmus paper red; and makes clear lime-water shaken up with it milky. If this solution is placed on one side, a white sediment is formed and the solution becomes clear again. Evidently, then, when charcoal, which the chemists call carbon, burns in oxygen, it gradually diminishes in amount, forming with the oxygen another gas which reddens a blue litmus paper and turns lime-water milky.

Sulphur.-In just the same way sulphur or brimstone disappears as it burns in oxygen. When, however, the contents of a bottle in which the burning has occurred are examined, it is seen that the results are quite different from those in the case of the carbon. The fumes which fill the bottle are very distressing when breathed, their smell is like that produced by a brimstone match when it is first lighted, or by burning sulphur. This is because the gas formed when sulphur or brimstone burns in the air is the same as when it burns in cxygen. A moistened blue litmus paper put into the gas is immediately turned red, the shade of colour being much brighter and deeper than in a jar in which carbon has beer burnt. As you learnt in an earlier lesson, substances which turn a blue litmus paper red are said to be acid, consequently the substances formed by the burning of carbon and sulphur in oxygen are both acid.

Phosphorus. - You are already familiar with the white powder which is formed when phosphorus burns in air, and if it is compared with that produced when phosphorus burns in oxygen 
the two are found to be exactly similar. By treating the white powder in the latter case in the same way as that formed when phosplzorus burns in air (p. 109) it is found that they are both alike, for each dissolves in water with a hissing noise and forms a solution which turns blue litmus paper red.

Burning of iron in oxygen.-Iron will not burn in the air even when made red hot. If it did, the iron of firegrates and furnaces would catch on fire and burn away. But iron when made red hot in oxygen does catch on fire, and burns so long as there is any oxygen and iron left. This shows how very much better oxygen supports combustion than air does, which is, of course, what you would expect, since the oxygen in the air is mixed with four times its rolume of nitrogen-a gas which will not allow things to burn in it at all.

In all the experiments performed with oxygen, you have doubtless observed that substances burn more vigorously in it than in any of the other gases so far considered; it is in fact the substance which causes them to burn. For this reason, oxygen is spoken of as a strong or vigorous supporter of combustion.

\section{To be Remembered.}

Carbon, sulphur, phosphorus, etc., at the temperature of the air, do not ignite when placed into oxygen.

Carbon if red-hot combines with oxygen when placed in it, burning brightly and forming an invisible odourless gas which turns lime-water milky. The solution of the gas in water turns blue litmus red, and is therefore acid.

Ignited sulphur burns much more brightly in oxygen than in the air. In burning it forms a gas which has a suffocating smell. The gas is soluble in water, and the solution turns a blue litmus paper a brilliant red colour, thus proving it to be acid.

Ignited phosphorus burns with a dazzling flame in oxygen, forming a snow-white powder which easily dissolves in water with a hissing noise. The solution thus obtained turns a blue litmus paper red.

Iron under suitable conditions will burn in oxygen.

\section{EXERCISE XXIV.}

I. Describe what you would see when phosphorus, carbon, and sulphur are burnt separately in oxygen.

2. What happens when a piece of cold charcoal is 1 ut into oxygen? 
3. Write what you can about the gas left behind after charcoal has burnt in oxygen.

4. What experiment would you do to show that iron burns in oxygen?

5. Compare the burning of sulphur in air and in oxygen.

6. If you were given a bottle in which phosphorus had been burnt, and another in which carbon had been burnt, how could you distinguish one from the other?

7. If the air consisted entirely of oxygen, how would burning differ from the way it takes place at present? 


\section{INDEX.}

Air, active part, search for, I24; chemical composition, 99; combination of other metals with active part, 100; damp, 26 ; dry, 26 ; inactive part, I0o; proportion used by iron in rusting, 99 ; rusting in, 96 ; volume used when phosphorus burns, IO2-4; where to look for active part, 125 .

Area, measurement of, 3 .

Archimedes, principle of, 6 .

Atmosphere, chemical propertics, 95, 99; general properties, 94; undergoes change when iron rusts, 96.

\section{Balance, 4 .}

Baiometer, 6.

Boiling point, 87 .

Burning, candle, I12 ; increase of mass in, 93; of magnesium, 93; oil and gas, 120 ; in relation to oxygen, I22.

\section{Calorie, 58.}

Candle, burning of, I12, II 4 , I16 ; gain of mass as it burns, 116; gas left after it burns in air, 112 , I14; moisture produced when it burns, II2, I 4 ; nothing is lost when it burns, 117, 118; volume of air used up by burning of, 113 , II 5 .
Capacity, heat, $6 \mathbf{1}, 63$; metals have different, 65; of copper, 67; of various substances, 68 ; of vessels, 63 ; of water for heat, 63 ; relative, for heat, 62 ; relative, 66 ; results in nature of high capacity of water for heat, 64 .

Clouds, 2., 25.

Combustible bodies, I2I.

Condensation, I7; common instances, 18 ; causes, 18.

Condenser, 20.

Convection, 83, 86; application of heating by, 87 ; currents, 83,86 ; definition, $87 ;$ in air, 84 .

Crystals, 9; soda, 9; sulphur, 9; water in, 9 .

Currents, convection, 83 ; direction of air, 83 .

Density, changes of, as water is cooled, 36 ; definition, 5; of hot and cold water, 33 ; of ice, 39 ; of liquids, 5 ; maximum, of water, 39, 40 ; of solids, 5 .

Dew, 25 .

Distillation, I6, I8; apparatus for, 20.

Equivalent, water, of calorimeter, 75.

Evaporation, assisted by heat, ro; cold produced by, II, I3; of 
different kinds of water, II ; everyday examples of, 12; not the same as boiling, I2, I4; rate of, 13.

Expansion, of water near freezing point, 35; when water freezes, $39,40$.

Flask, distilling, 2 I.

Fogs, 25.

Foot, 3 .

Frost, hoar-, 25 ; figures, 26.

Fusion of ice, heat absorbed in, $77-9$.

Gas, burning of, I20; products formed by burning of, 122 .

Gases, 2 .

Grans, 4.

Hail, 25.

Heat, capacity, 6r, 70; capacity of copper, 67 ; capacities of various substances, 68 ; determination of units, 57; difference from temperature, 49; latent, 79; measurement of, 53 ; of water, 80 ; quantity, 56, 57; specific, 7 I ; unit quantity of, $5^{8}$.

Heat-level, 46; changes of, 5I ; rise and fall of, 48,53 .

Hygrometer, chenical, 30 ; construction of, 29.

lce, density of, 39 ; floats on water, 40 ; how formed on ponds, 42 ; heat absorbed in fusion of. 77 .

Inch, 3 .

Iron, burning in oxygen, 136.

Kilogram, 4 .

Lead, changes when red lead is heated, I24; compounds of, with oxygen, 126; heating in air, 124.
Length, measurement of, 2 ; standard, 2.

Lime-water, test, Iog.

Litmus, use of, rog.

Litre, 3 .

Liquids, 2.

Mass, measurement of, 4 .

Matter, I.

Melting point, $7^{8}$.

Metals, heating of, in air, 95 .

Metre, 3.

Mists, 25.

Moisture, in air, 22 ; determination of proportion in air, 29: effects of, in air, 26 ; substances which take it out of air, 23.

Nitrogen, Ioo.

Oil, burning of, 120 ; products formed by burning, 122 .

Uxygen, burning of iron in, 136 ; chemical conduct of, I32; cold substances do not burn in, 133 . I34; collection of, r29, I30 ; combustion in, I33, I34; from oxygen mixture, I29; from potassium chlorate, I28; obtained from oxide of mercury, I27; obtained from red lead, I26; physical character of, I29, I3I ; preparation of, I28, 130; products of combustion in, I33, 135 .

Phosphorus, amorphous, so6; burning of, IO2; change produced in air by burning, I06; different kinds of, I05; increase of mass when it burns, IO9, III ; readily burns in air, I06 ; red, I05; slowly takes out active part of air, I07; volume of air used up when it burns, IO2, IO3, IO4; white 
powder produced when it burns, Io8, iro; yellow, ro5.

Potash, chlorate of, 130.

Potassium, chlorate, I3o.

Properties, of common stuffs, 2 .

Rain, 25.

Receiver, 2 I.

Rust, heating mercury, I25.

Rusting of iron, 94, 96, 98, 99.

Senses, I.

Snow, 25.

Solids, I.

Solution, 7; no loss during, 8; saturated, 8.

Specific heat, 7 r, 74 ; determination of, 74 ; method of measuring, 73.

Steam, determination of quantity of heat required to convert water into, 91 ; latent heat of, 89.

Temperature, 46 ; difference from heat, 49; similarity with waterlevel, 50.
Therm, $5^{8}$.

Thermometer, $7 ;$ fixed points, 7 ; liquid in, 7 ; two common kinds, 7 ; wet and dry bulb, 29, 3 r.

Vaporisation, of water, 84 ; latent heat of, 86 ; temperature of, 84 .

Ventilation, of mines, 84,89 ; of rooms, 88.

Volume, changes of, as water is cooled, $3^{6}$; changes of, as water is warmcd, 36 ; measurement of, 3 .

Water, differences between distilled and ordinary, 21 ; distillation of, I6; how obtained from air, I6: rain-, I5.

Water-level, 46; change of, 50 ; rise and fall of, 46,53 .

Wax, density of solid and liquid. 40 .

Yard. 3. 


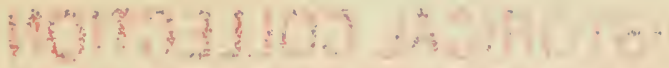

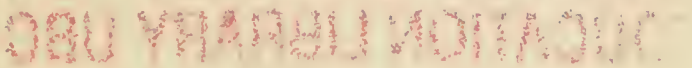




\section{HISTORICAL COLLECTION EDUCATION LIBRARY UBC}




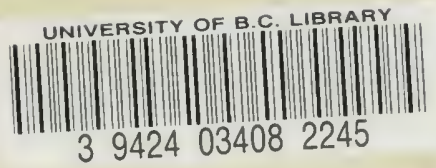




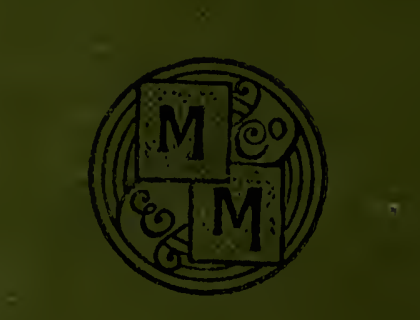

